\title{
Controlled Hydrogen Fleet and Infrastructure Demonstration and Validation Project
}

Technical Report NREL/TP-560-45451

March 2009

Spring 2009

Composite Data Products Final Version March 13, 2009

Keith Wipke, Sam Sprik, Jennifer Kurtz, and Todd Ramsden 


\section{NPEI National Renewable Energy Laboratory}

\section{Innovation for Our Energy Future}

\section{Disclaimer and Government License}

This work has been authored by Midwest Research Institute (MRI) under Contract No. DE-AC36-99GO10337 with the U.S. Department of Energy (the "DOE"). The United States Government (the "Government") retains and the publisher, by accepting the work for publication, acknowledges that the Government retains a non-exclusive, paid-up, irrevocable, worldwide license to publish or reproduce the published form of this work, or allow others to do so, for Government purposes.

Neither MRI, the DOE, the Government, nor any other agency thereof, nor any of their employees, makes any warranty, express or implied, or assumes any liability or responsibility for the accuracy, completeness, or usefulness of any information, apparatus, product, or process disclosed, or represents that its use would not infringe any privately owned rights. Reference herein to any specific commercial product, process, or service by trade name, trademark, and opinions of the authors and/or presenters expressed herein do not necessarily state or reflect those of MRI, the DOE, the Government, or any agency and opinions of the authors and/or presenters expressed herein do not necessarily 


\section{Controlled Hydrogen Fleet and Infrastructure Demonstration and Validation Project}

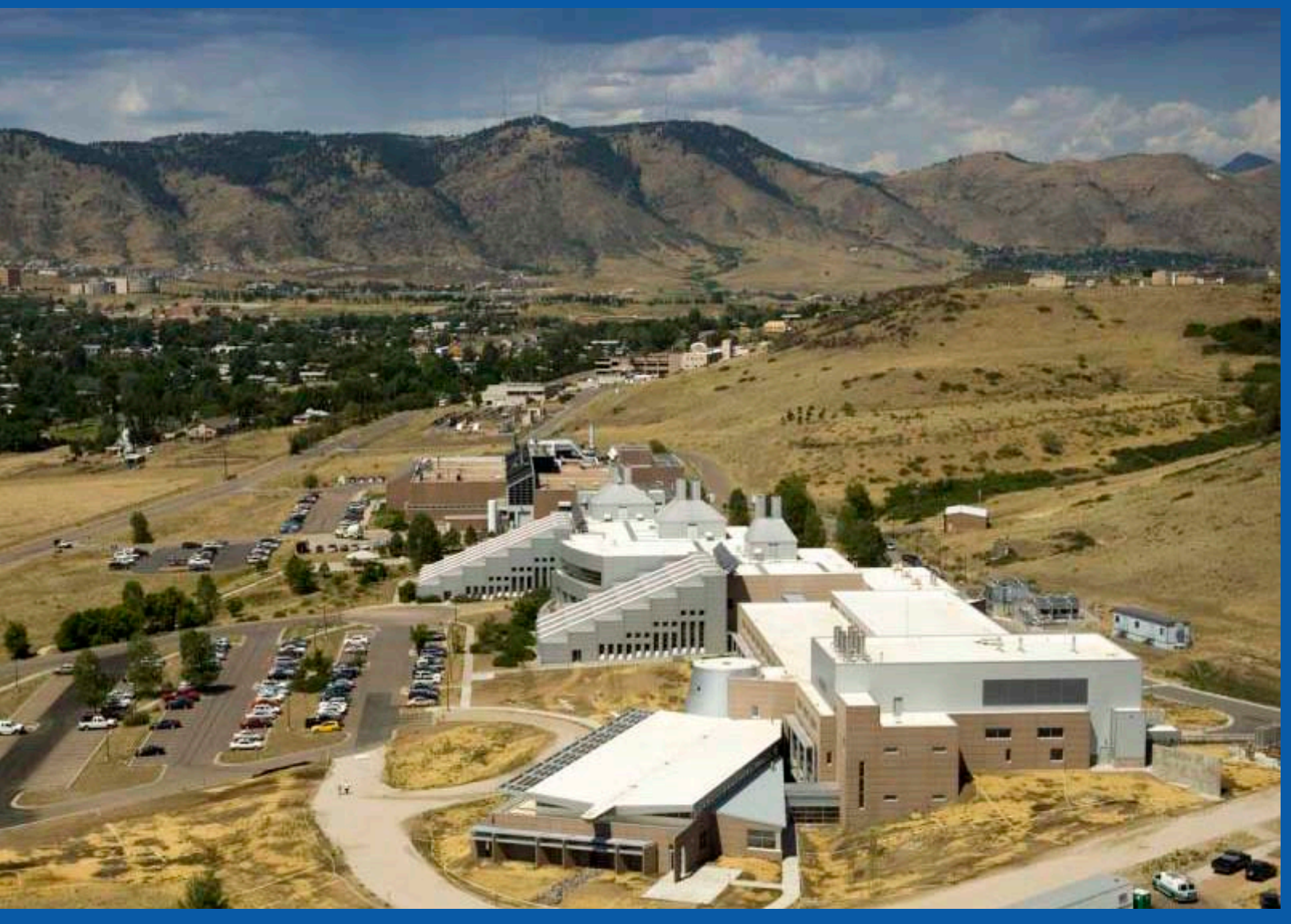

Spring 2009

Composite Data

Products

March 13, 2009

Keith Wipke, Sam Sprik, Jennifer Kurtz, Todd Ramsden 


\section{CDP\#1: Hours Accumulated and Projected Hours to $10 \%$ Stack Voltage Degradation}

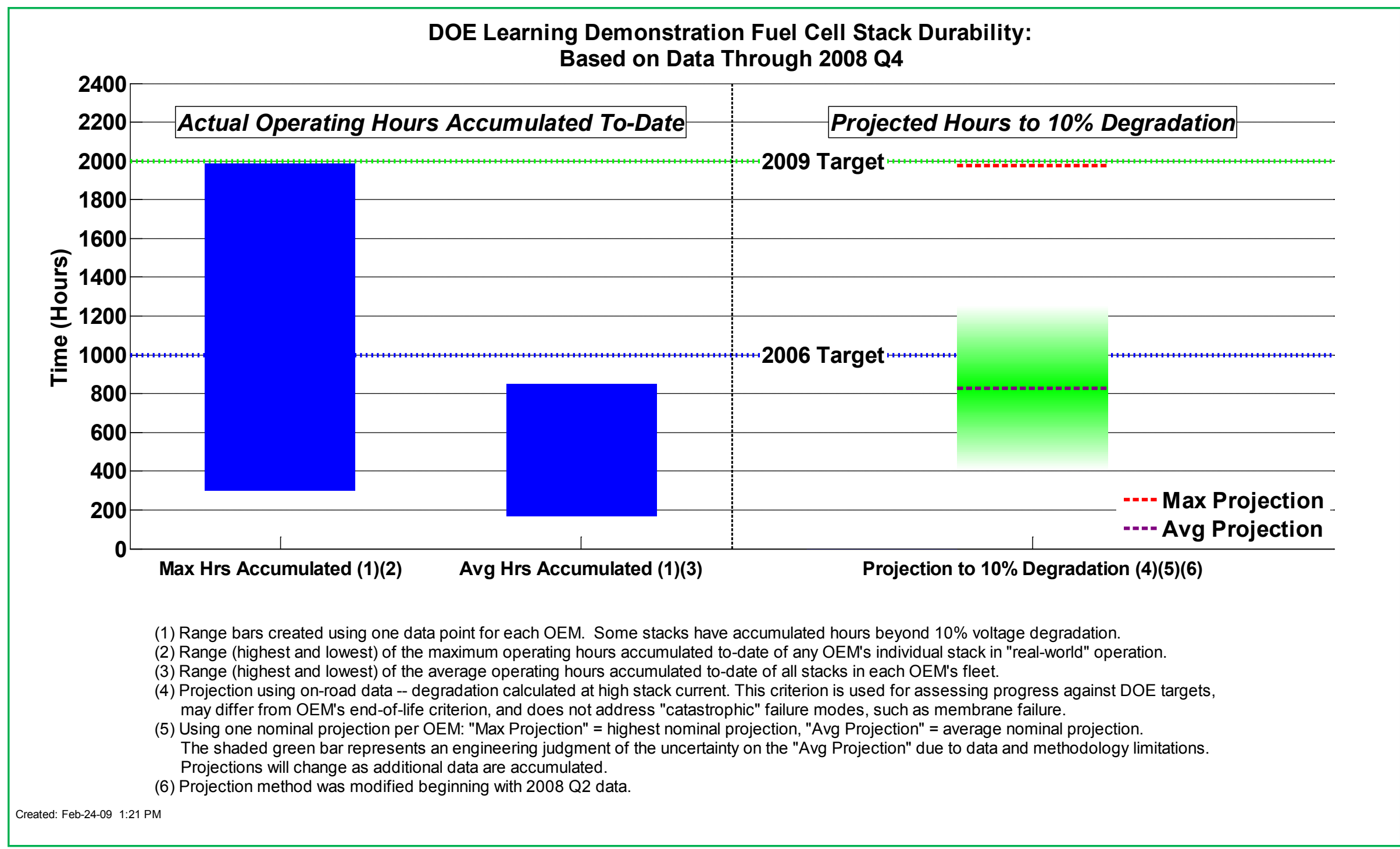




\section{CDP\#2: Vehicle Range}

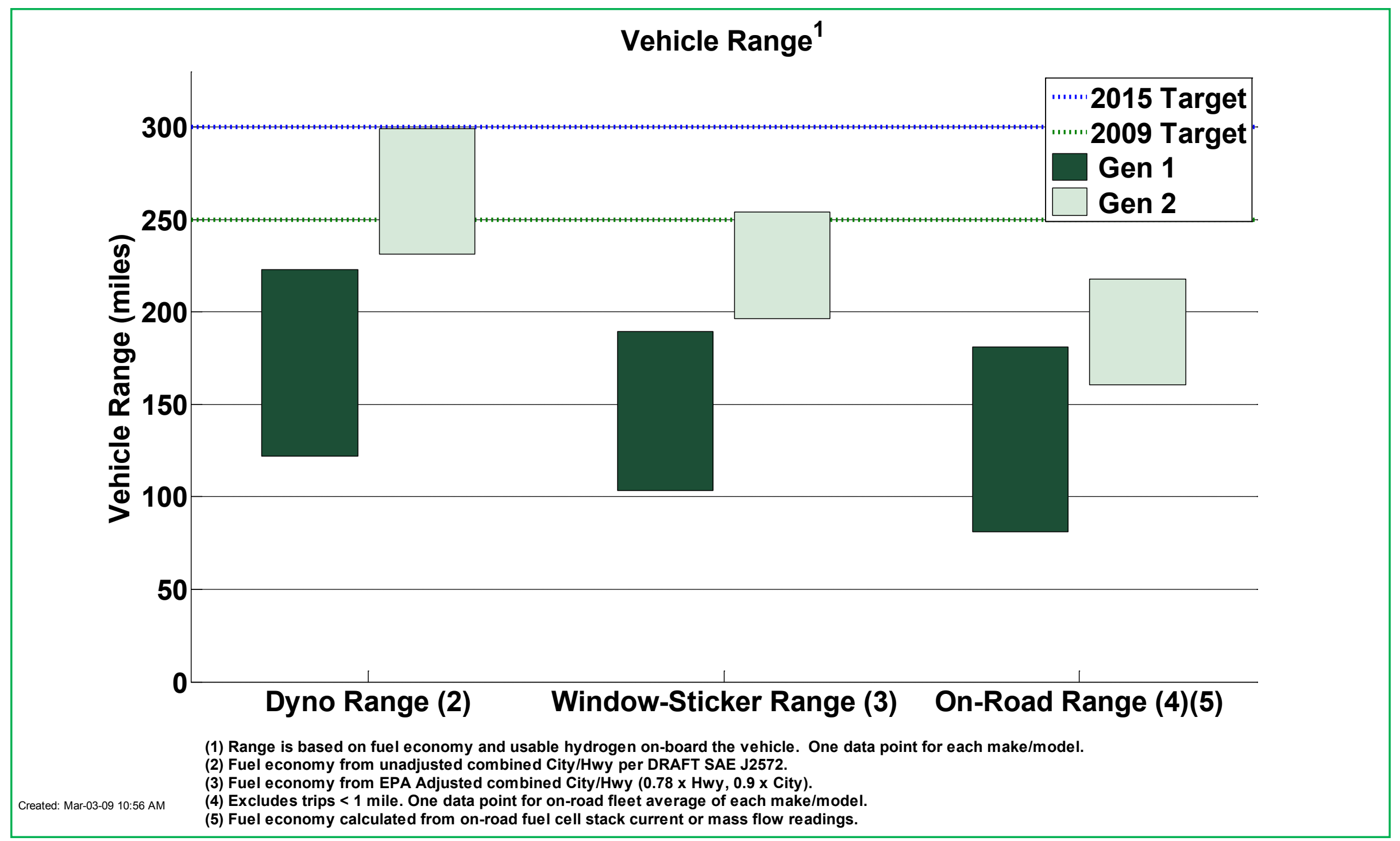




\section{CDP\#6: Fuel Economy}

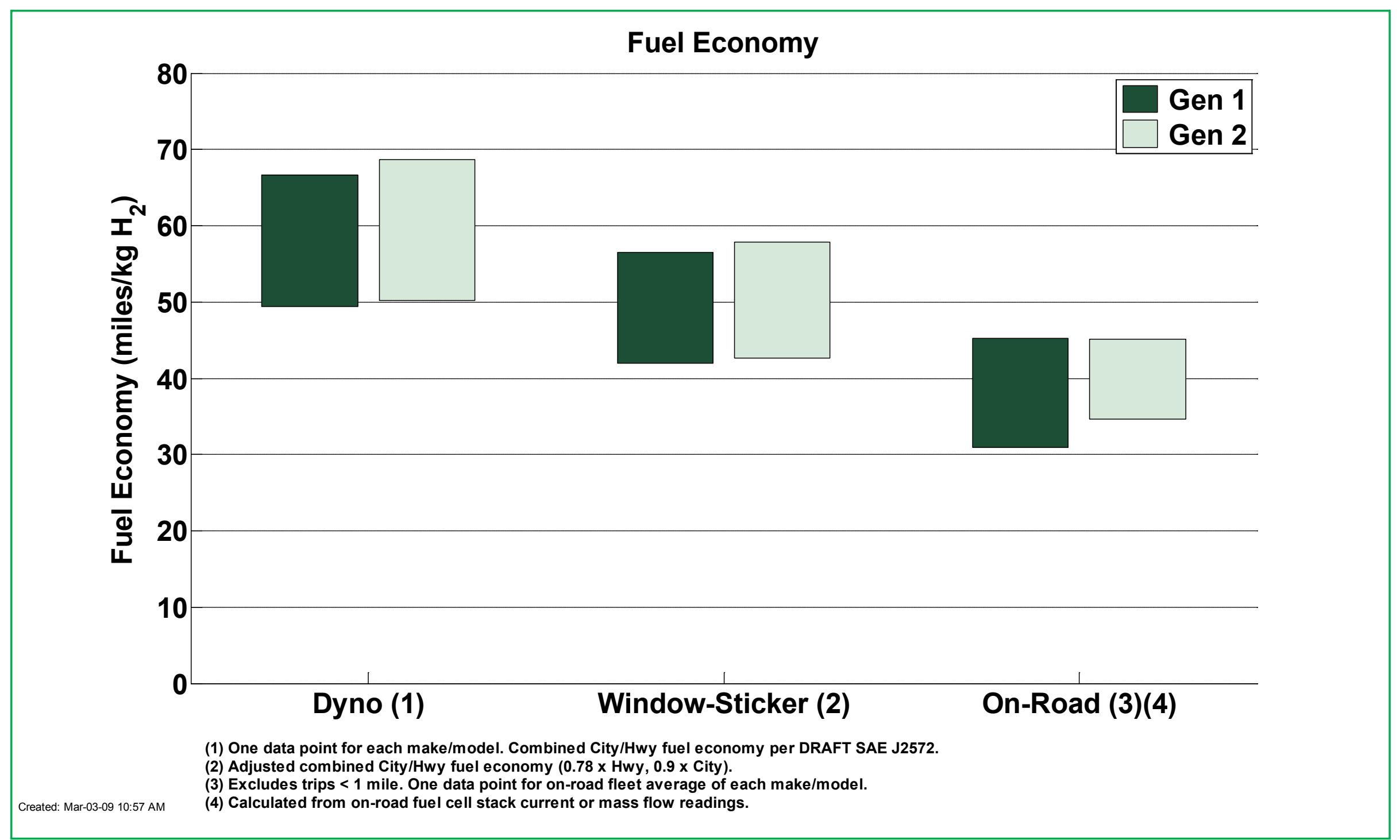




\section{CDP\#7: Fuel Cell Voltage}

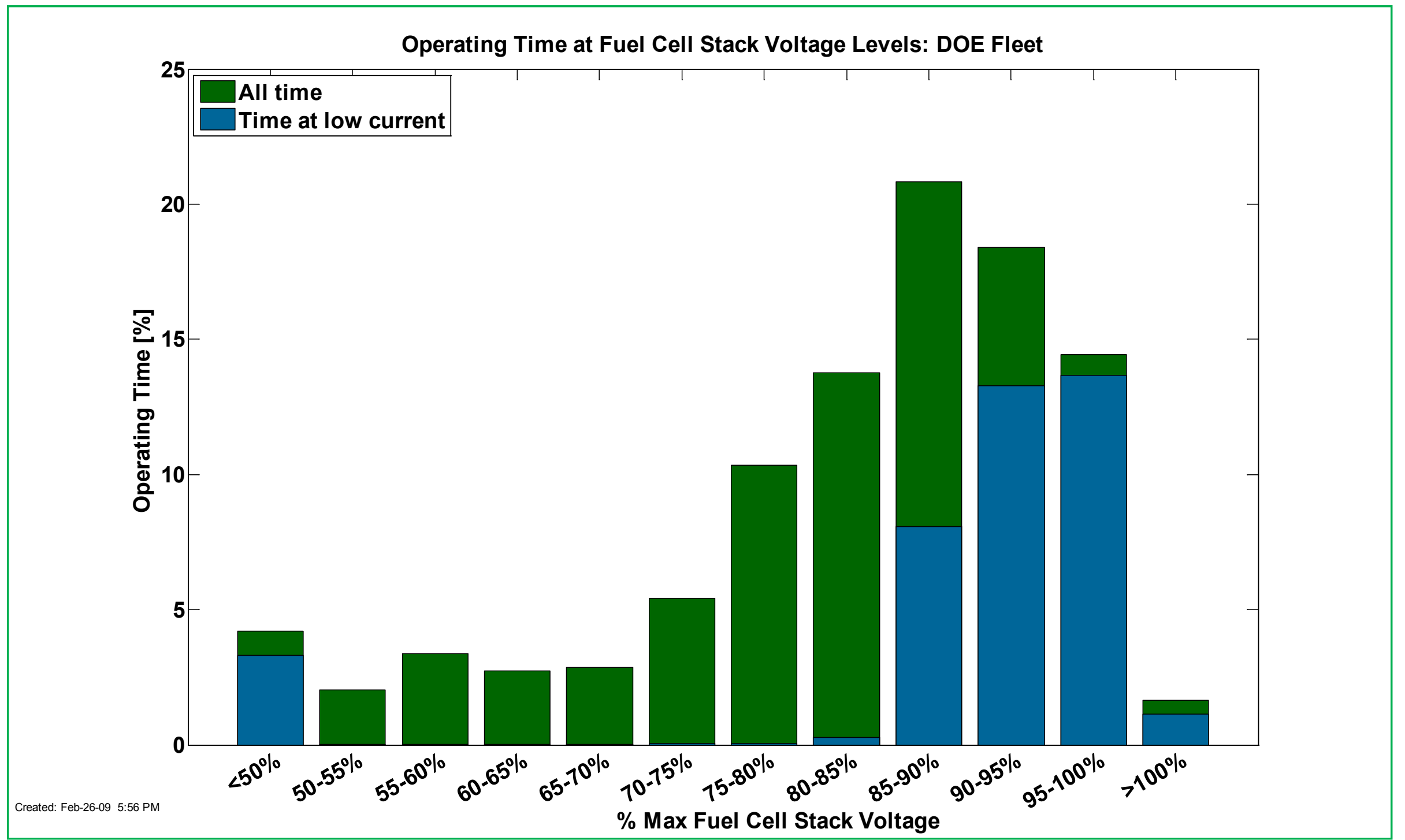




\section{CDP\#8: FC System Efficiency}

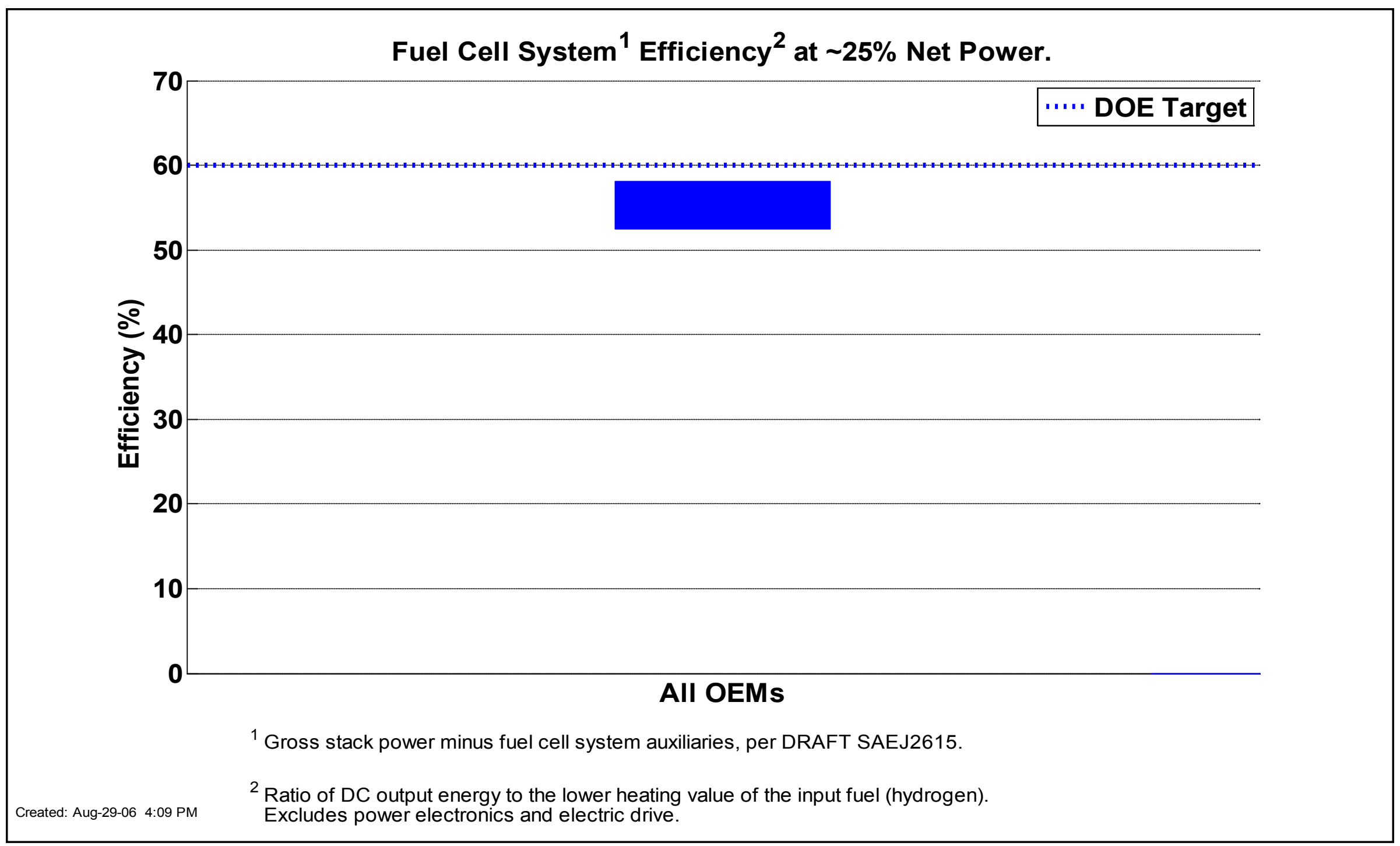




\section{CDP\#9: Safety Reports - Vehicles}

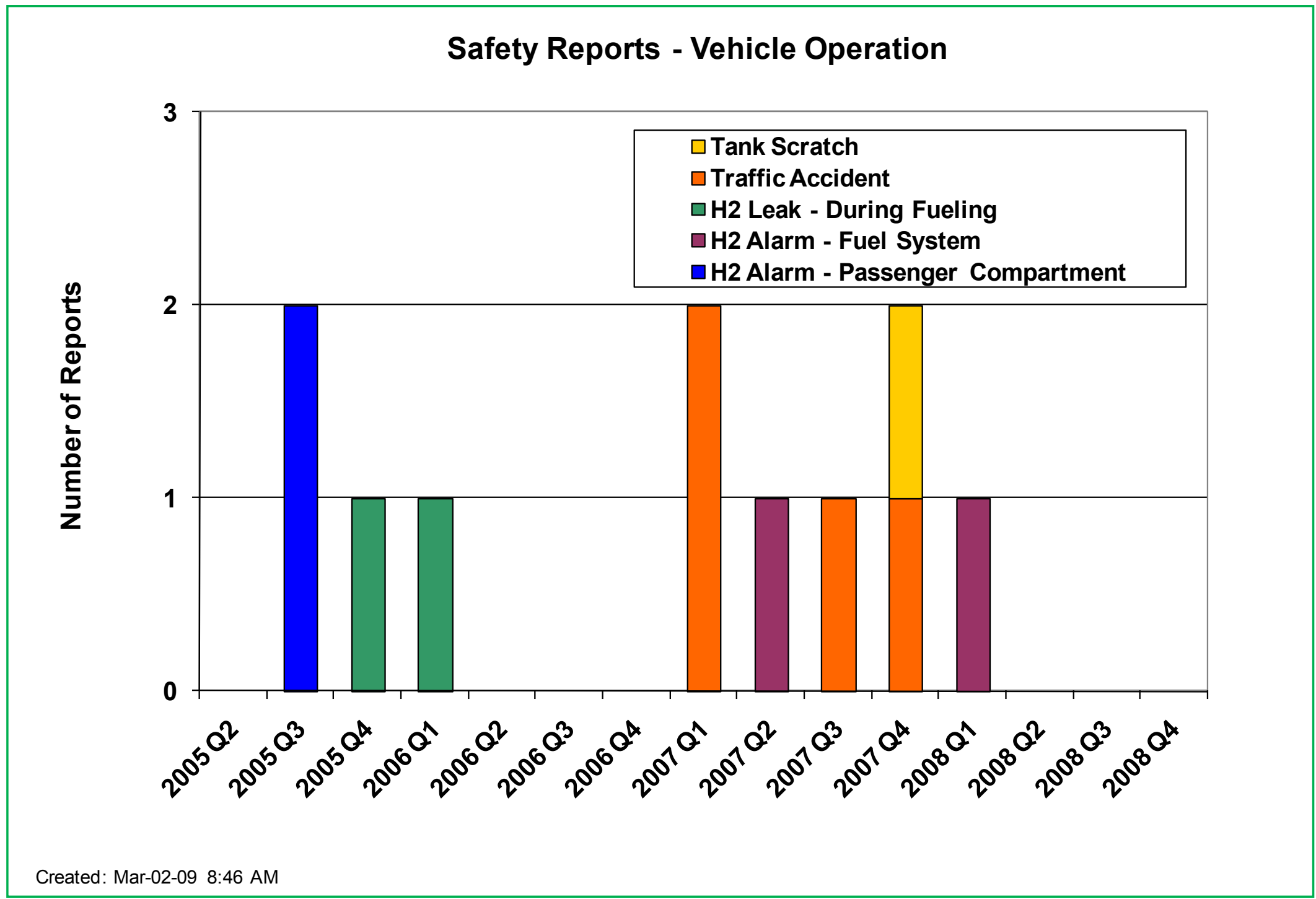




\section{CDP\#10: Storage Weight \% Hydrogen}

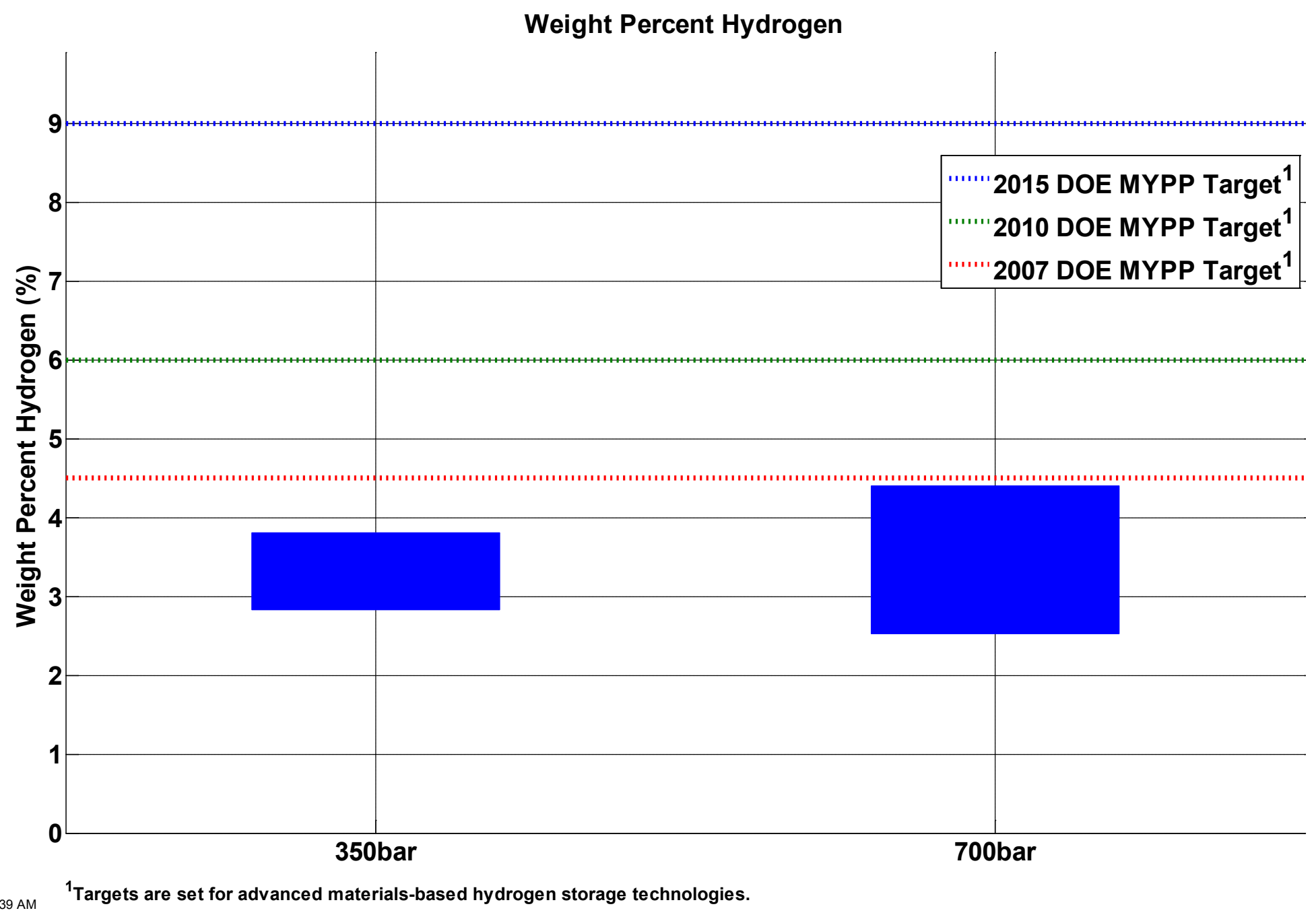




\section{CDP\#11: Volumetric Capacity of H2 Storage}

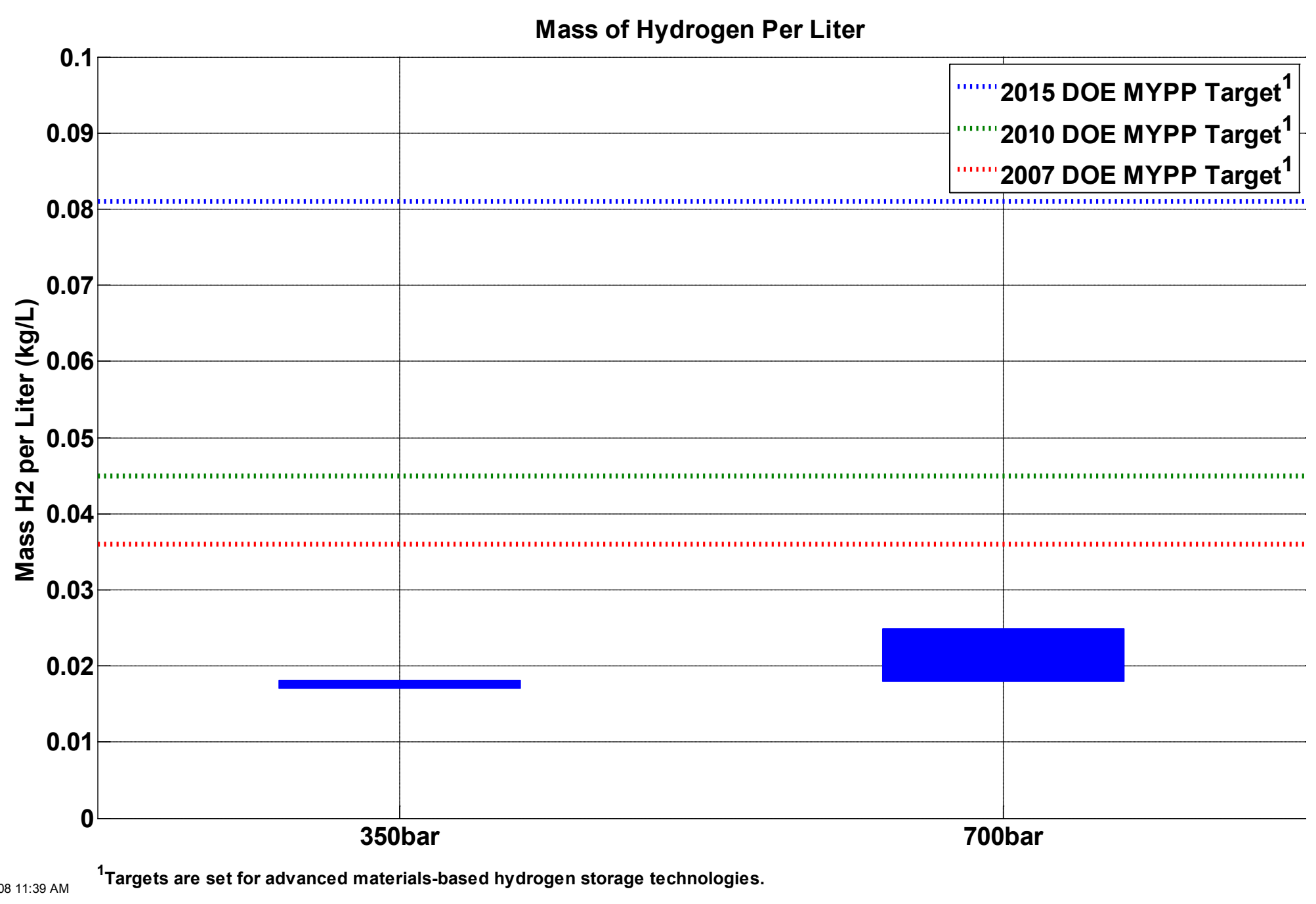




\section{CDP\#12: Vehicle Hydrogen Tank Cycle Life}

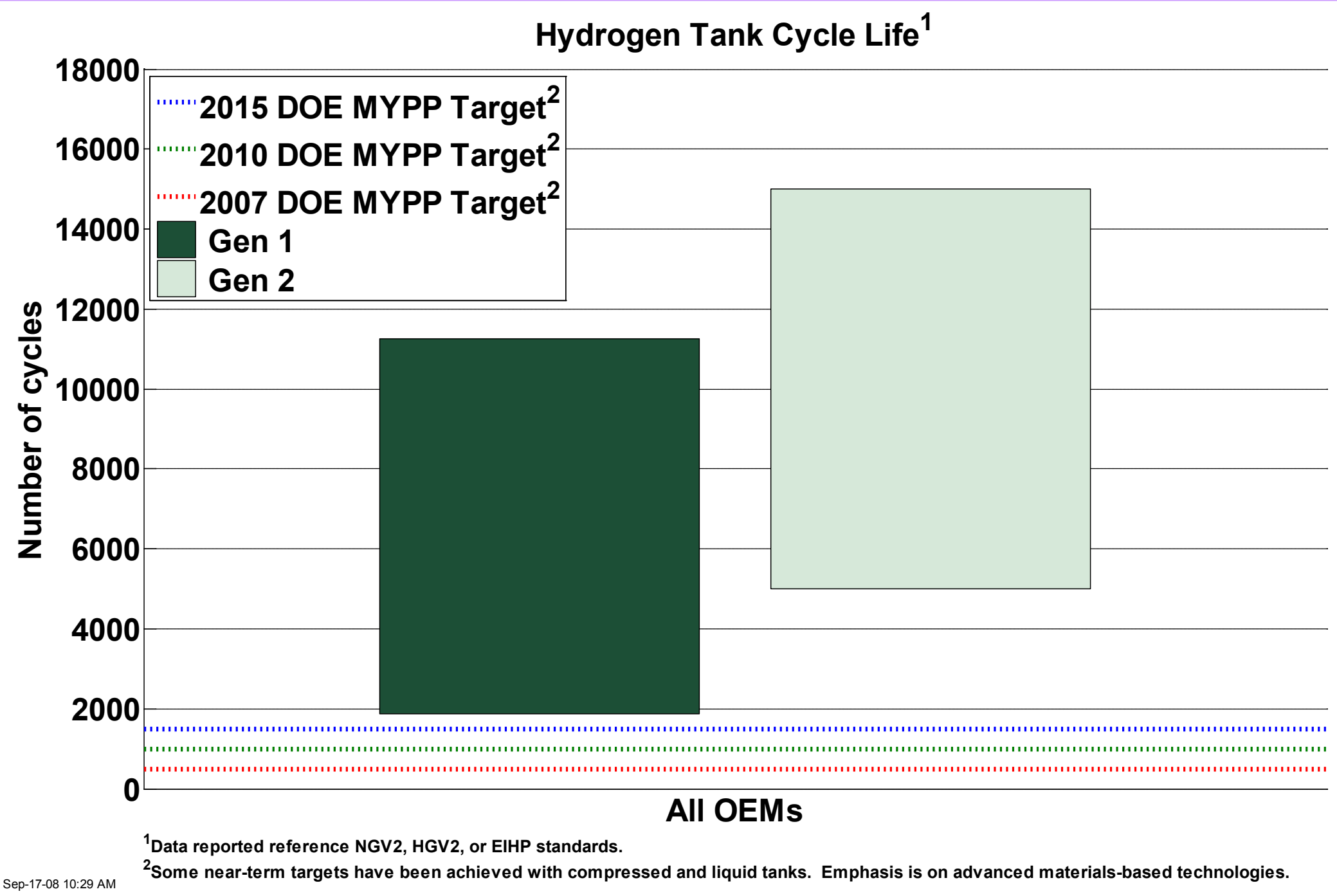




\section{CDP\#13: On-Site Hydrogen Production Efficiency}

Hydrogen Production Conversion Efficiency ${ }^{1}$

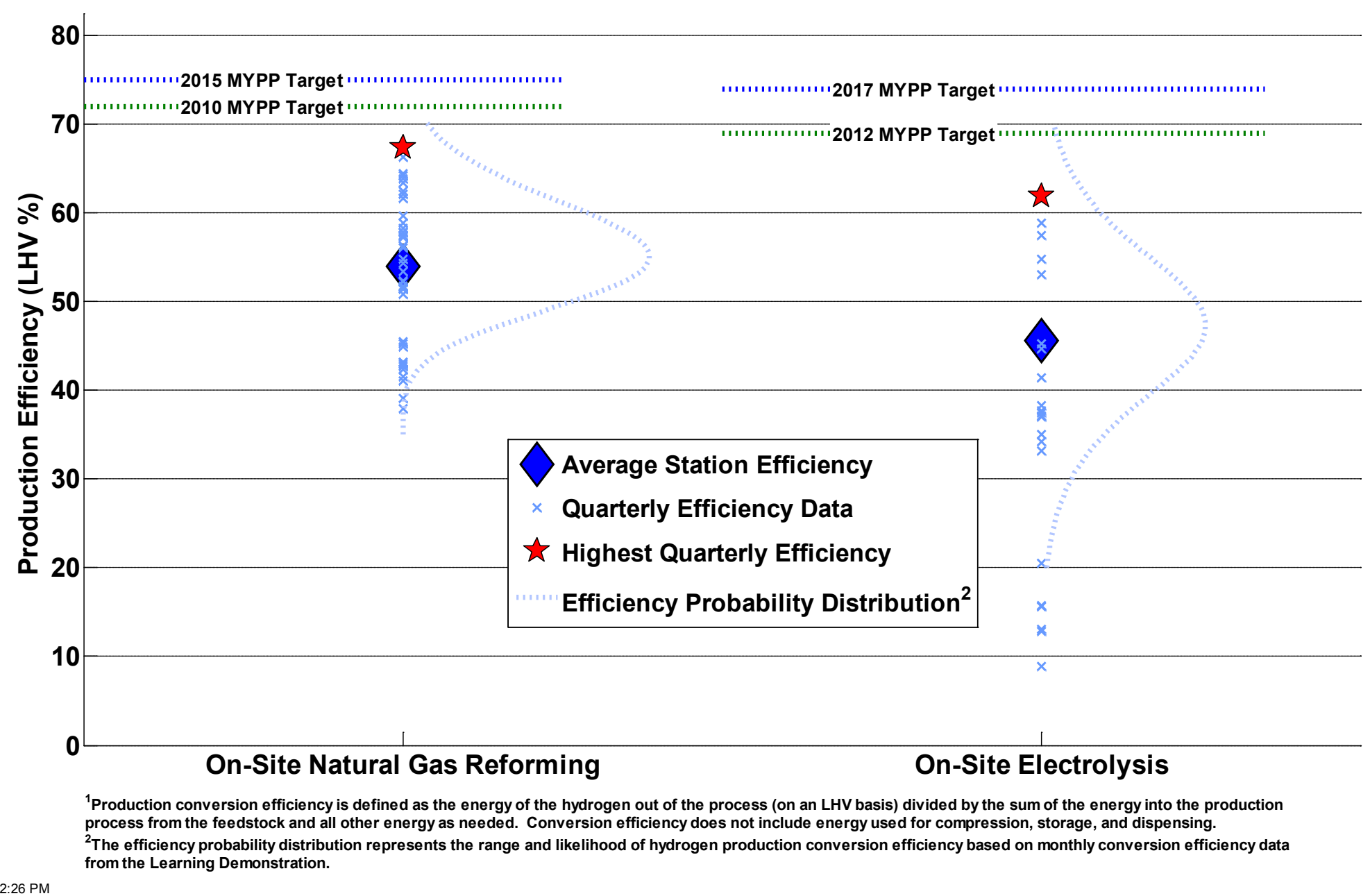




\section{CDP\#14: Fueling Rates - 350 and 700 bar}

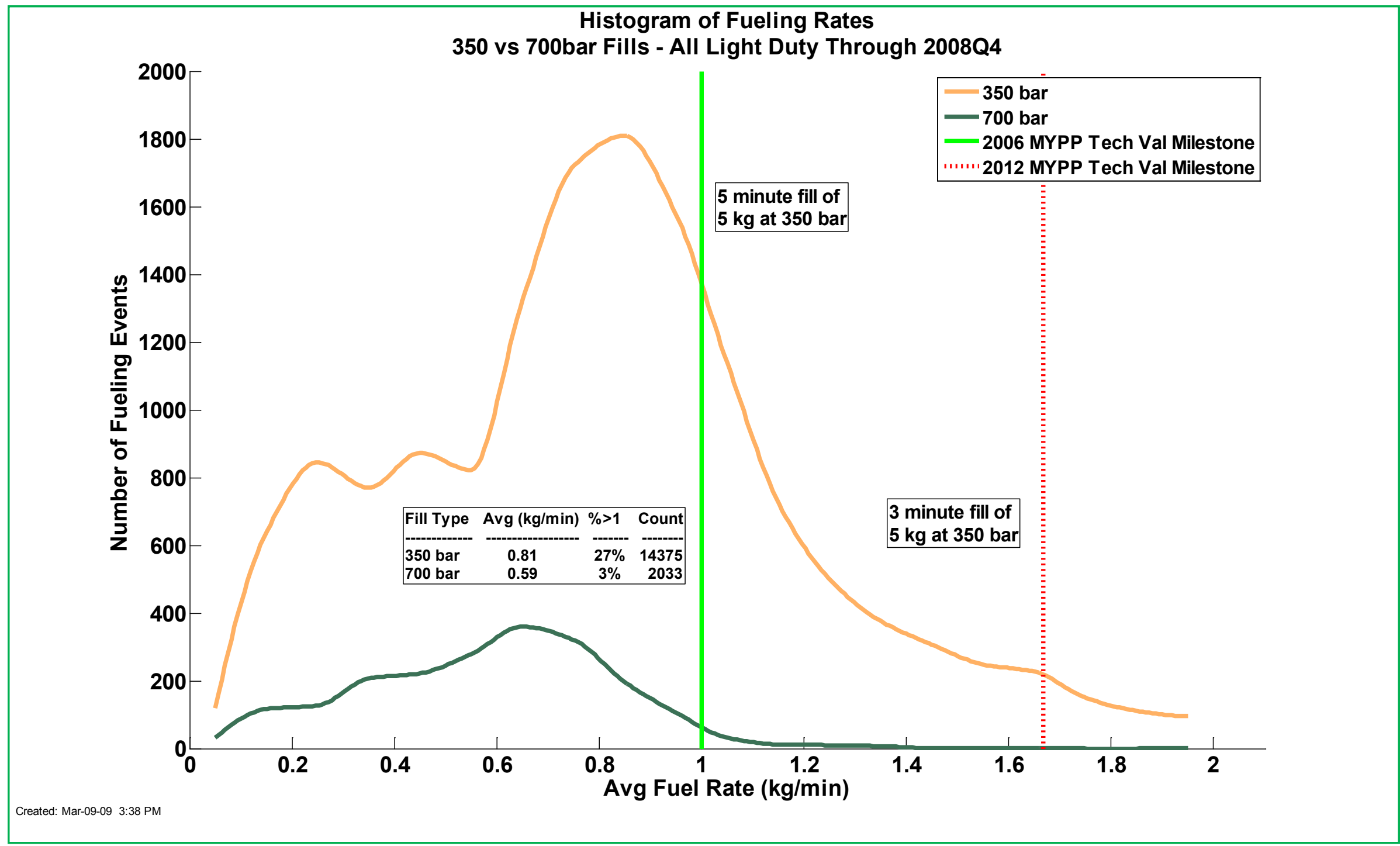




\section{CDP\#16: Fuel Cell Stack Trips Per Hour Histogram}

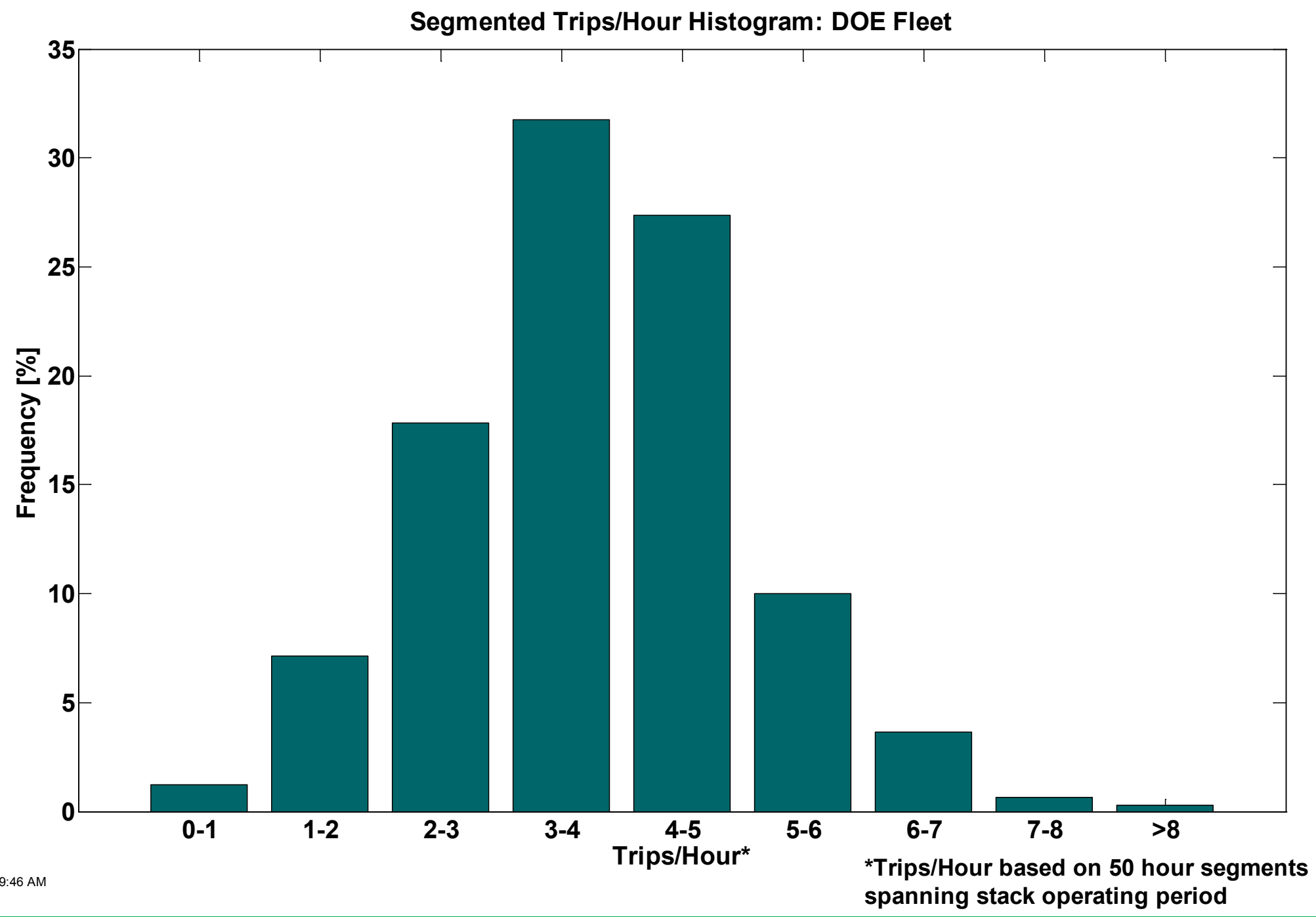




\section{CDP\#17: Statistics of Trips/Hour vs. Operating Hour}

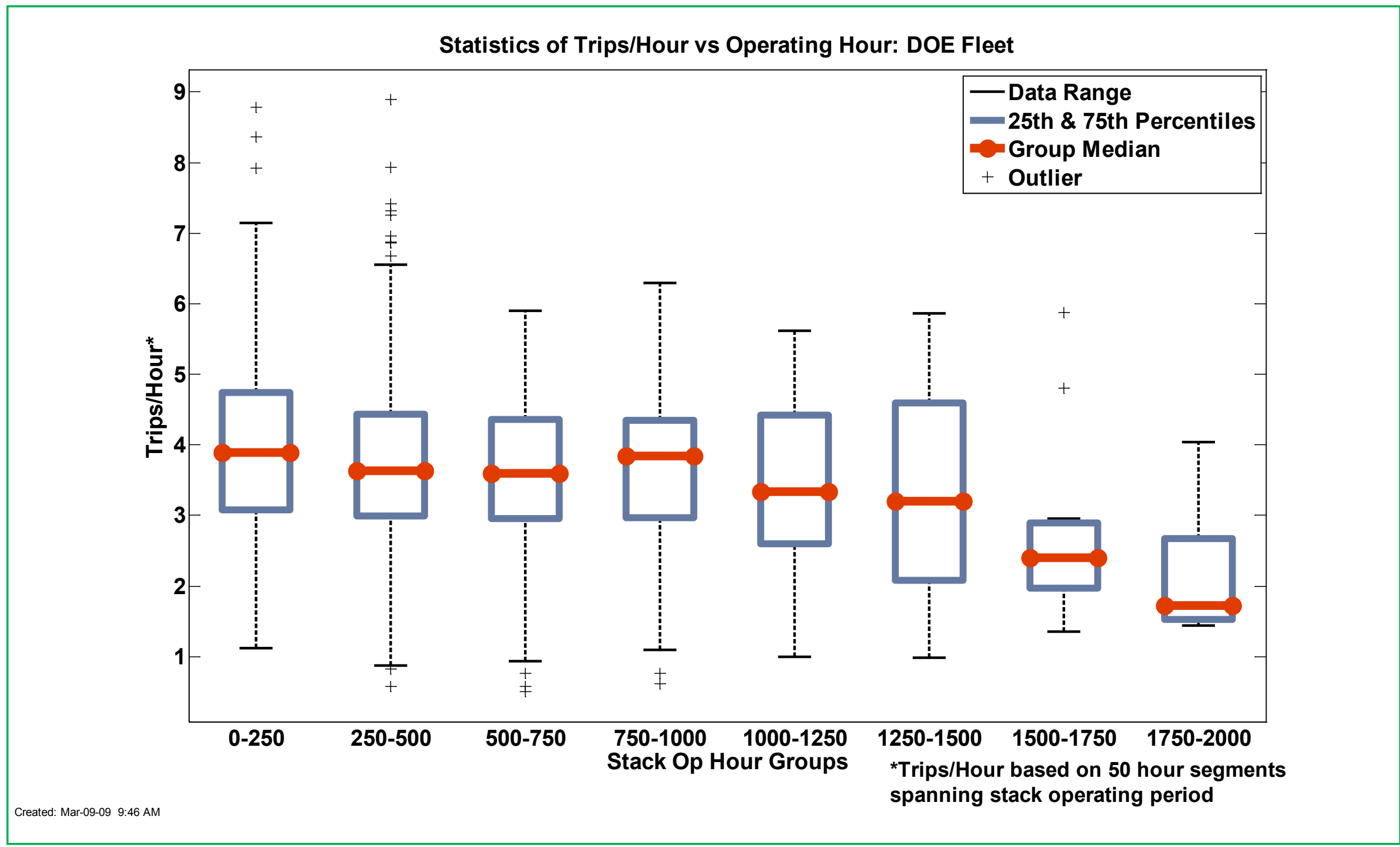




\section{CDP\#18: Refueling Rates}

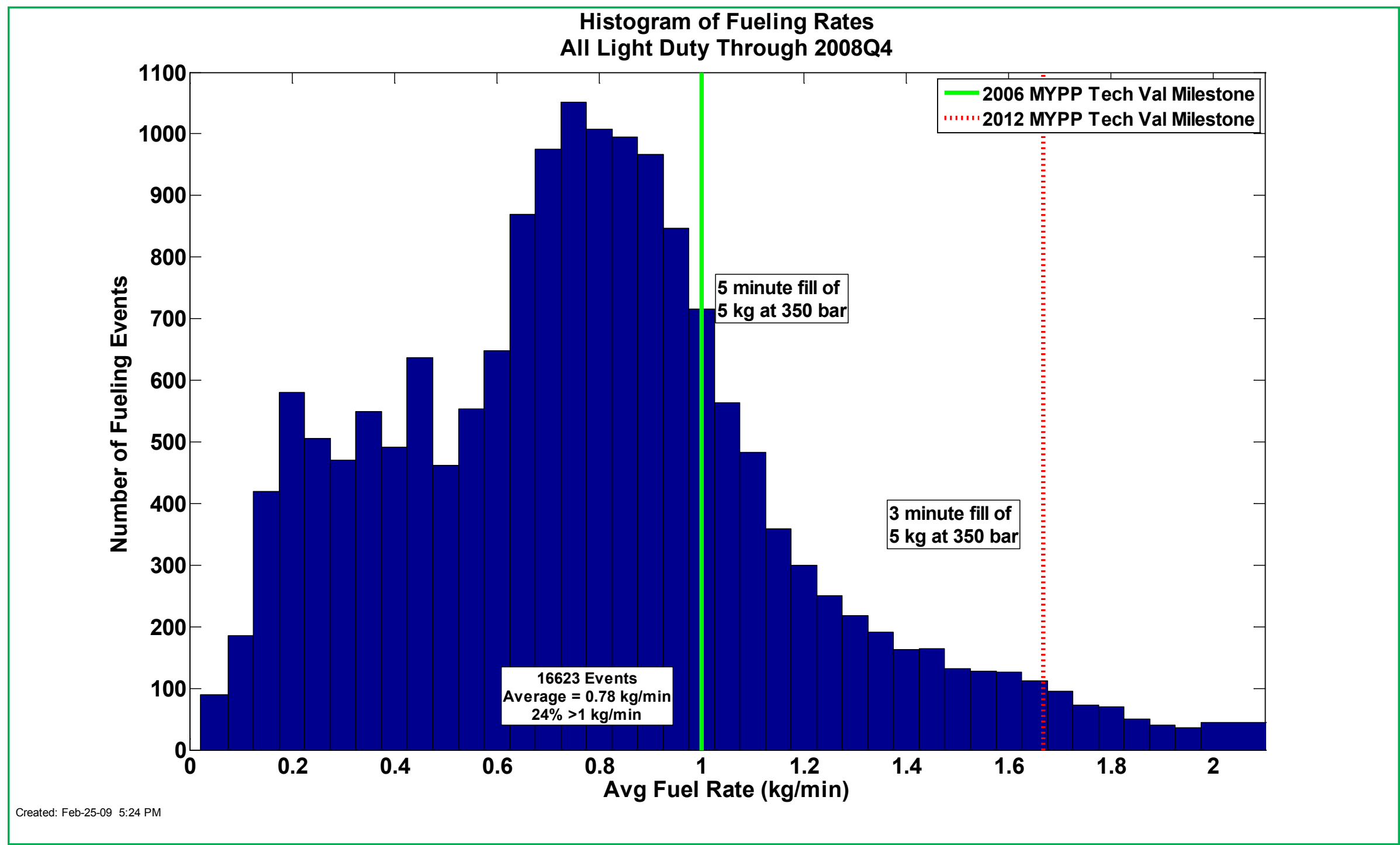




\section{CDP\#19: Time Between Trips \& Ambient Temperature}

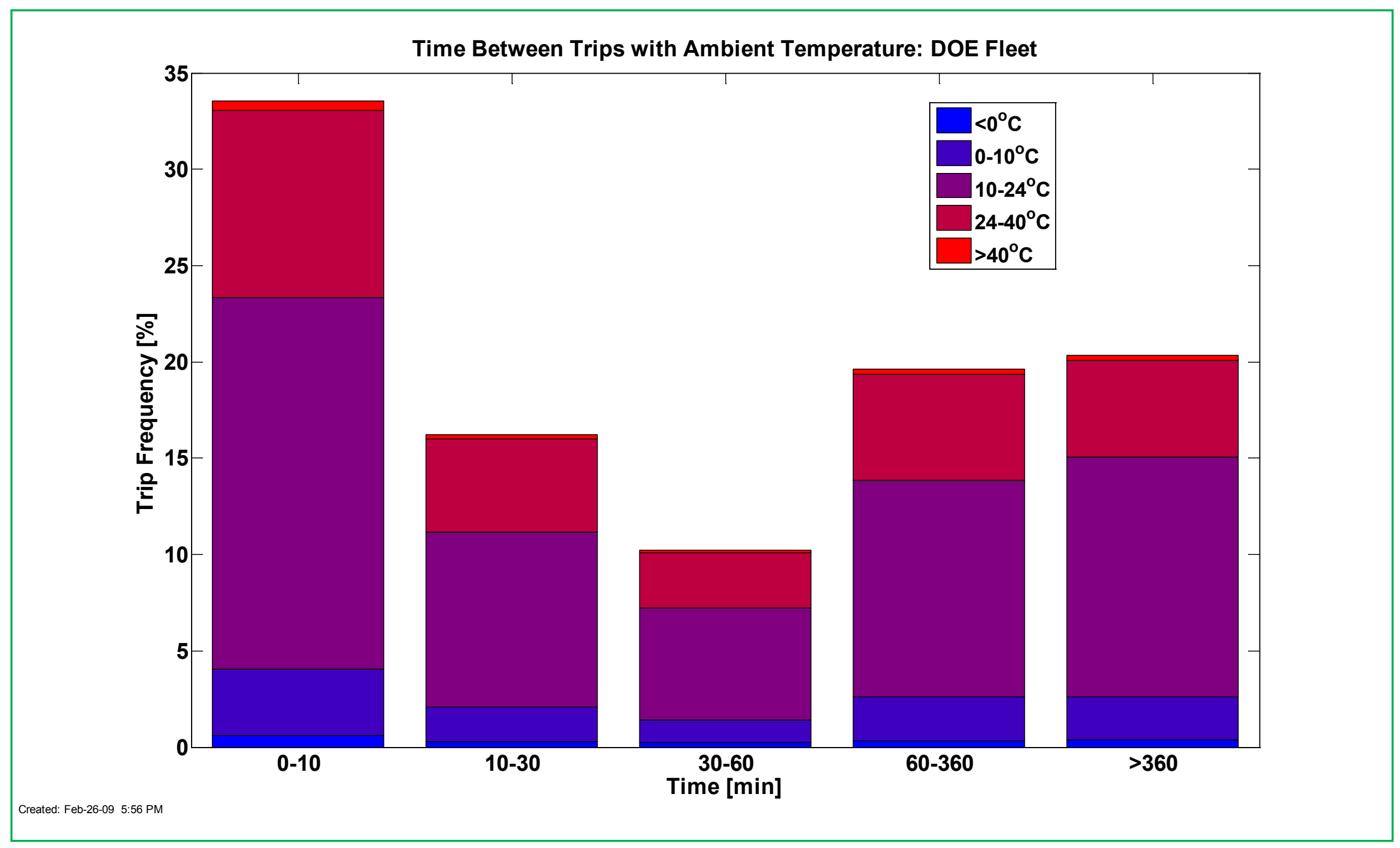




\section{CDP\#20: Safety Reports - Infrastructure}

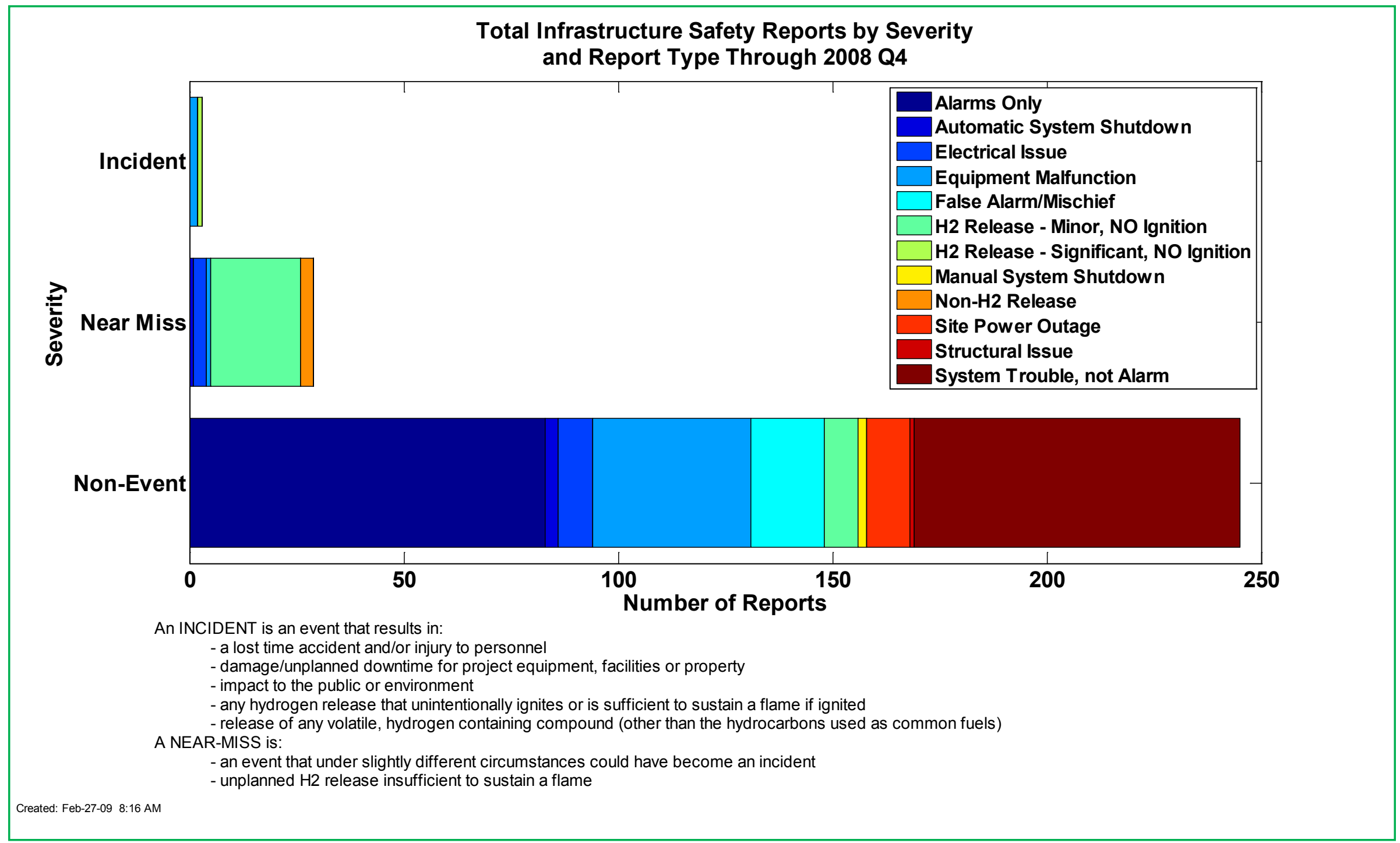




\section{CDP\#21: Range of Ambient Temperature During Vehicle Operation}

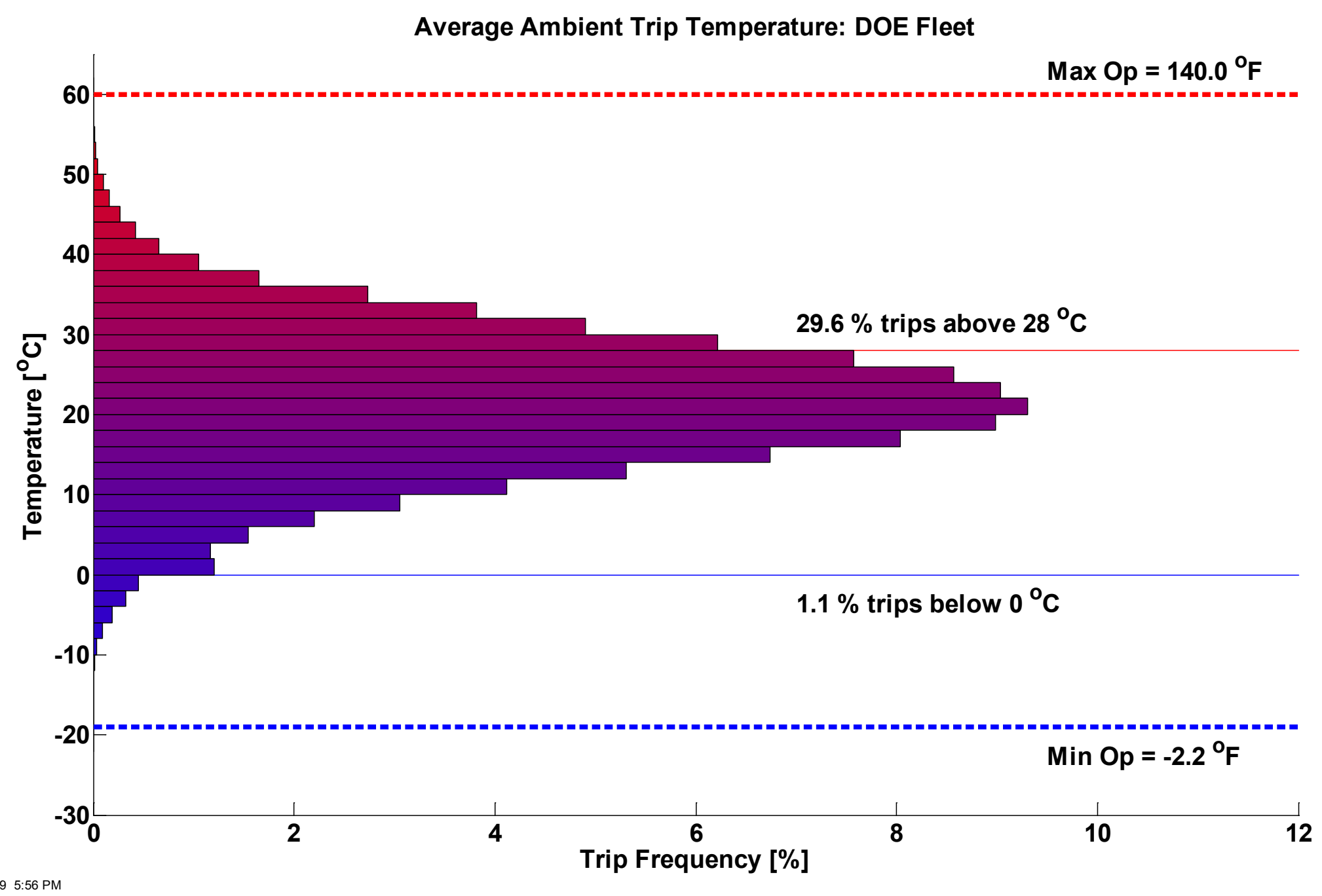




\section{CDP\#22: Vehicle Operating Hours}

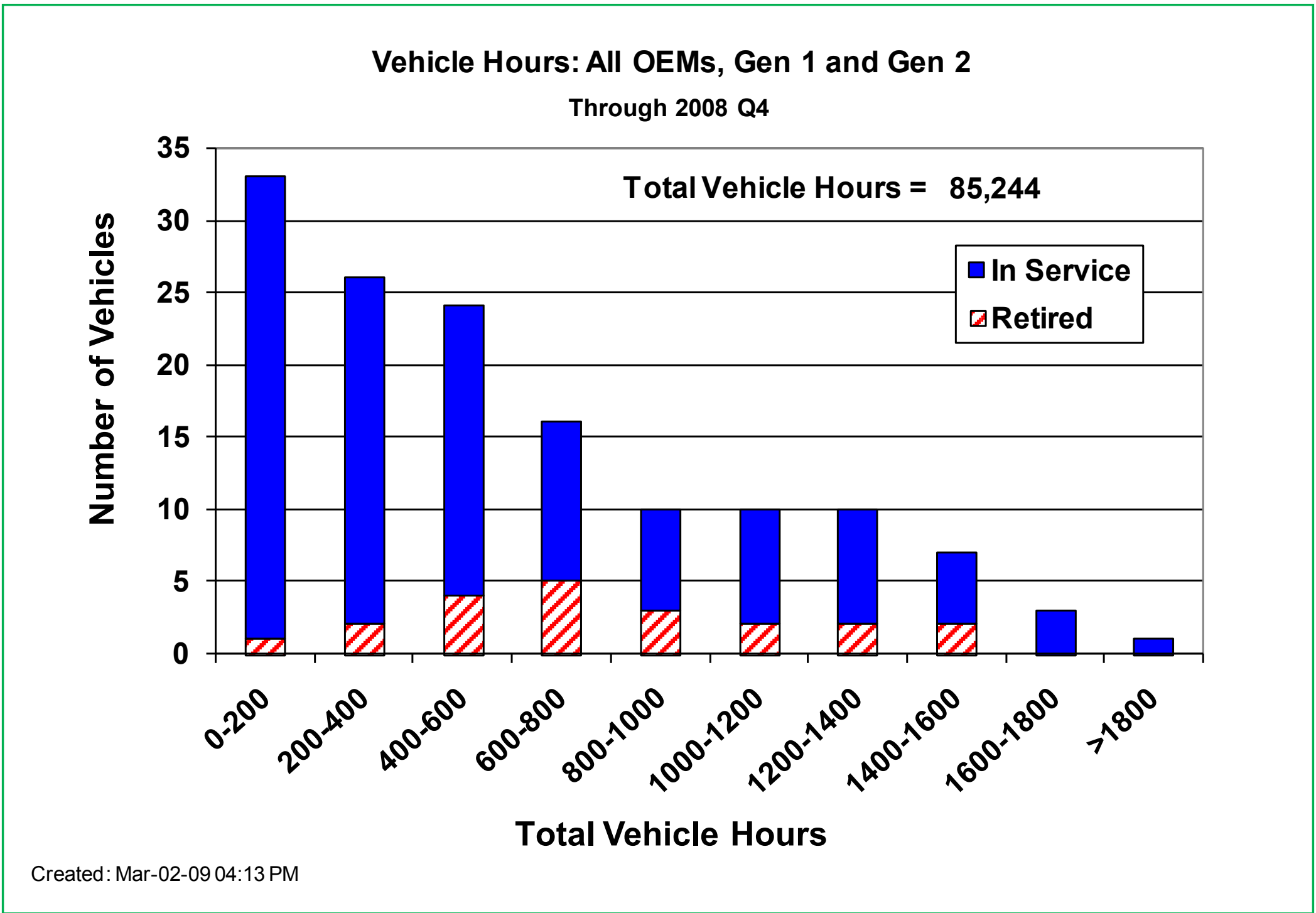




\section{CDP\#23: Vehicles vs. Miles Traveled}

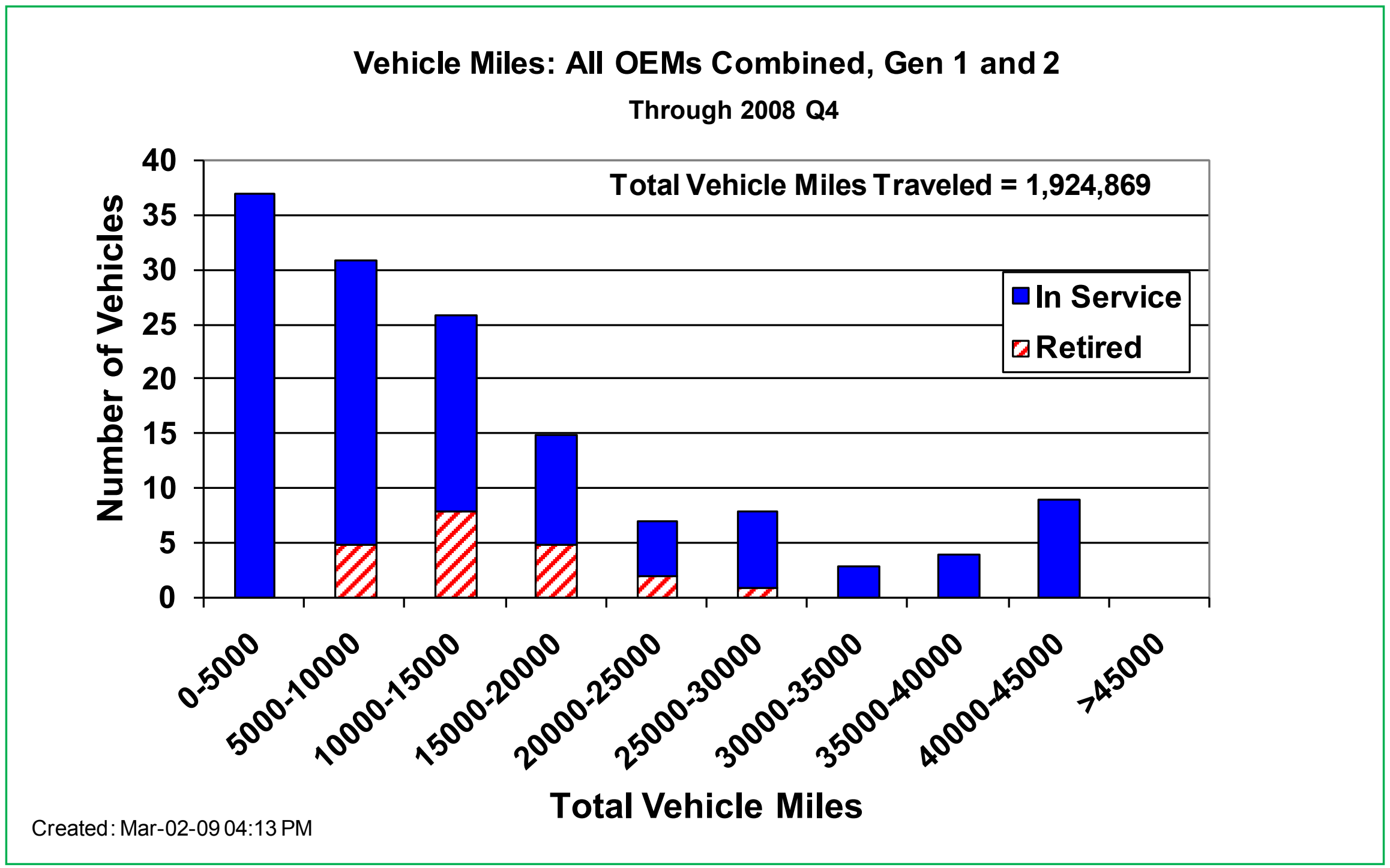




\section{CDP\#24: Cumulative Vehicle Miles Traveled}

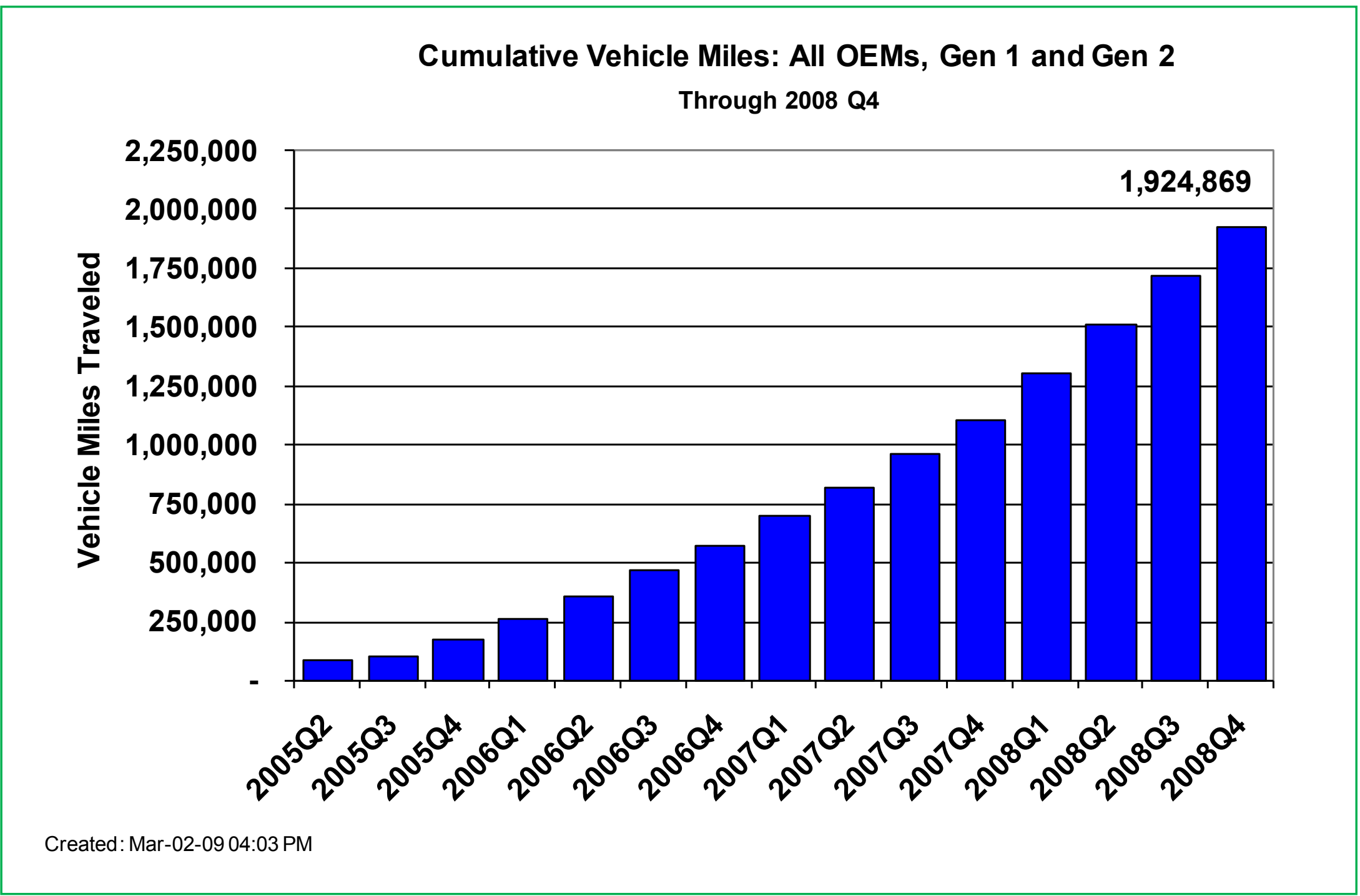




\section{CDP\#25: Vehicle H2 Storage Technologies}

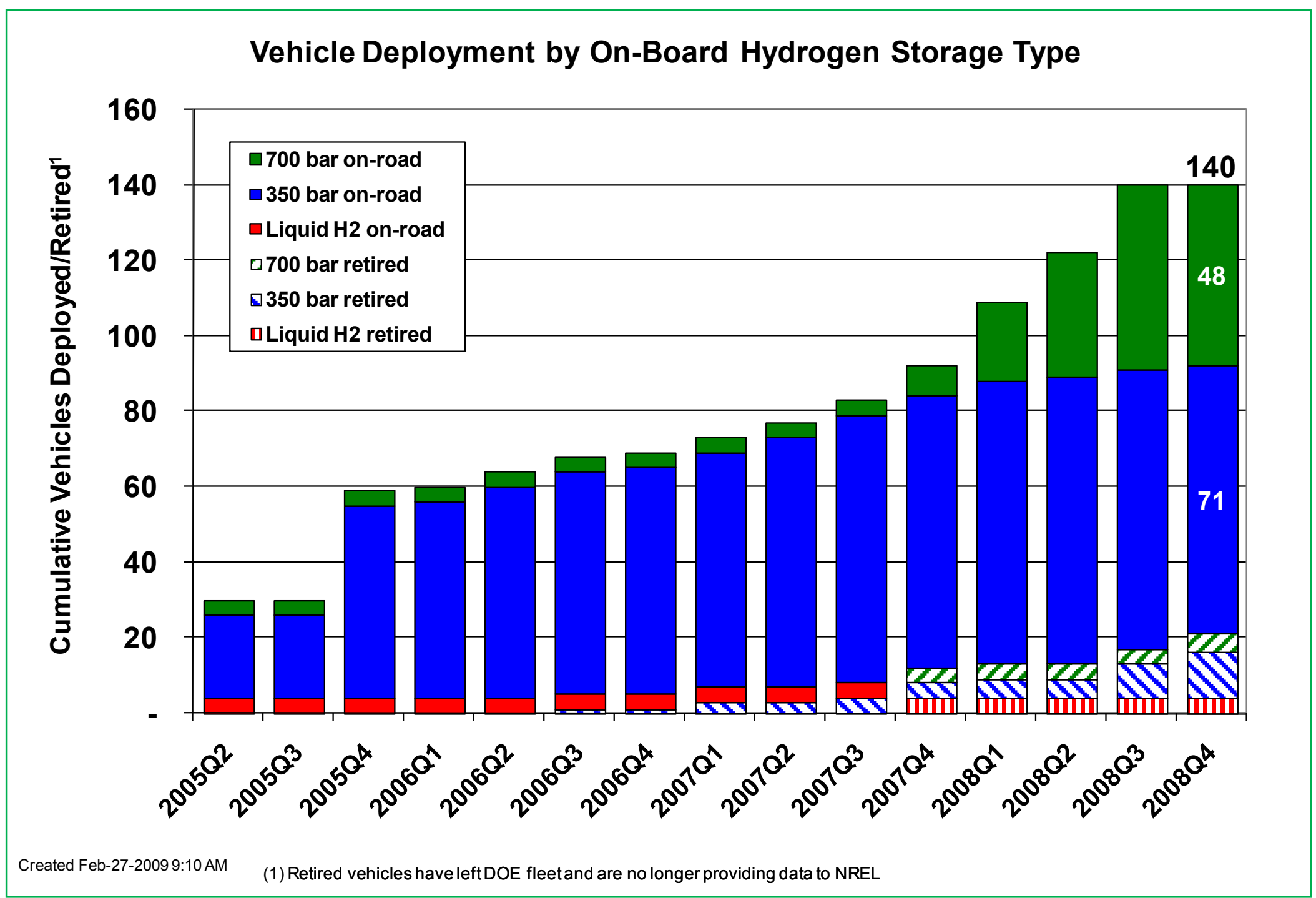




\section{CDP\#26: Cumulative H2 Produced or Dispensed}

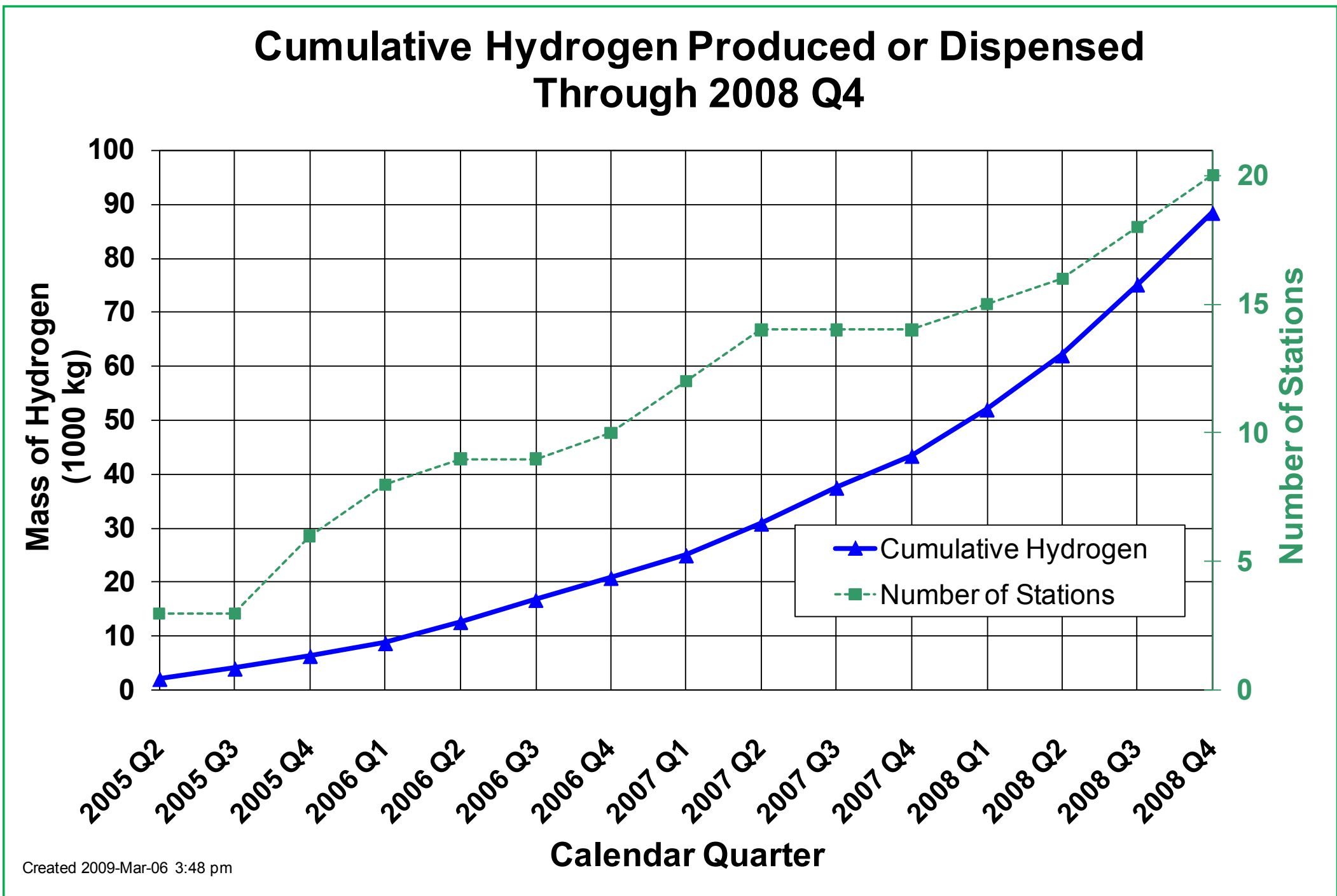




\section{CDP\#27: Hydrogen Quality Index}

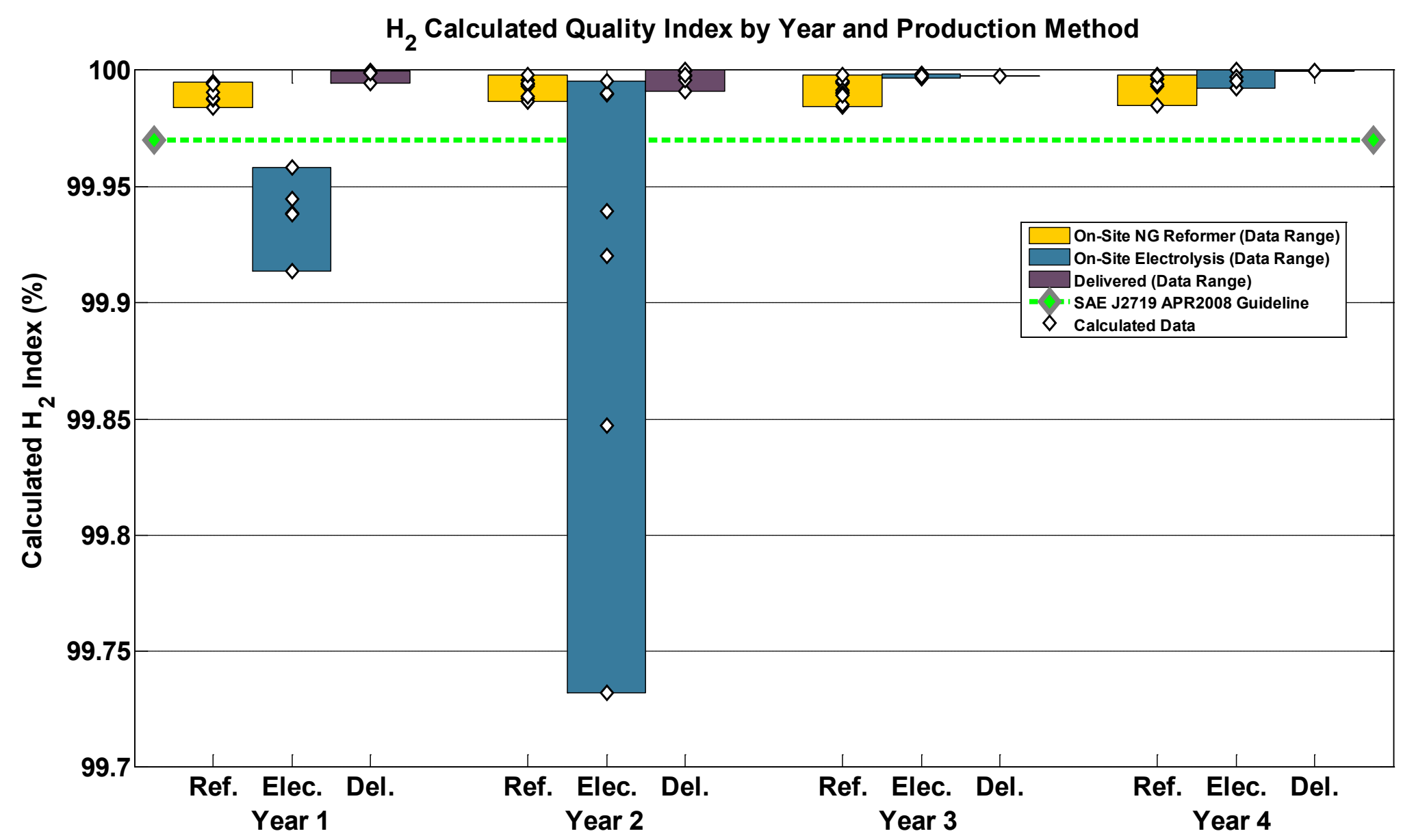

Data is from Learning Demonstration and California Fuel Cell Partnership testing

Year 1 is 2005Q3-2006Q2, Year 2 is 2006Q3-2007Q2, Year 3 is 2007Q3-2008Q2, and Year 4 is 2008Q3-2008Q4 


\section{CDP\#28: Hydrogen Fuel Constituents}

\section{$\mathrm{H}_{2}$ Fuel Constituents}
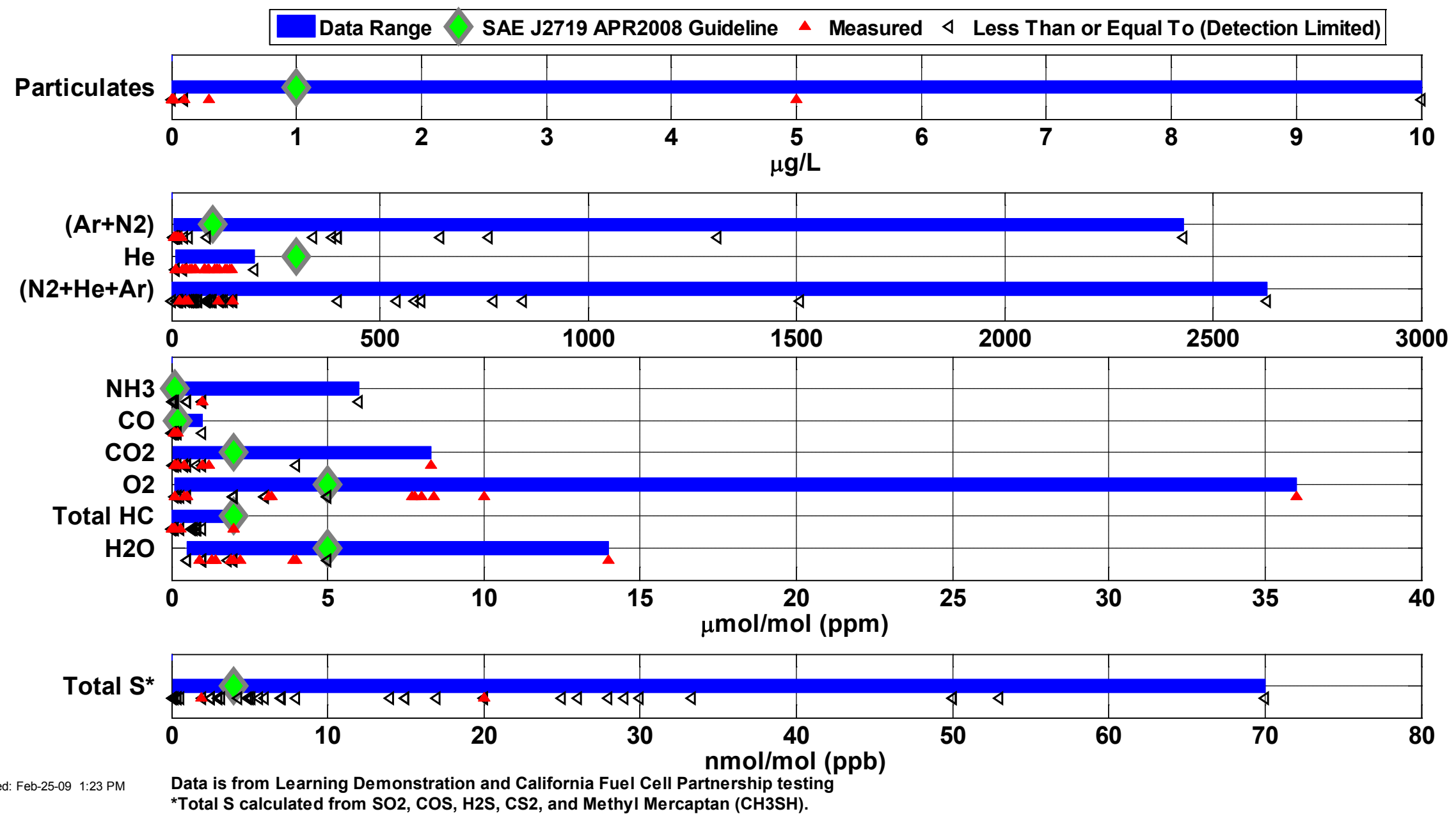


\section{CDP\#28 Supplemental: Hydrogen Constituents by Year and Production Method}

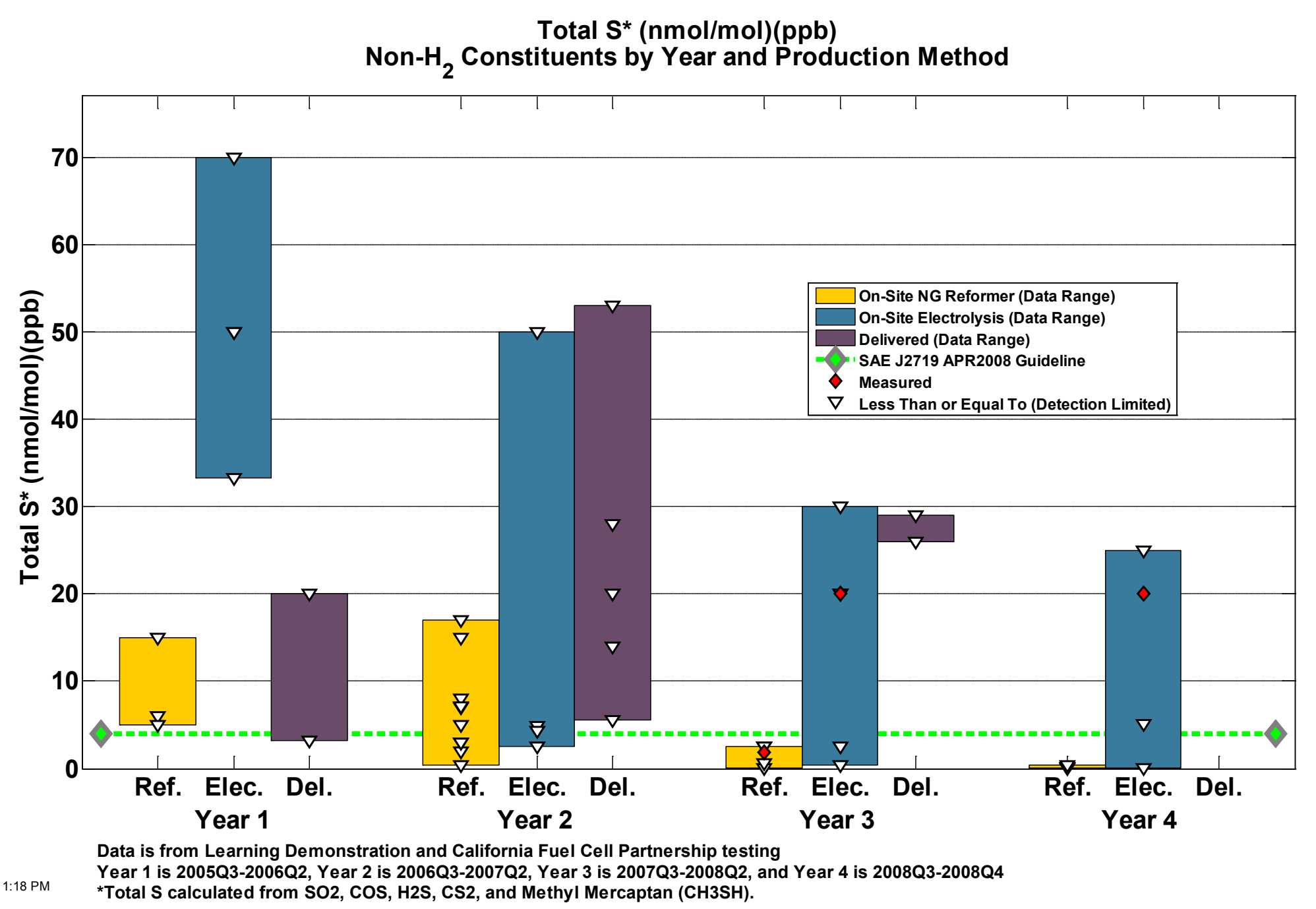




\section{CDP\#28 Supplemental: Hydrogen Constituents by Year and Production Method}

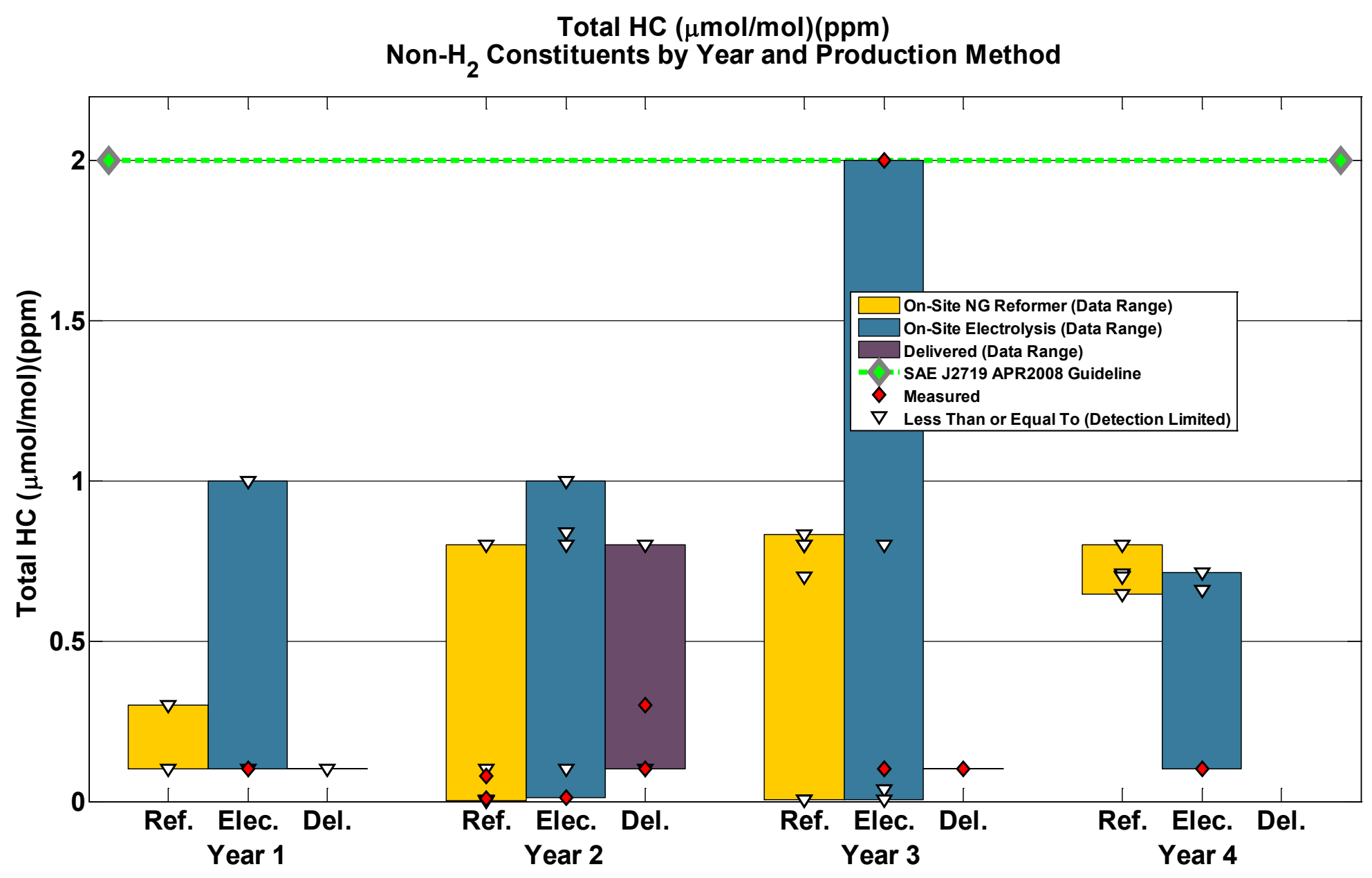

Data is from Learning Demonstration and California Fuel Cell Partnership testing

Year 1 is 2005Q3-2006Q2, Year 2 is 2006Q3-2007Q2, Year 3 is 2007Q3-2008Q2, and Year 4 is 2008Q3-2008Q4 


\section{CDP\#28 Supplemental: Hydrogen Constituents by Year and Production Method}

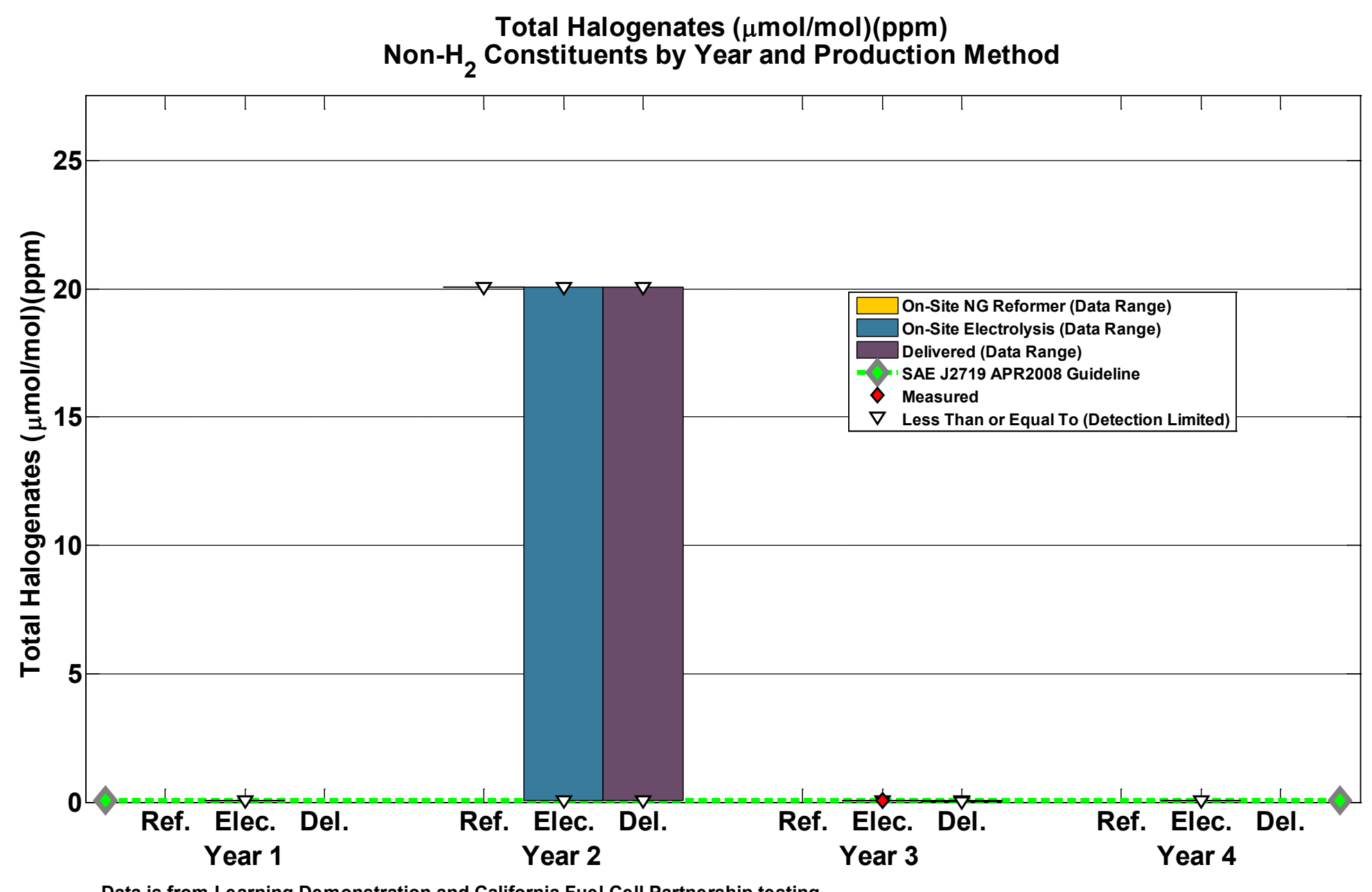

Data is from Learning Demonstration and California Fuel Cell Partnership testing

Year 1 is 2005Q3-2006Q2, Year 2 is 2006Q3-2007Q2, Year 3 is 2007Q3-2008Q2, and Year 4 is 2008Q3-2008Q4 


\section{CDP\#28 Supplemental: Hydrogen Constituents by Year and Production Method}

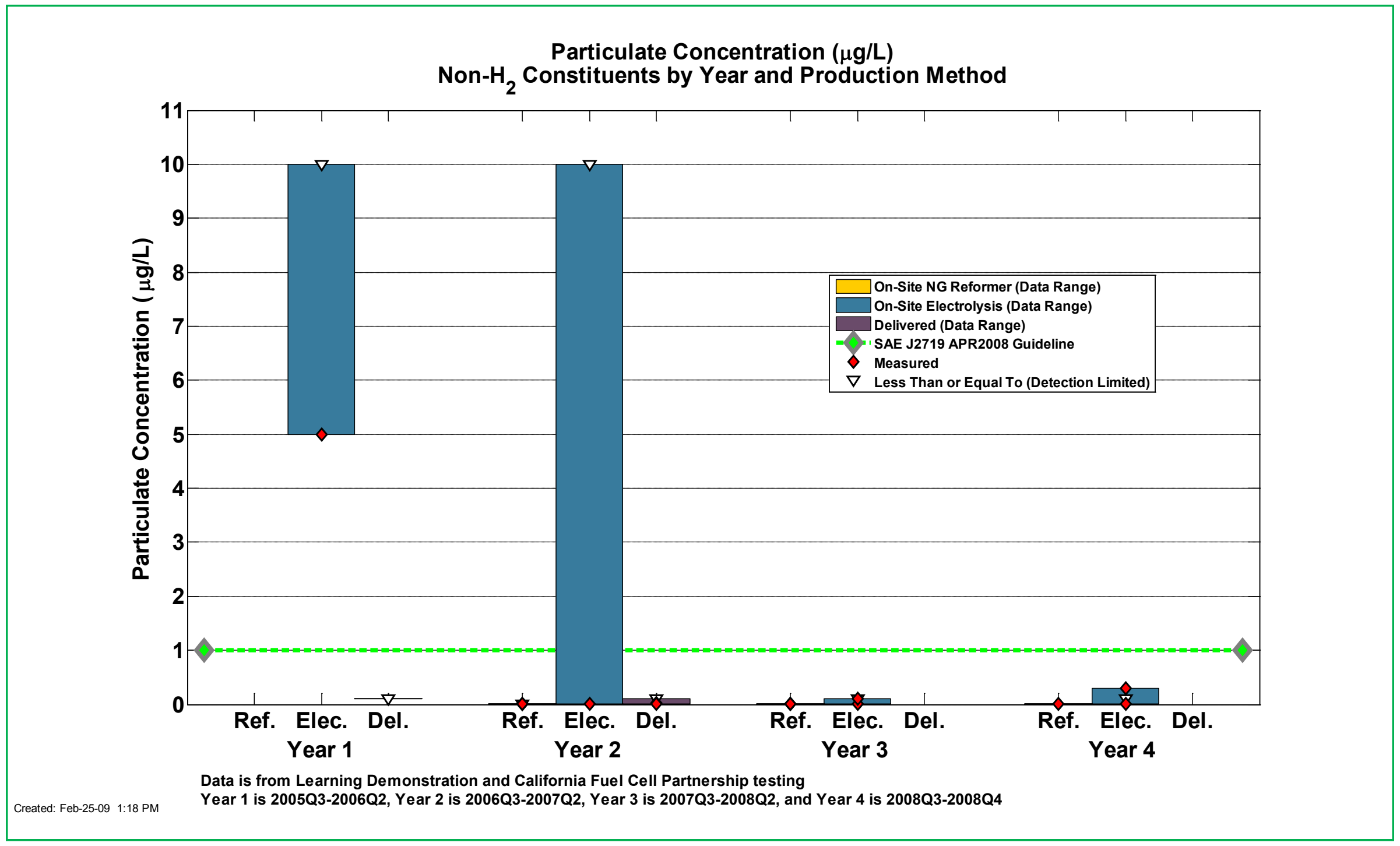




\section{CDP\#28 Supplemental: Hydrogen Constituents by Year and Production Method}

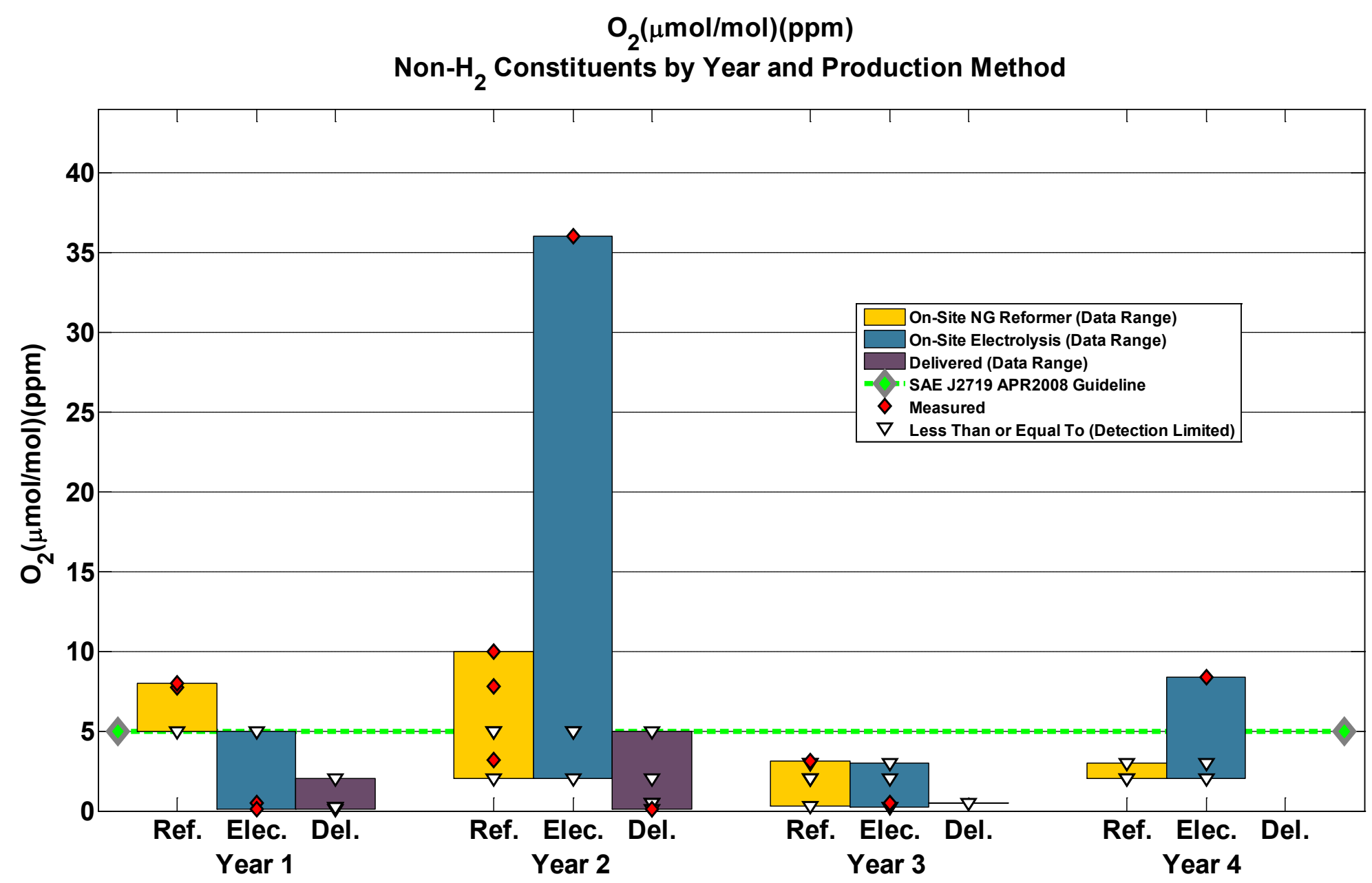

Data is from Learning Demonstration and California Fuel Cell Partnership testing

Year 1 is 2005Q3-2006Q2, Year 2 is 2006Q3-2007Q2, Year 3 is 2007Q3-2008Q2, and Year 4 is 2008Q3-2008Q4 


\section{CDP\#28 Supplemental: Hydrogen Constituents by Year and Production Method}

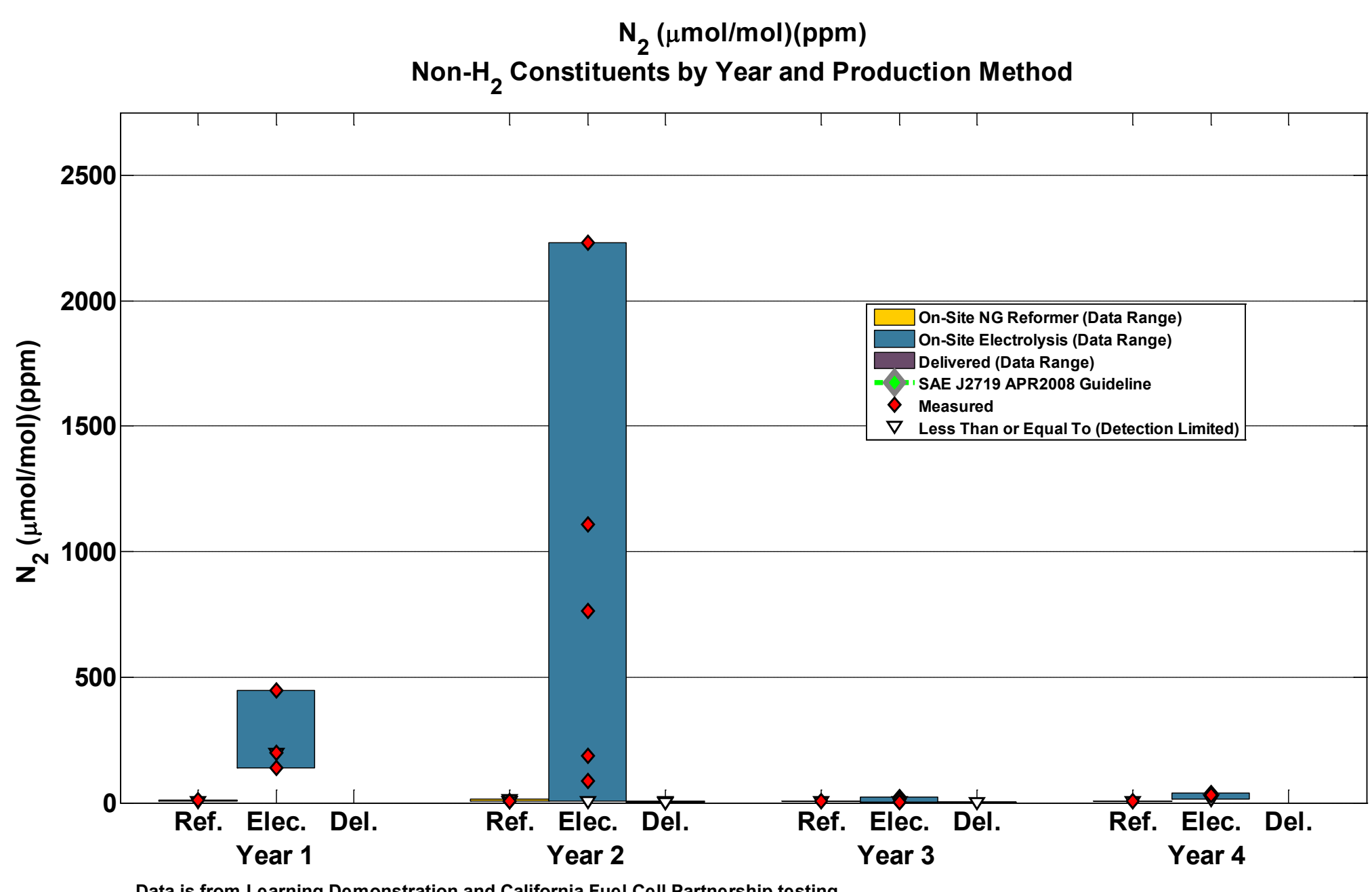

Data is from Learning Demonstration and California Fuel Cell Partnership testing

Year 1 is 2005Q3-2006Q2, Year 2 is 2006Q3-2007Q2, Year 3 is 2007Q3-2008Q2, and Year 4 is 2008Q3-2008Q4 


\section{CDP\#28 Supplemental: Hydrogen Constituents by Year and Production Method}

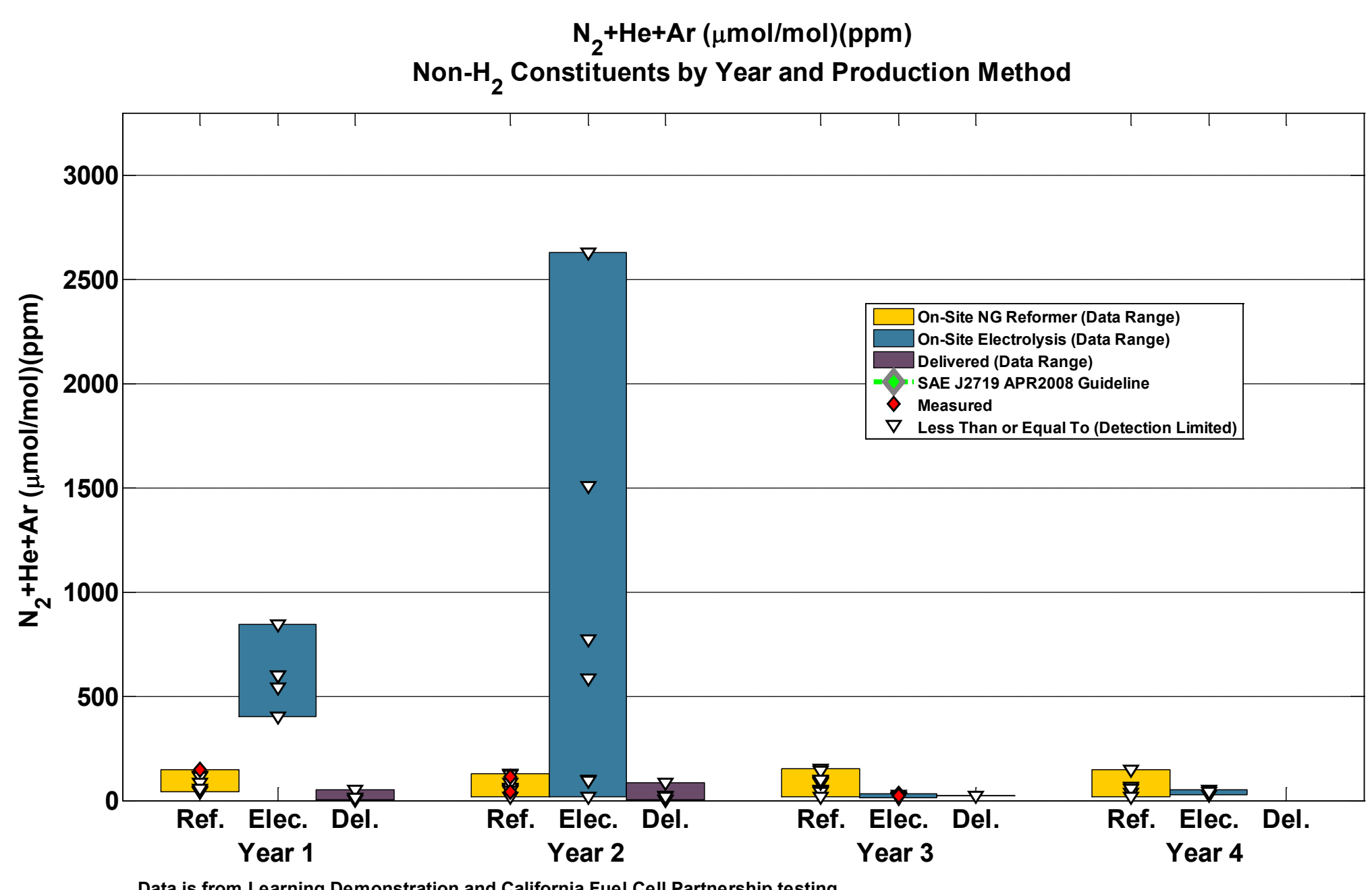

Data is from Learning Demonstration and California Fuel Cell Partnership testing

Year 1 is 2005Q3-2006Q2, Year 2 is 2006Q3-2007Q2, Year 3 is 2007Q3-2008Q2, and Year 4 is 2008Q3-2008Q4 


\section{CDP\#28 Supplemental: Hydrogen Constituents by Year and Production Method}

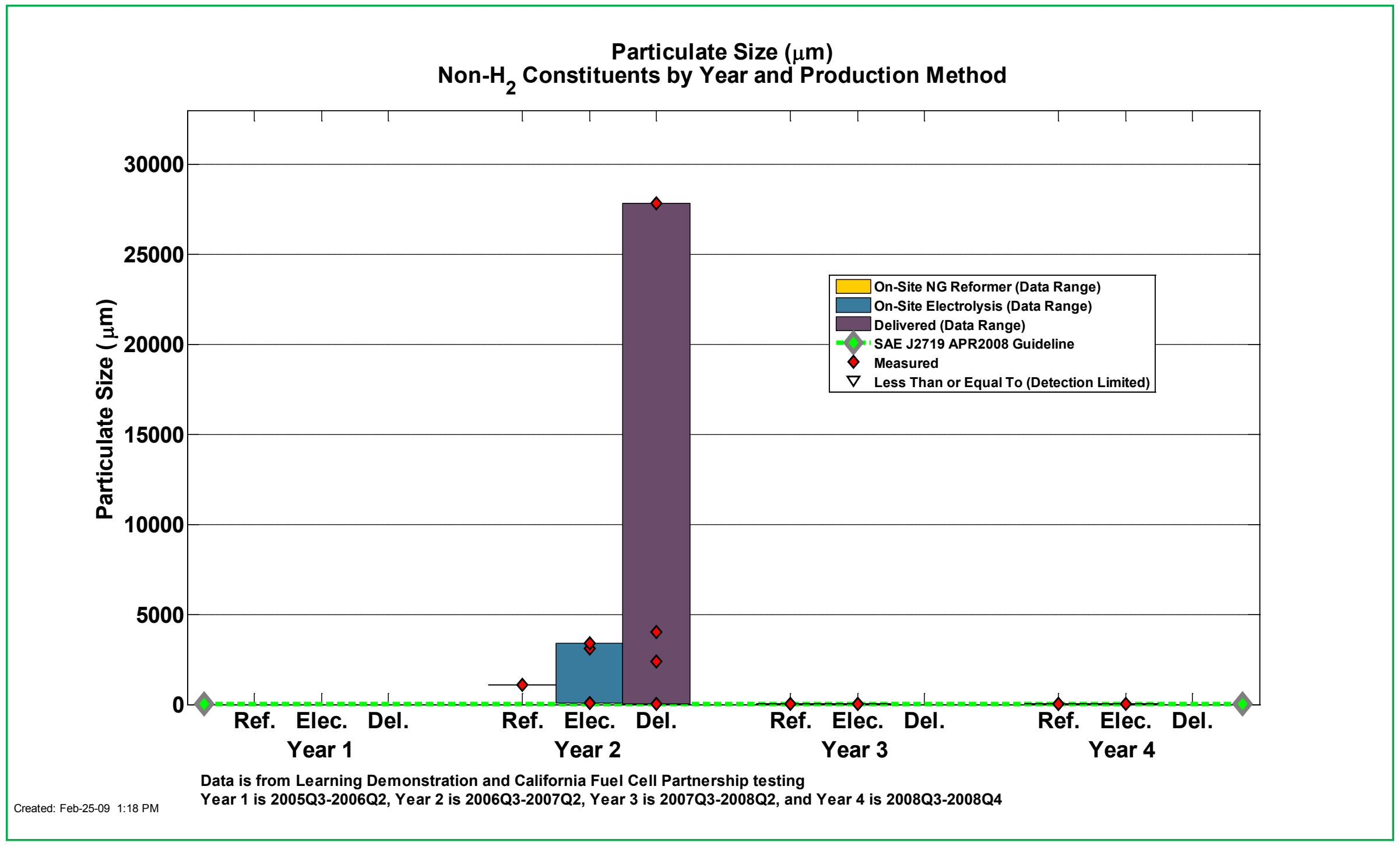




\section{CDP\#28 Supplemental: Hydrogen Constituents by Year and Production Method}

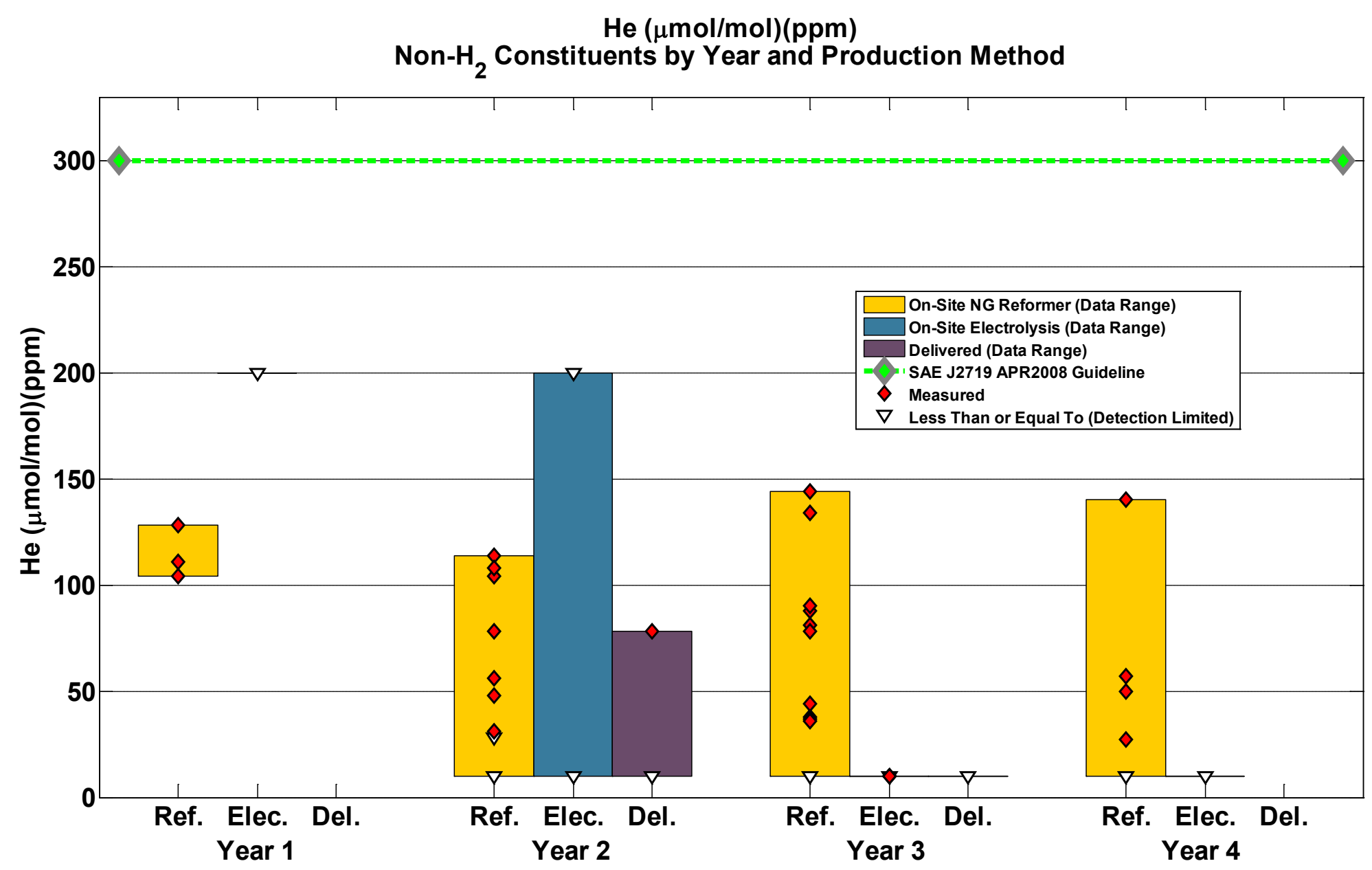

Data is from Learning Demonstration and California Fuel Cell Partnership testing

Year 1 is 2005Q3-2006Q2, Year 2 is 2006Q3-2007Q2, Year 3 is 2007Q3-2008Q2, and Year 4 is 2008Q3-2008Q4 


\section{CDP\#28 Supplemental: Hydrogen Constituents by Year and Production Method}

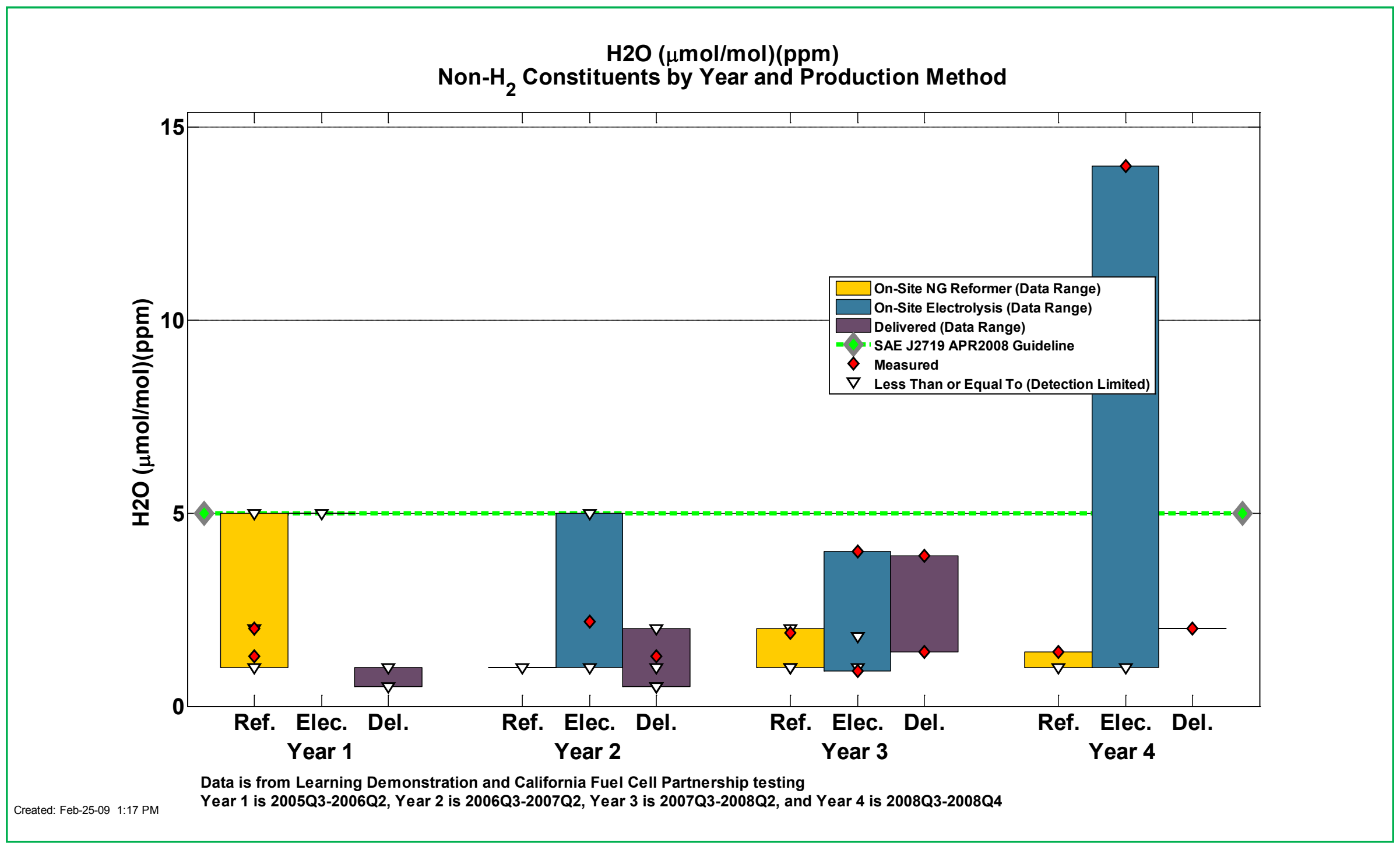




\section{CDP\#28 Supplemental: Hydrogen Constituents by Year and Production Method}

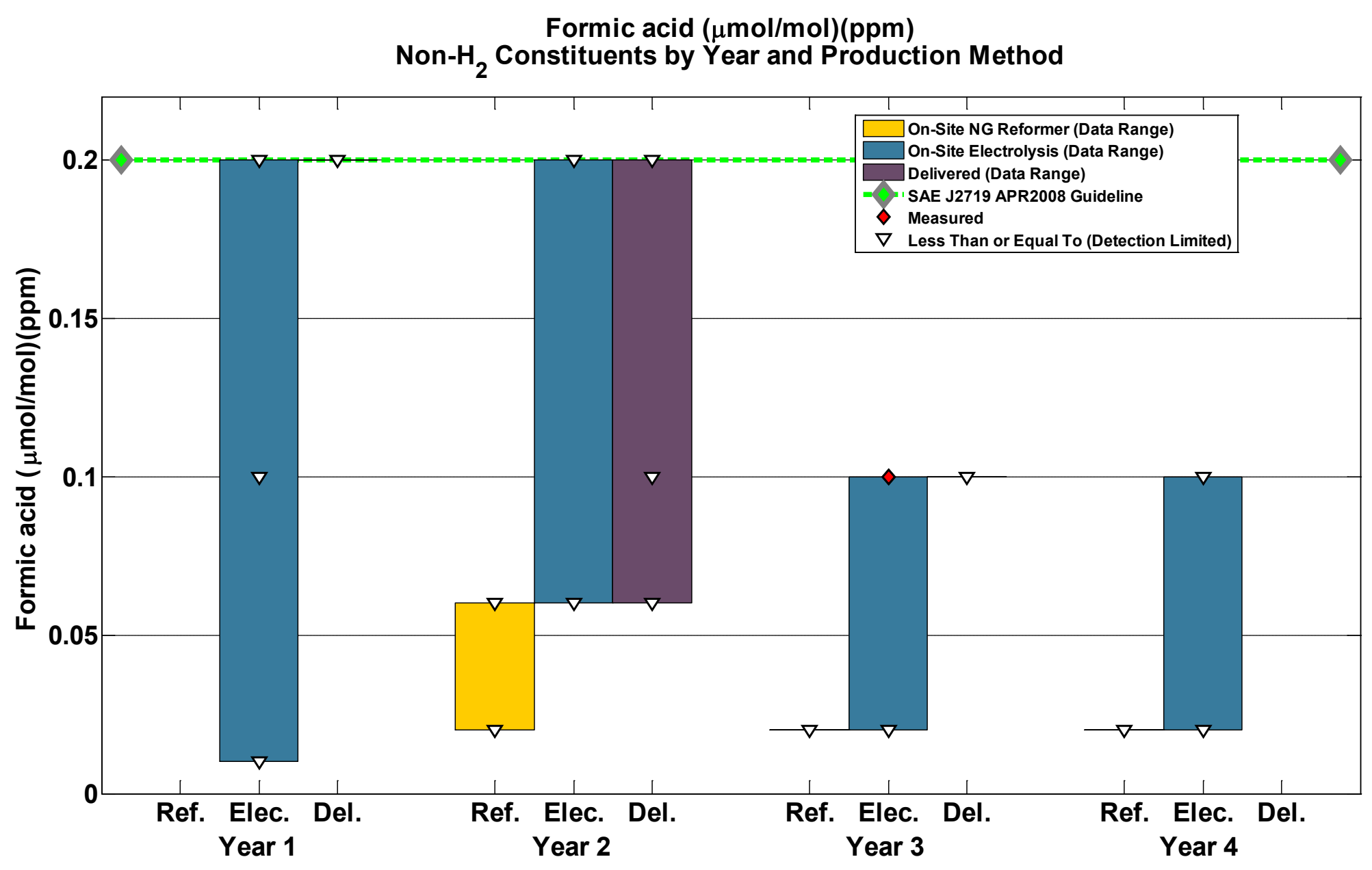

Data is from Learning Demonstration and California Fuel Cell Partnership testing

Year 1 is 2005Q3-2006Q2, Year 2 is 2006Q3-2007Q2, Year 3 is 2007Q3-2008Q2, and Year 4 is 2008Q3-2008Q4 


\section{CDP\#28 Supplemental: Hydrogen Constituents by Year and Production Method}

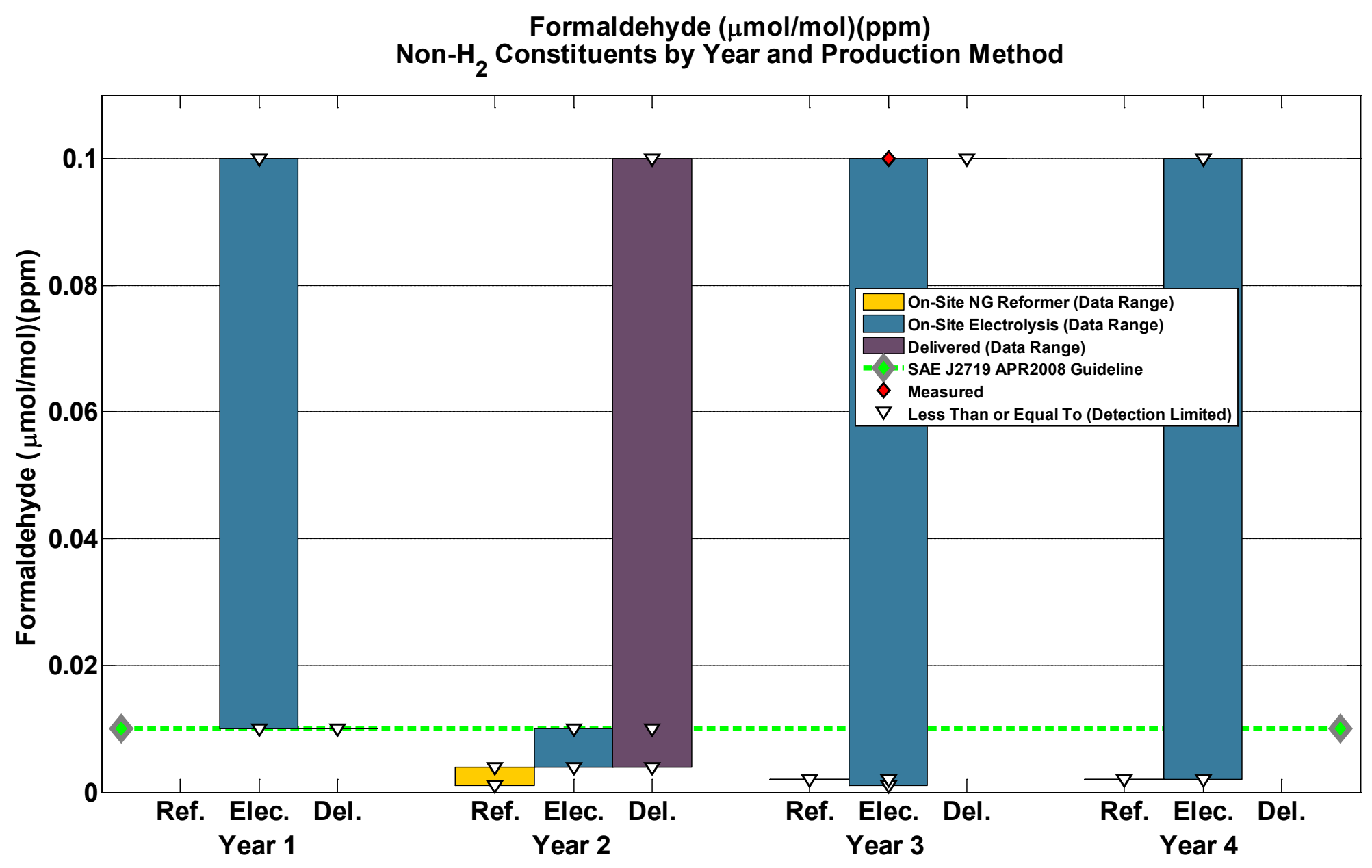

Data is from Learning Demonstration and California Fuel Cell Partnership testing

Year 1 is 2005Q3-2006Q2, Year 2 is 2006Q3-2007Q2, Year 3 is 2007Q3-2008Q2, and Year 4 is 2008Q3-2008Q4 


\section{CDP\#28 Supplemental: Hydrogen Constituents by Year and Production Method}

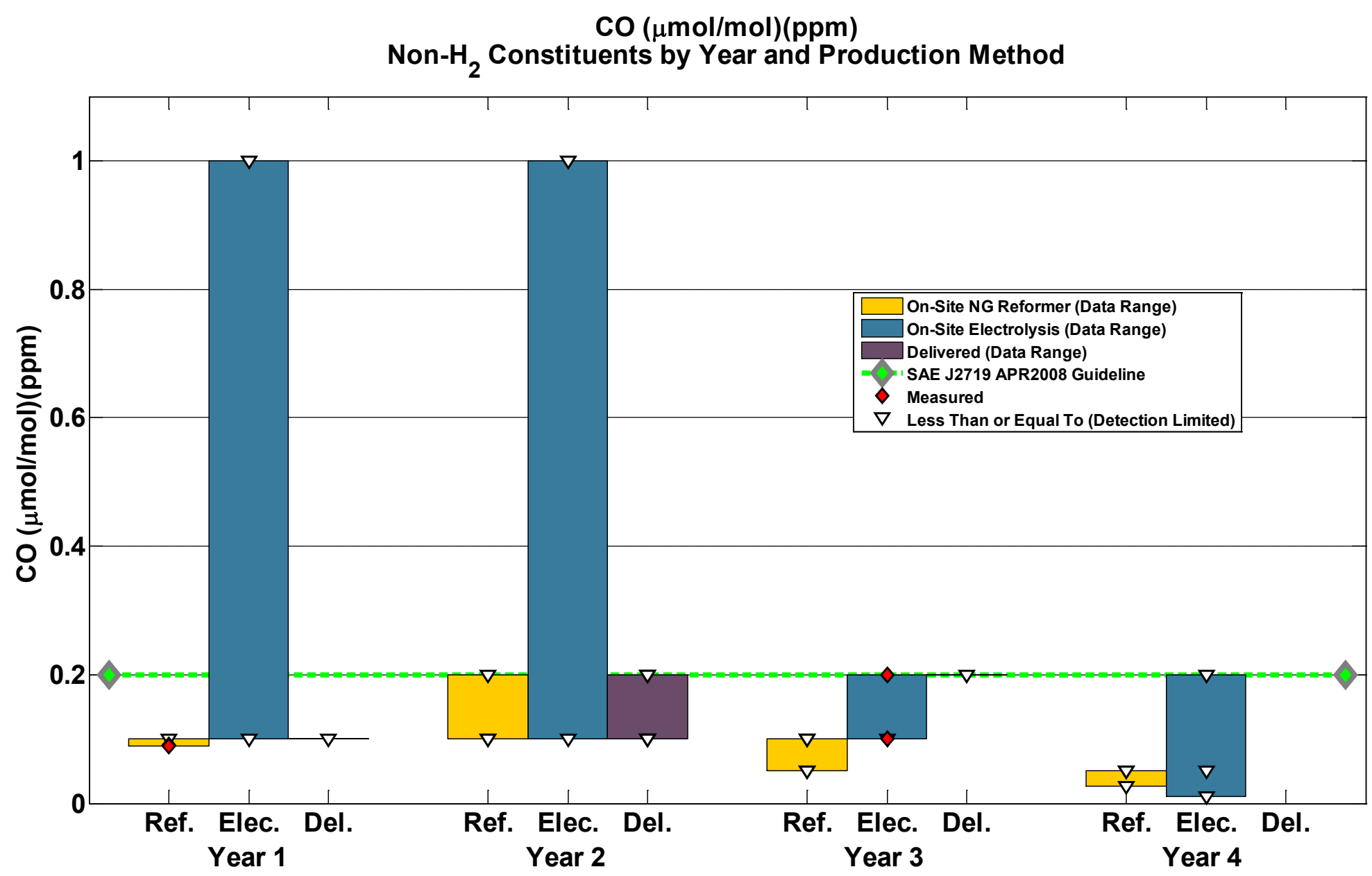

Data is from Learning Demonstration and California Fuel Cell Partnership testing

Year 1 is 2005Q3-2006Q2, Year 2 is 2006Q3-2007Q2, Year 3 is 2007Q3-2008Q2, and Year 4 is 2008Q3-2008Q4 


\section{CDP\#28 Supplemental: Hydrogen Constituents by Year and Production Method}

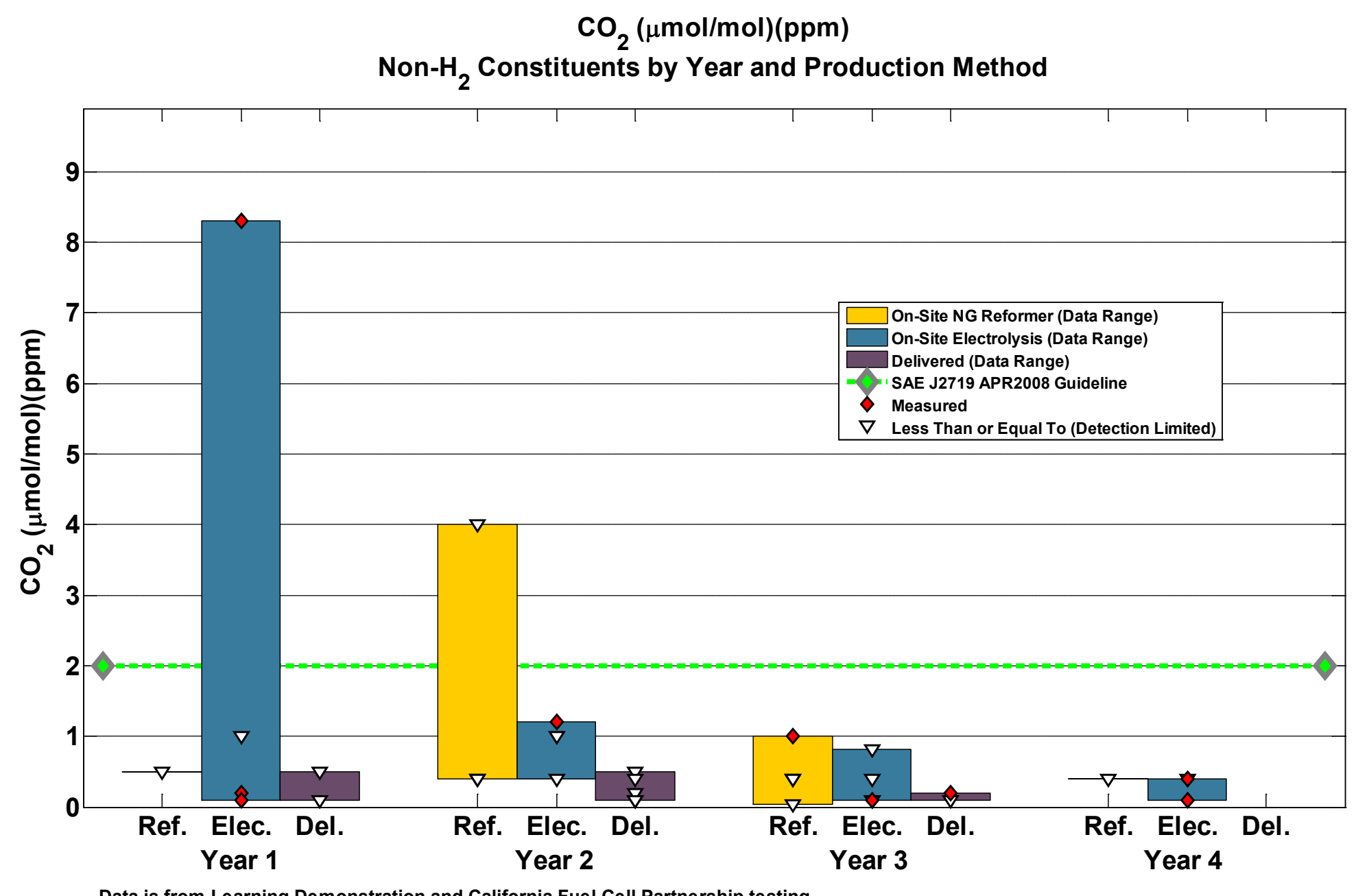

Data is from Learning Demonstration and California Fuel Cell Partnership testing

Year 1 is 2005Q3-2006Q2, Year 2 is 2006Q3-2007Q2, Year 3 is 2007Q3-2008Q2, and Year 4 is 2008Q3-2008Q4 


\section{CDP\#28 Supplemental: Hydrogen Constituents by Year and Production Method}

Calcultated Total Impurities $(\mu \mathrm{mol} / \mathrm{mol})(\mathrm{ppm})$ Non- $\mathrm{H}_{2}$ Constituents by Year and Production Method

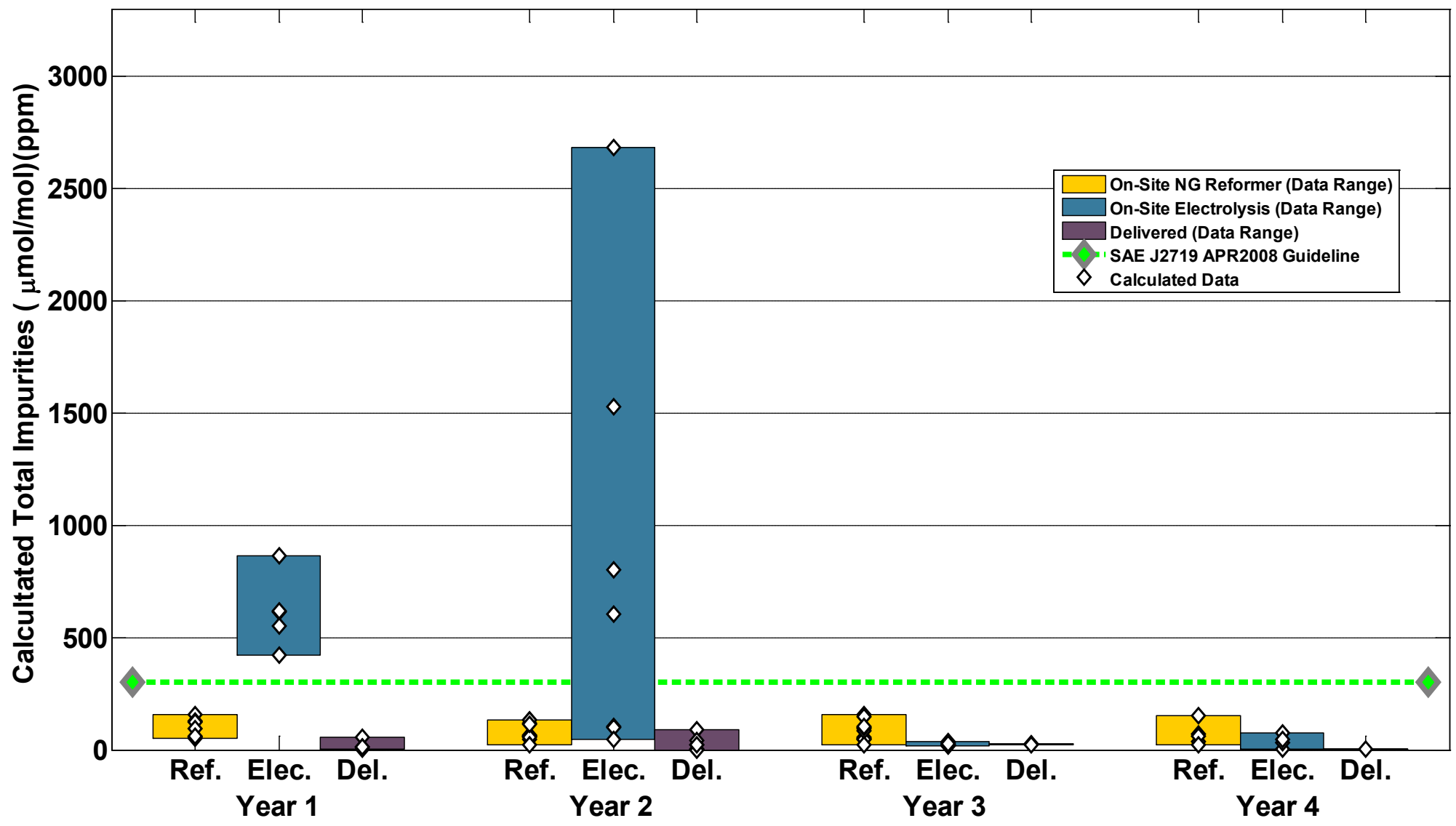

Data is from Learning Demonstration and California Fuel Cell Partnership testing

Year 1 is 2005Q3-2006Q2, Year 2 is 2006Q3-2007Q2, Year 3 is 2007Q3-2008Q2, and Year 4 is 2008Q3-2008Q4 


\section{CDP\#28 Supplemental: Hydrogen Constituents by Year and Production Method}

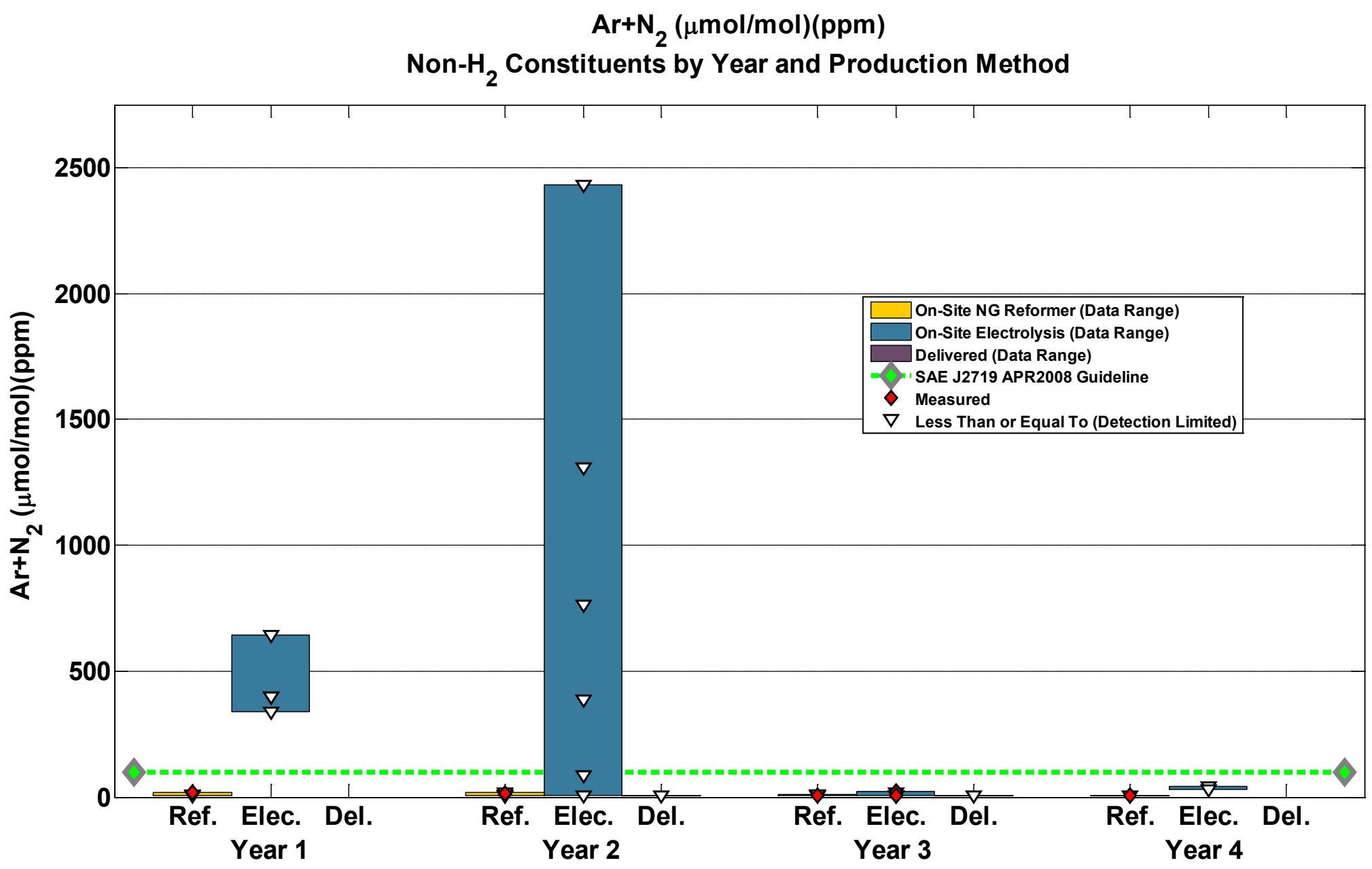

Data is from Learning Demonstration and California Fuel Cell Partnership testing

Year 1 is 2005Q3-2006Q2, Year 2 is 2006Q3-2007Q2, Year 3 is 2007Q3-2008Q2, and Year 4 is 2008Q3-2008Q4 


\section{CDP\#28 Supplemental: Hydrogen Constituents by Year and Production Method}

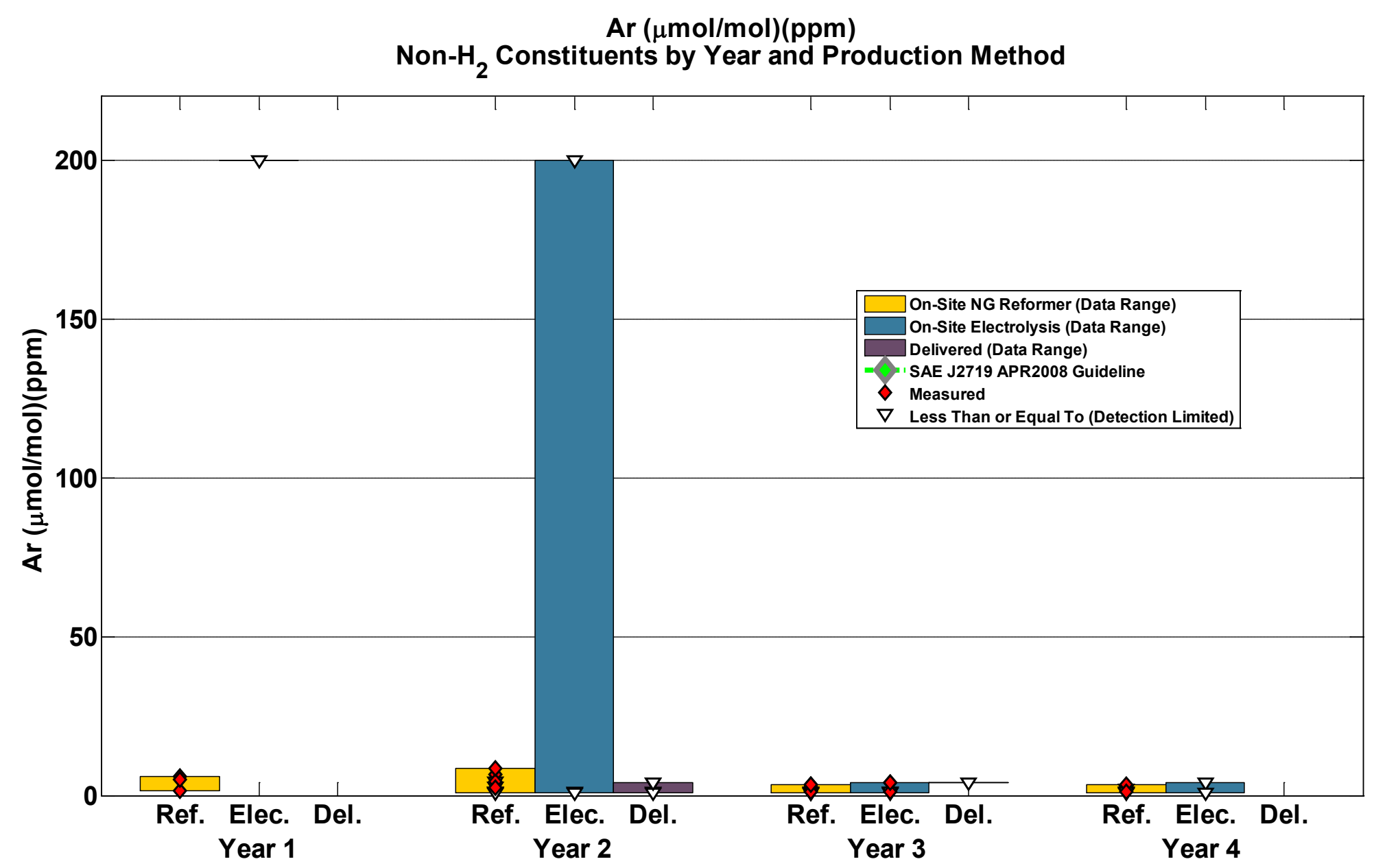

Data is from Learning Demonstration and California Fuel Cell Partnership testing

Year 1 is 2005Q3-2006Q2, Year 2 is 2006Q3-2007Q2, Year 3 is 2007Q3-2008Q2, and Year 4 is 2008Q3-2008Q4 


\section{CDP\#28 Supplemental: Hydrogen Constituents by Year and Production Method}

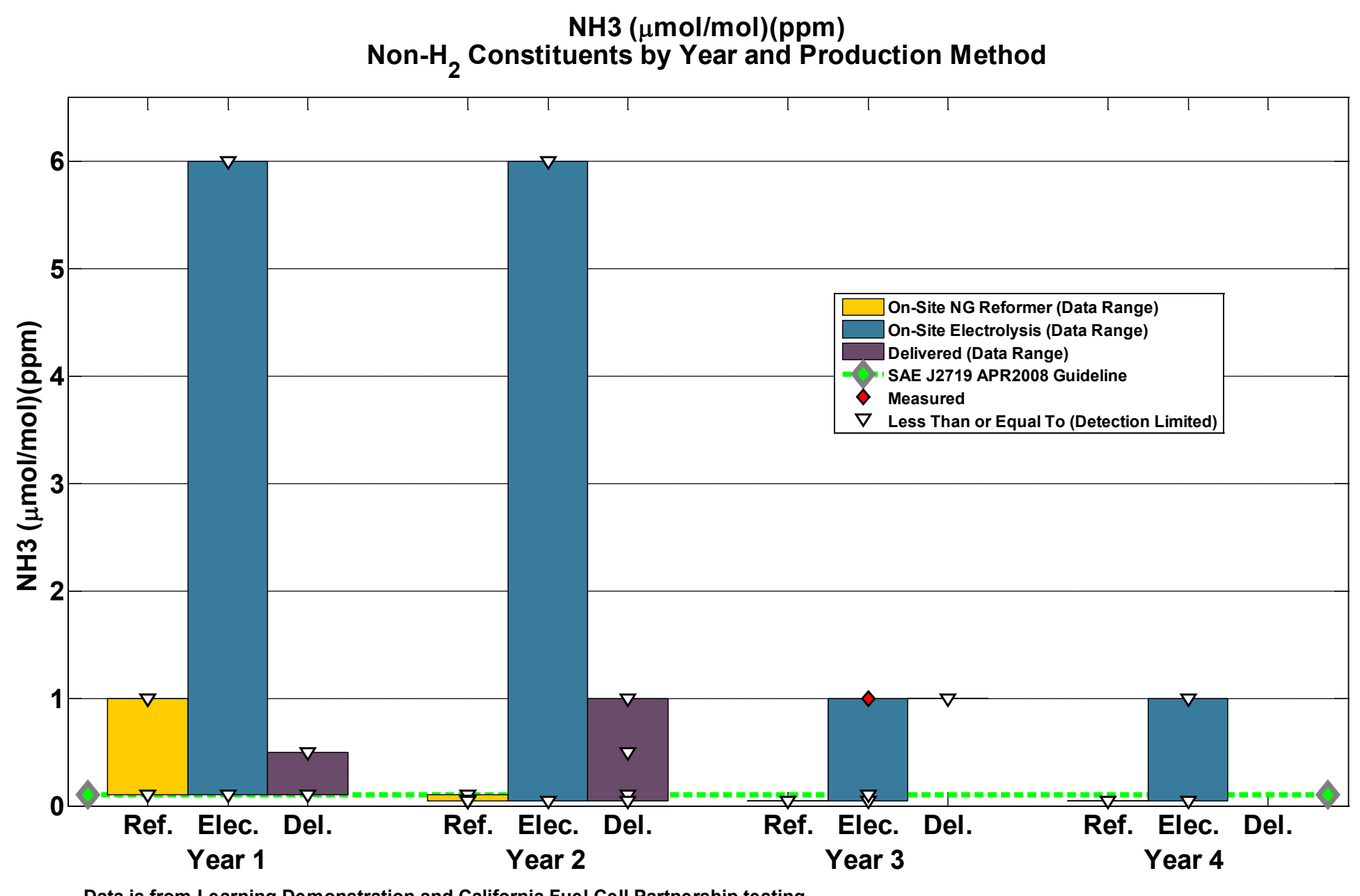

Data is from Learning Demonstration and California Fuel Cell Partnership testing

Year 1 is 2005Q3-2006Q2, Year 2 is 2006Q3-2007Q2, Year 3 is 2007Q3-2008Q2, and Year 4 is 2008Q3-2008Q4 


\section{CDP\#29: Fueling Rates Communication and Non-Communication Fills}

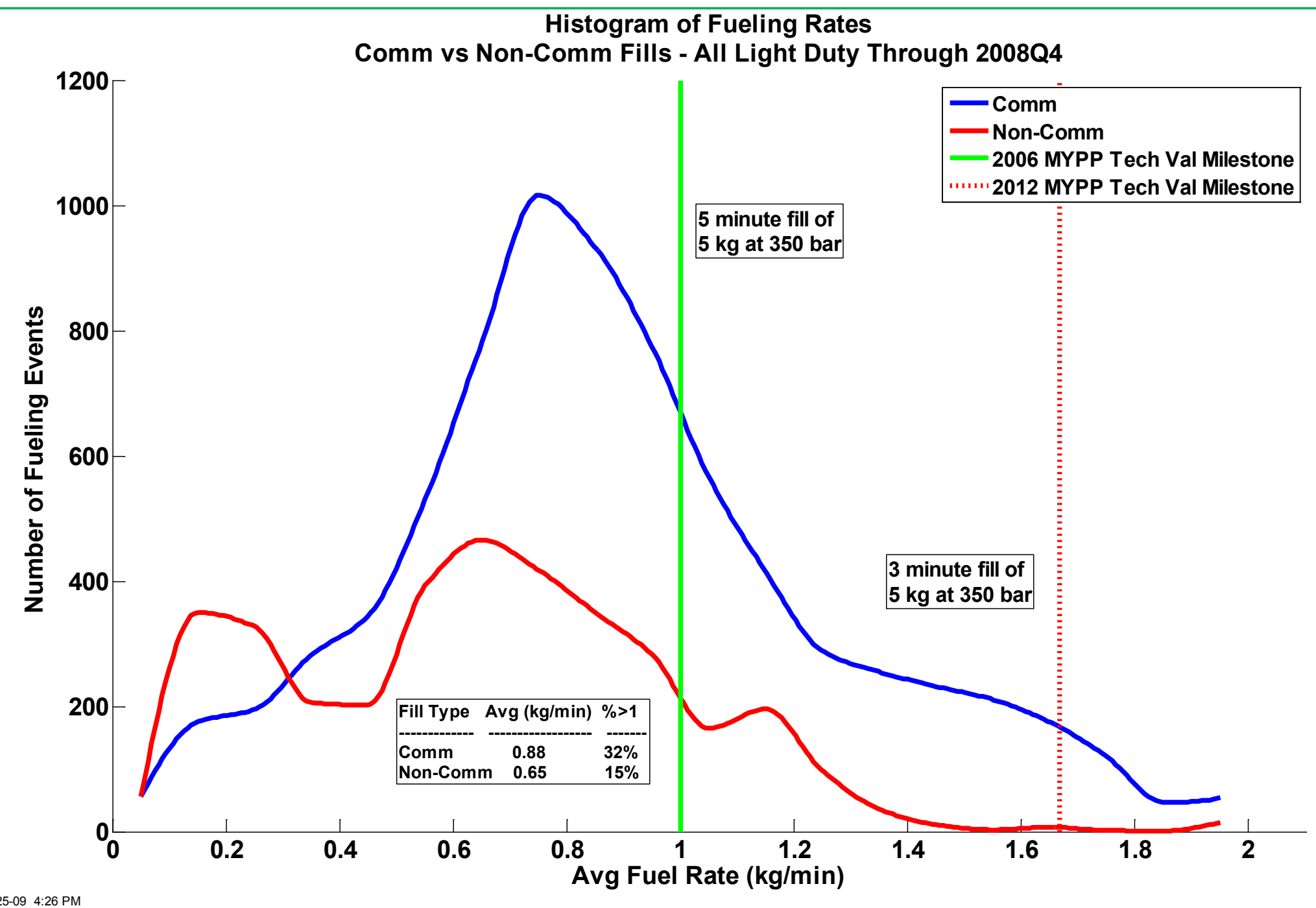




\section{CDP\#30: Infrastructure Maintenance}

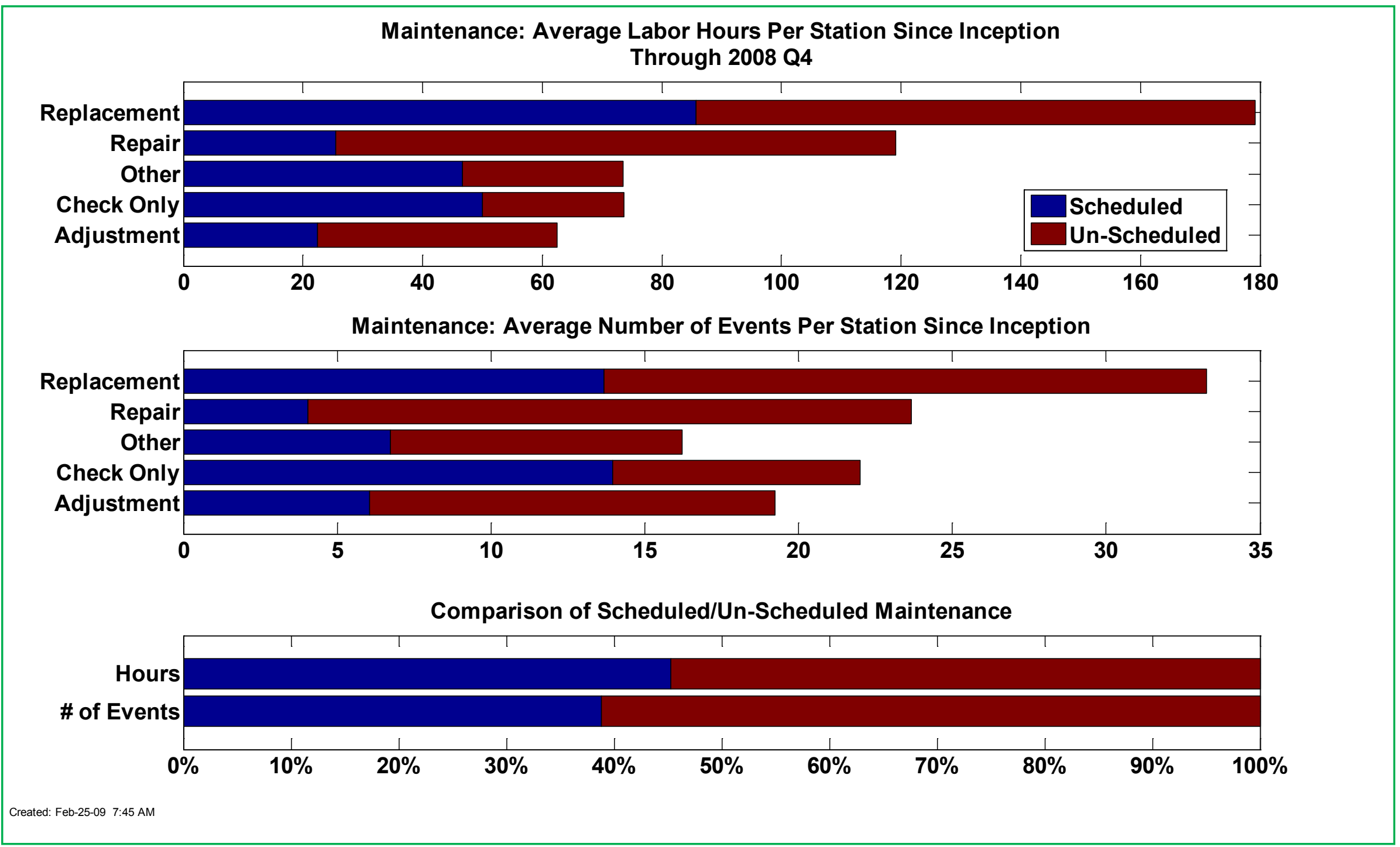




\section{CDP\#31: Number of Online Stations}

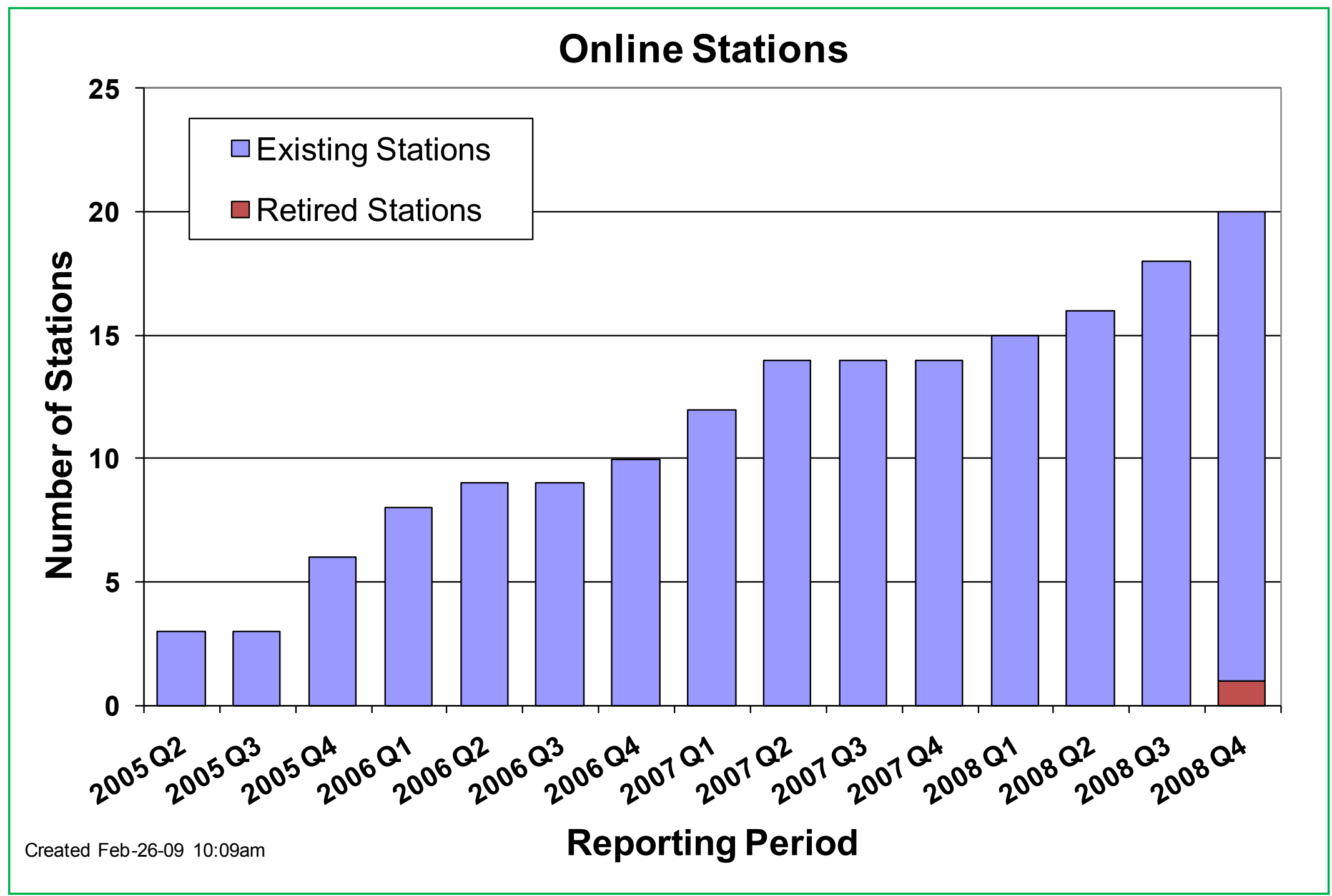




\section{CDP\#32: Infrastructure Hydrogen Production Methods}

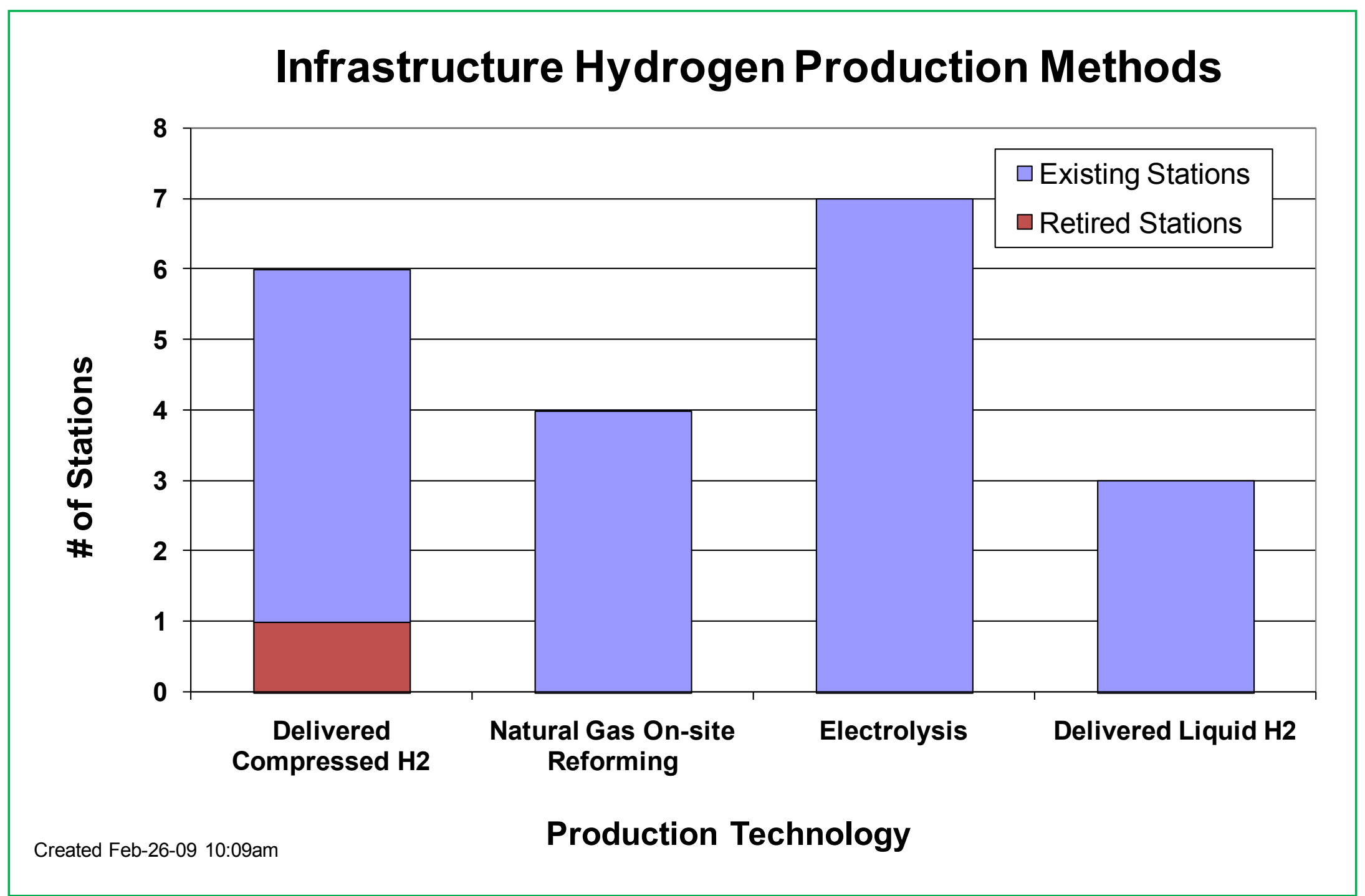




\section{CDP\#33: Percentage of Theoretical Range Traveled Between Refuelings}

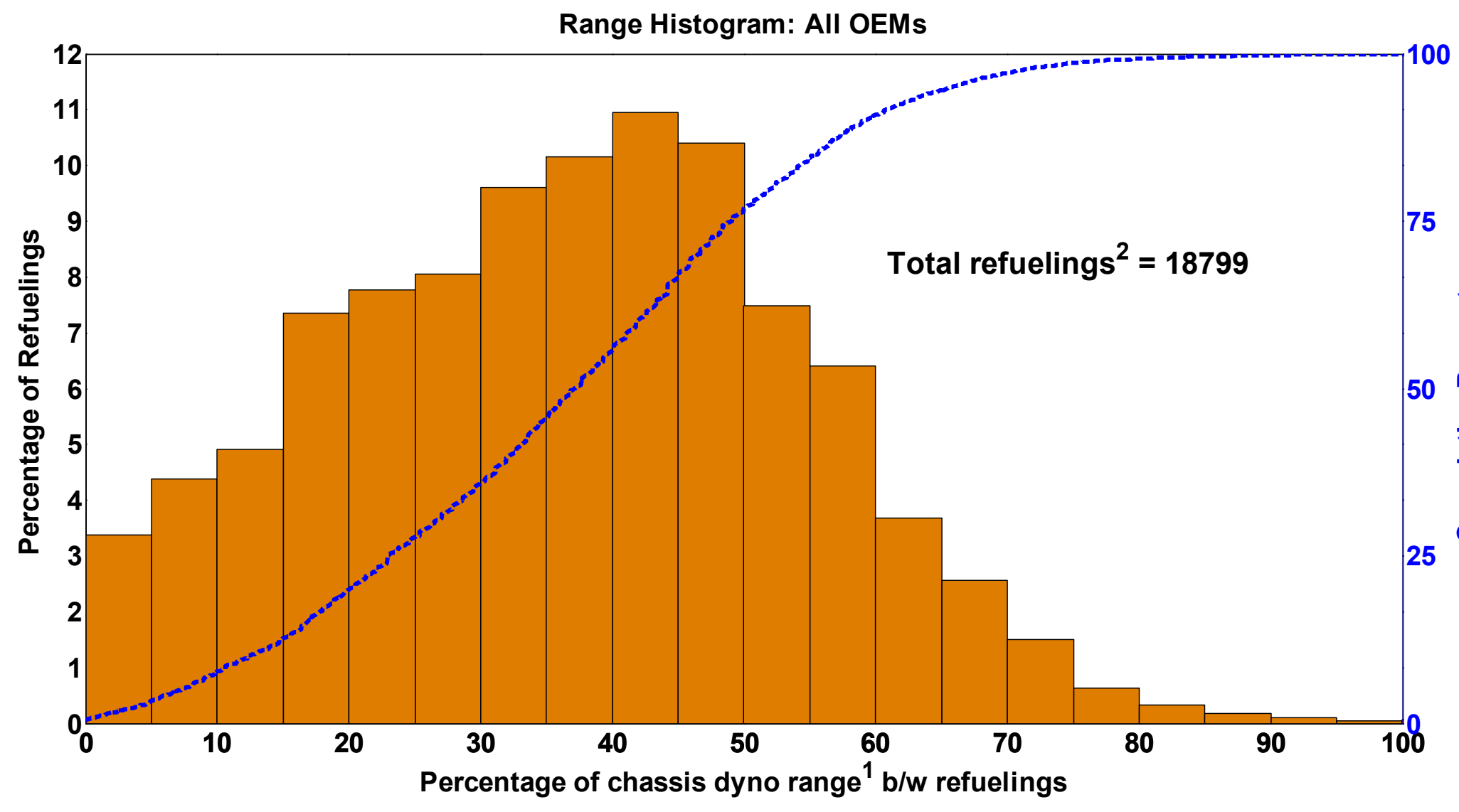

1. Range calculated using the combined City/Hwy fuel economy from dyno testing (not EPA adjusted) and usable fuel on board.

2. Some refueling events are not detected/reported due to data noise or incompleteness. 


\section{CDP\#34: Effective Vehicle Range}

Vehicle Range Factors

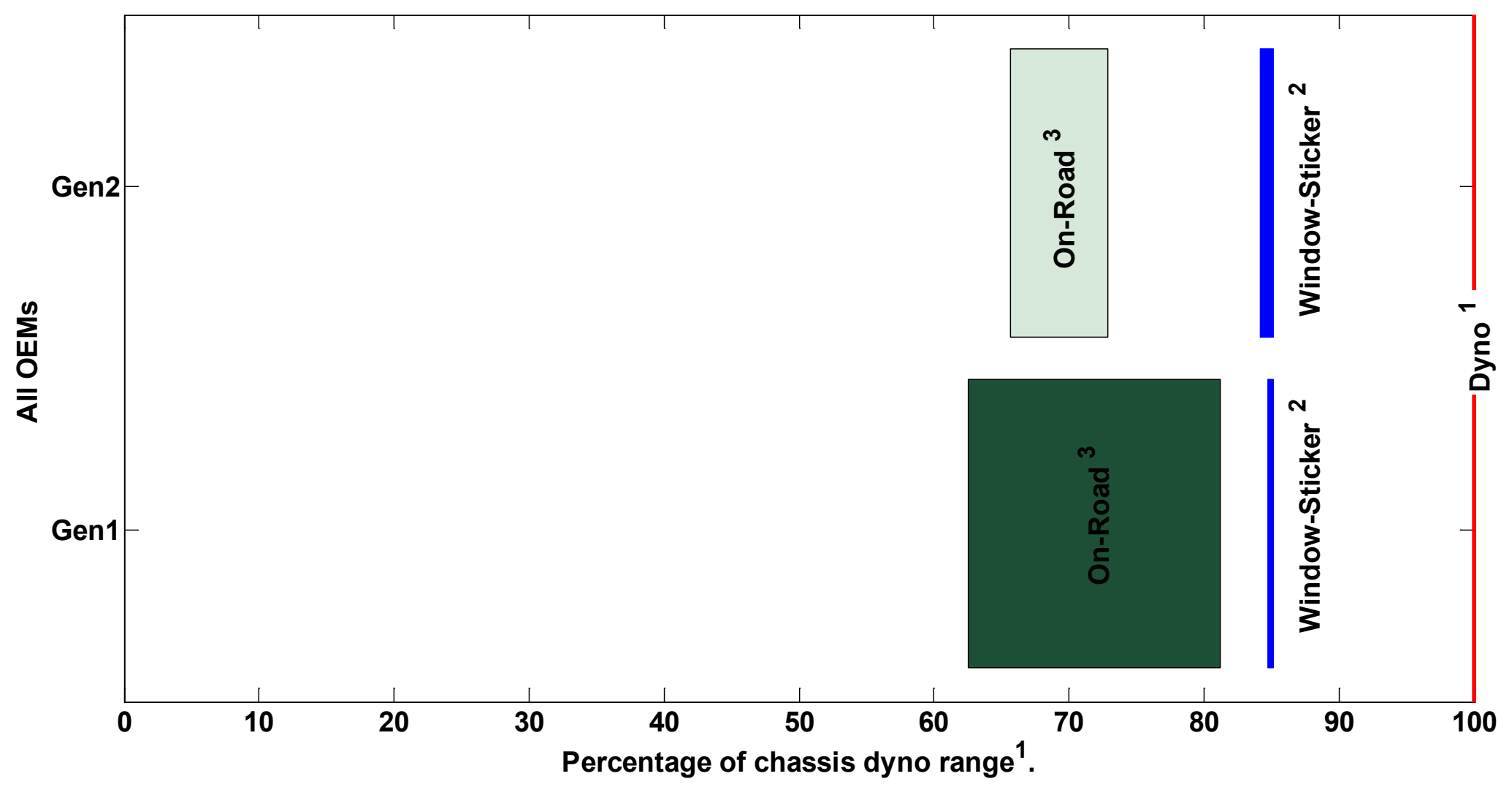

1. Calculated using the combined City/Hwy fuel economy from dyno testing (non-adjusted) and usable fuel on board.

2. Applying window-sticker correction factors for fuel economy: $0.78 \times$ Hwy and $0.9 \times$ City.

3. Using fuel economy from on-road data (excluding trips $>1$ mile, consistent with other data products). 


\section{CDP\#35: Average Refuelings Between Infrastructure Safety Reports}

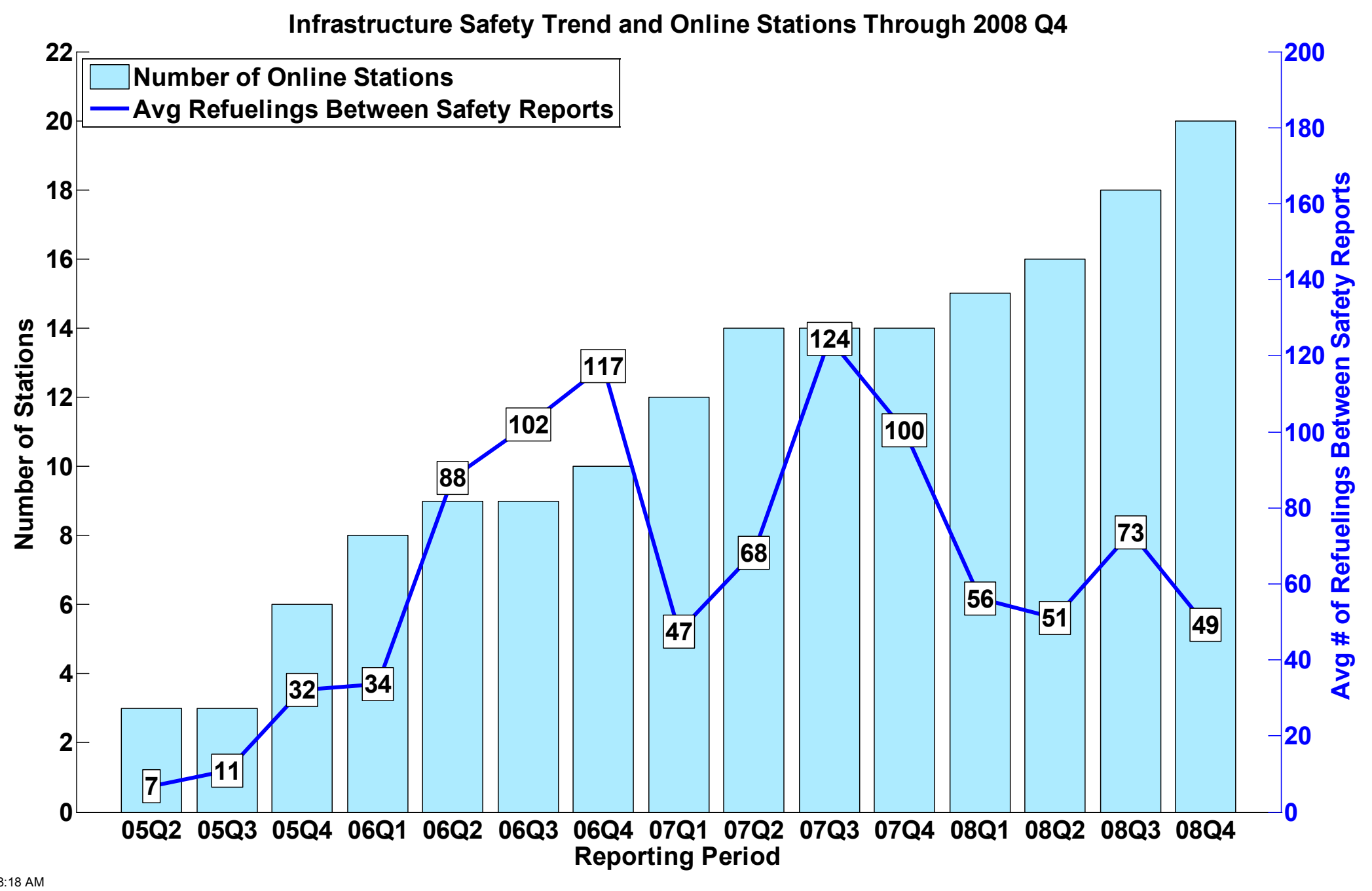




\section{CDP\#36: Type of Infrastructure Safety Report By Quarter}

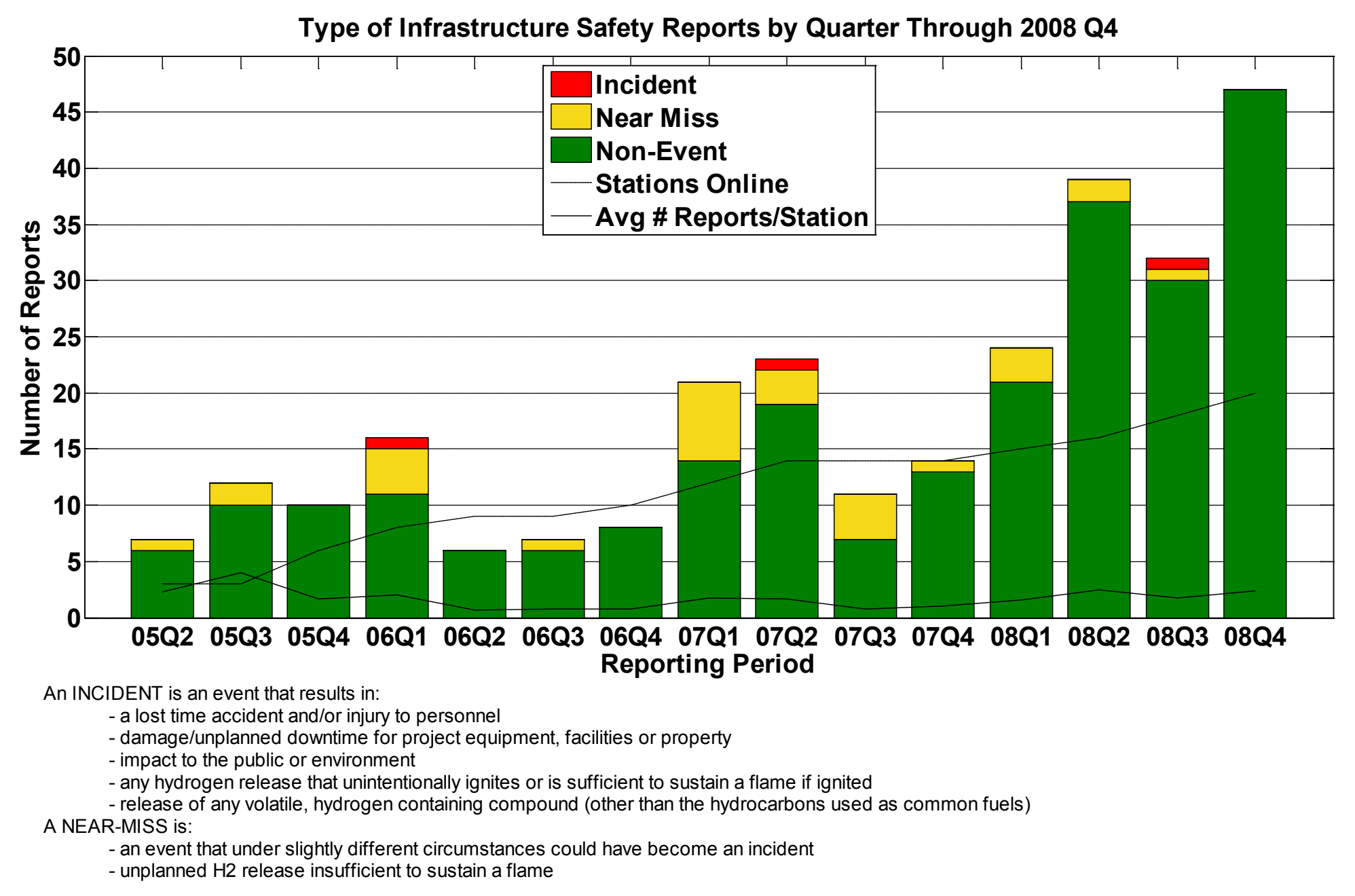




\section{CDP\#37: Primary Factors of Infrastructure Safety Reports}

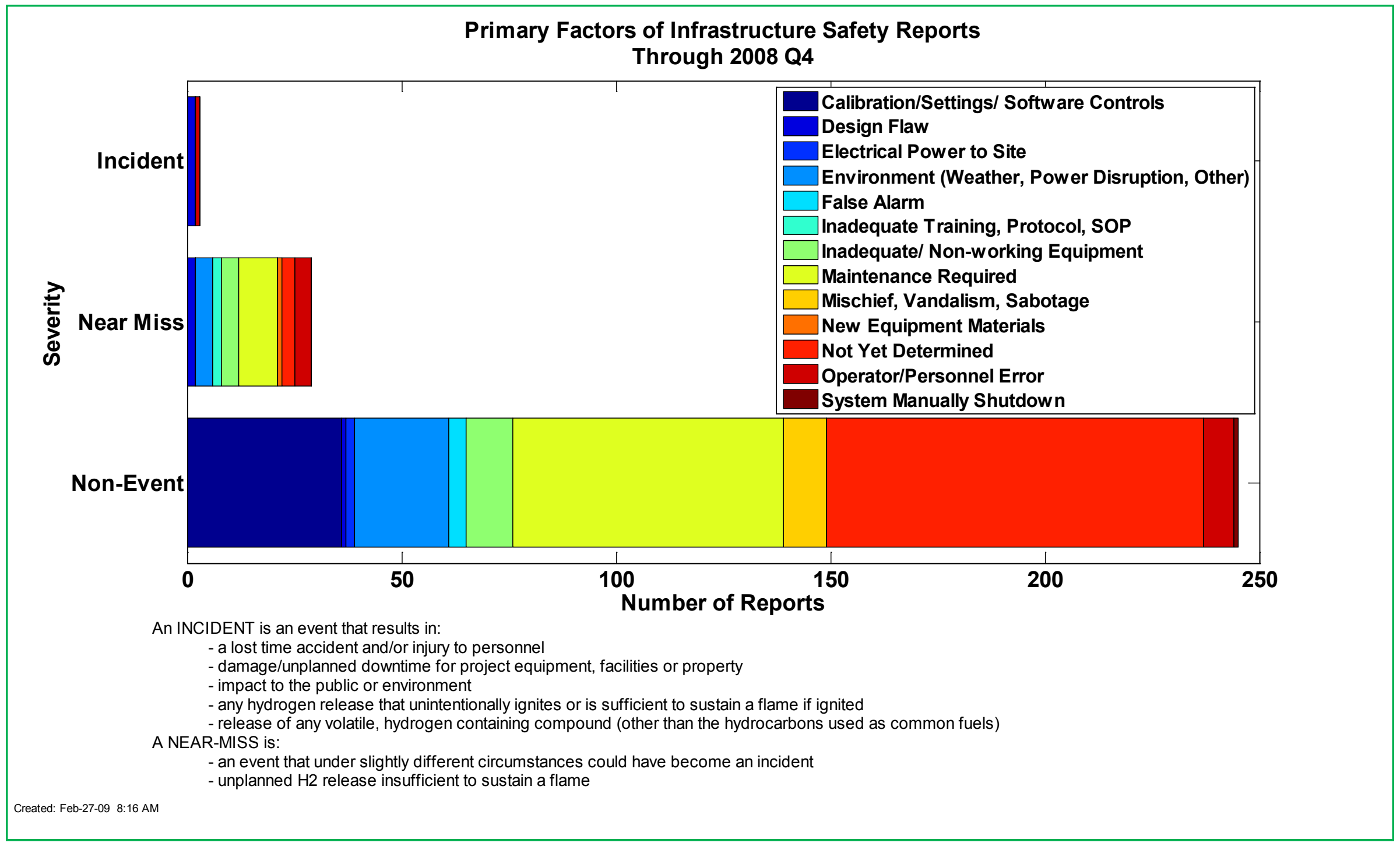




\section{CDP\#38: Refueling Times}

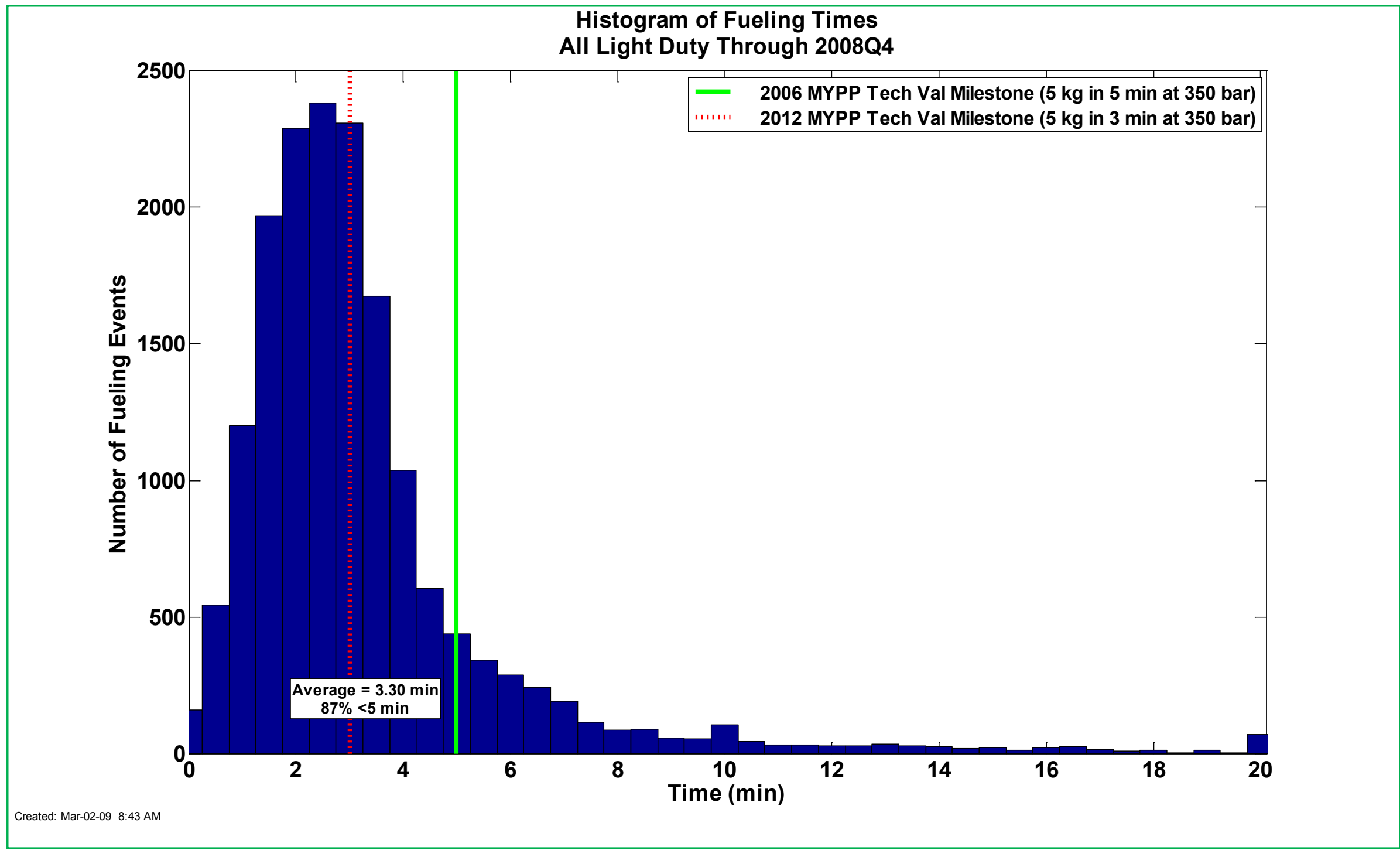




\section{CDP\#39: Refueling Amounts}

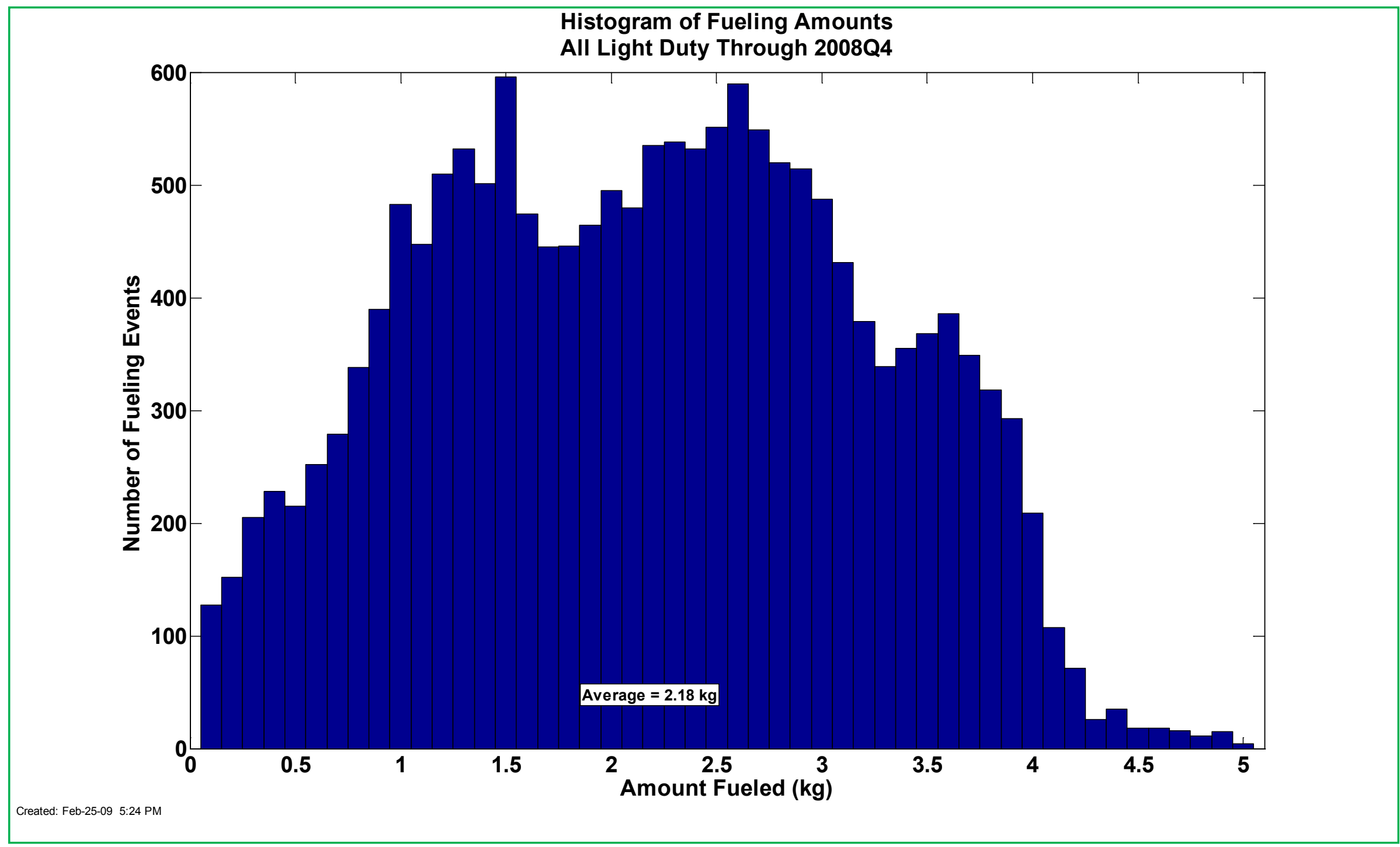




\section{CDP\#40: H2 Tank Level at Refueling}

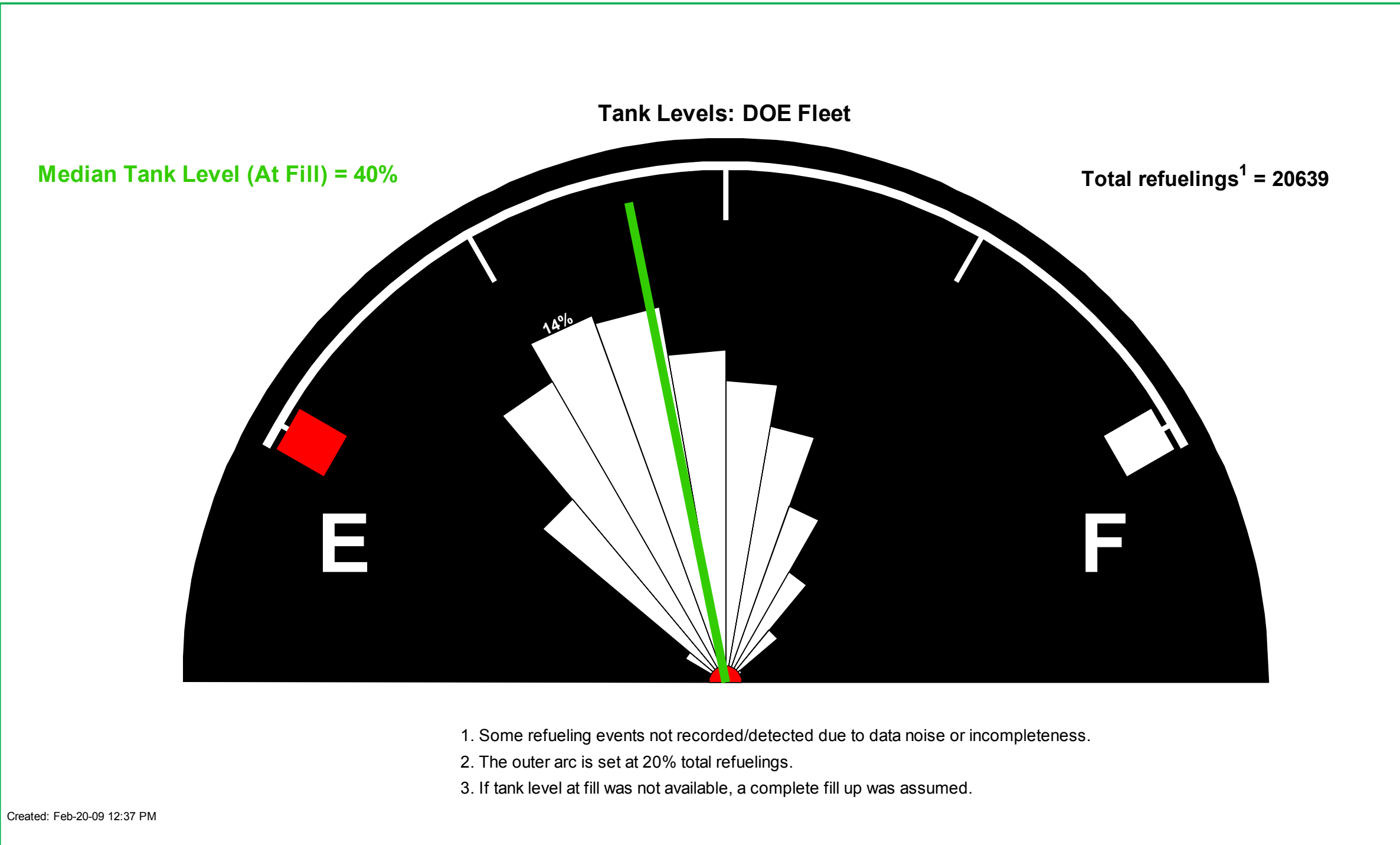




\section{CDP\#41: Refueling Tank Levels - Medians}

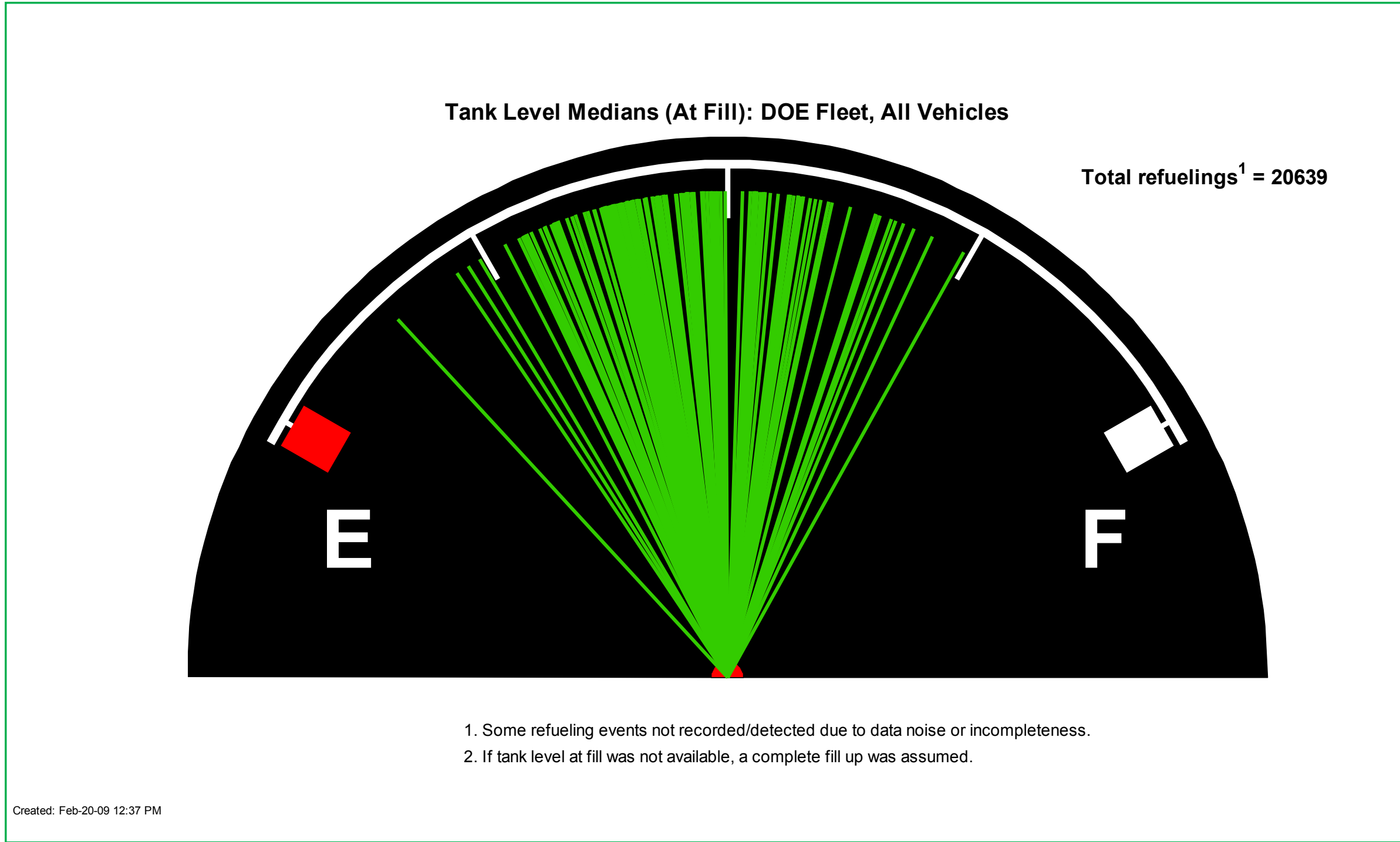




\section{CDP\#42: Refueling by Time of Day}

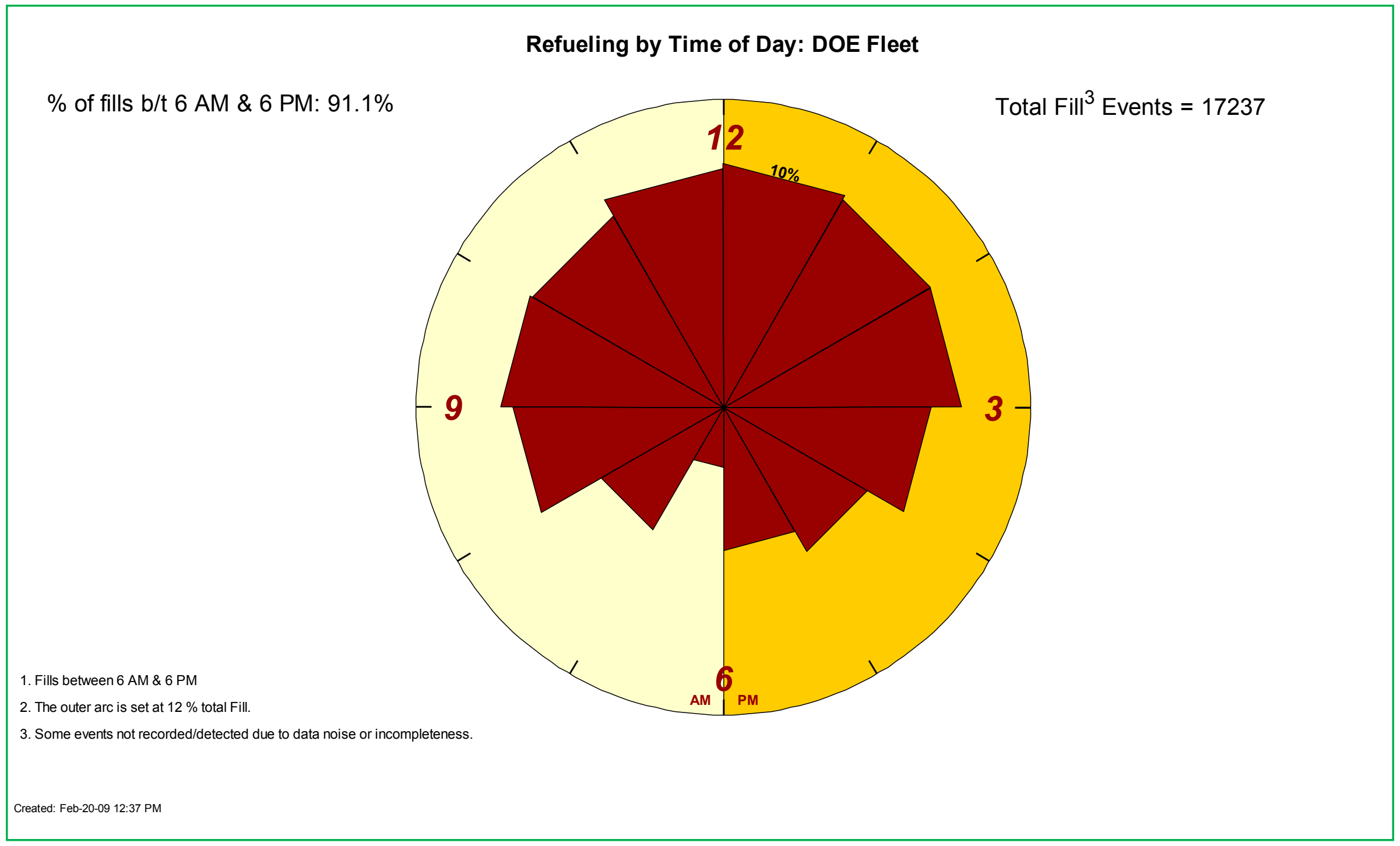




\section{CDP\#43: Refueling by Day of Week}

Fills by Day of Week: DOE Fleet

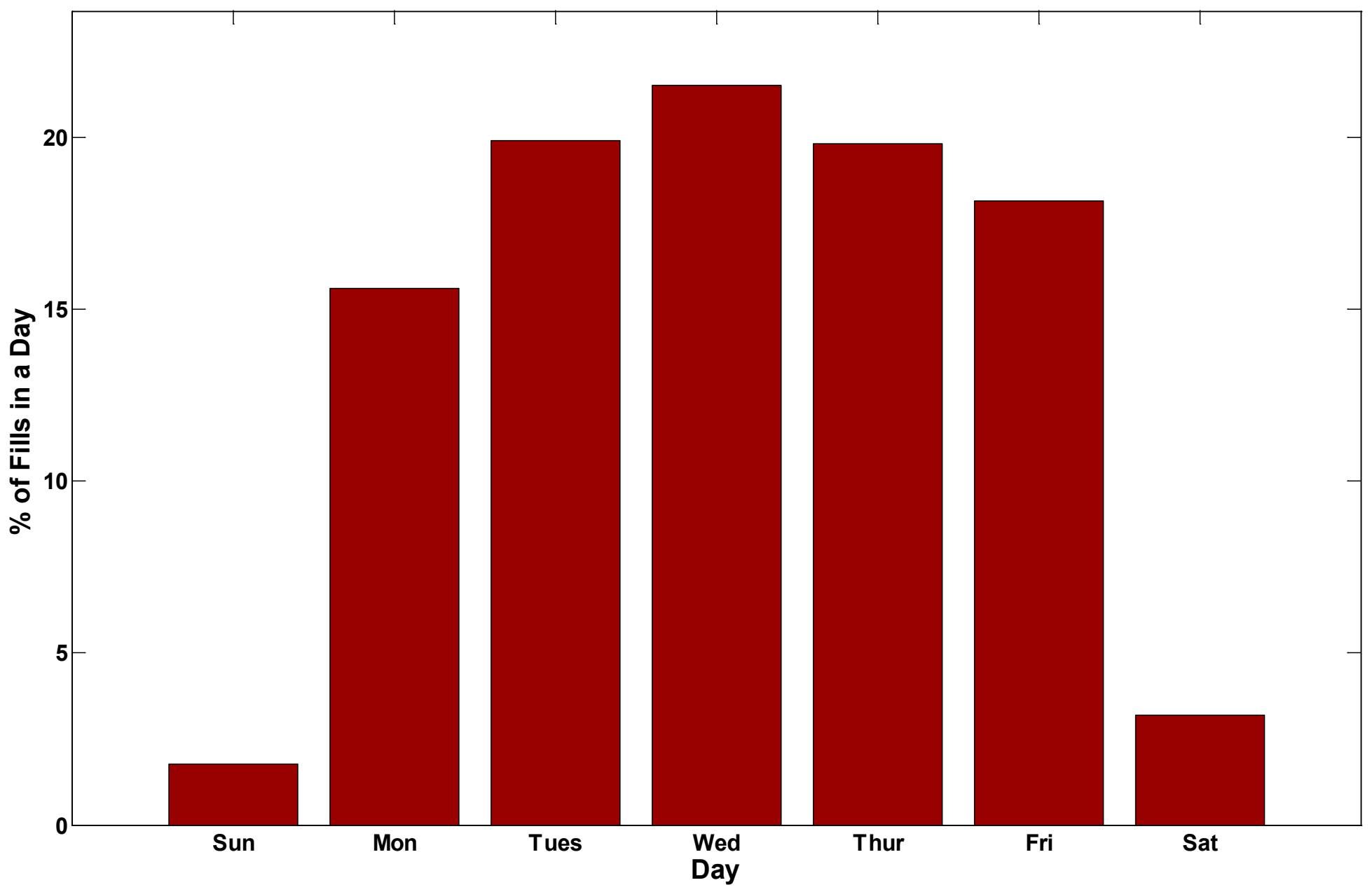




\section{CDP\#44: Driving Start Time - Day}

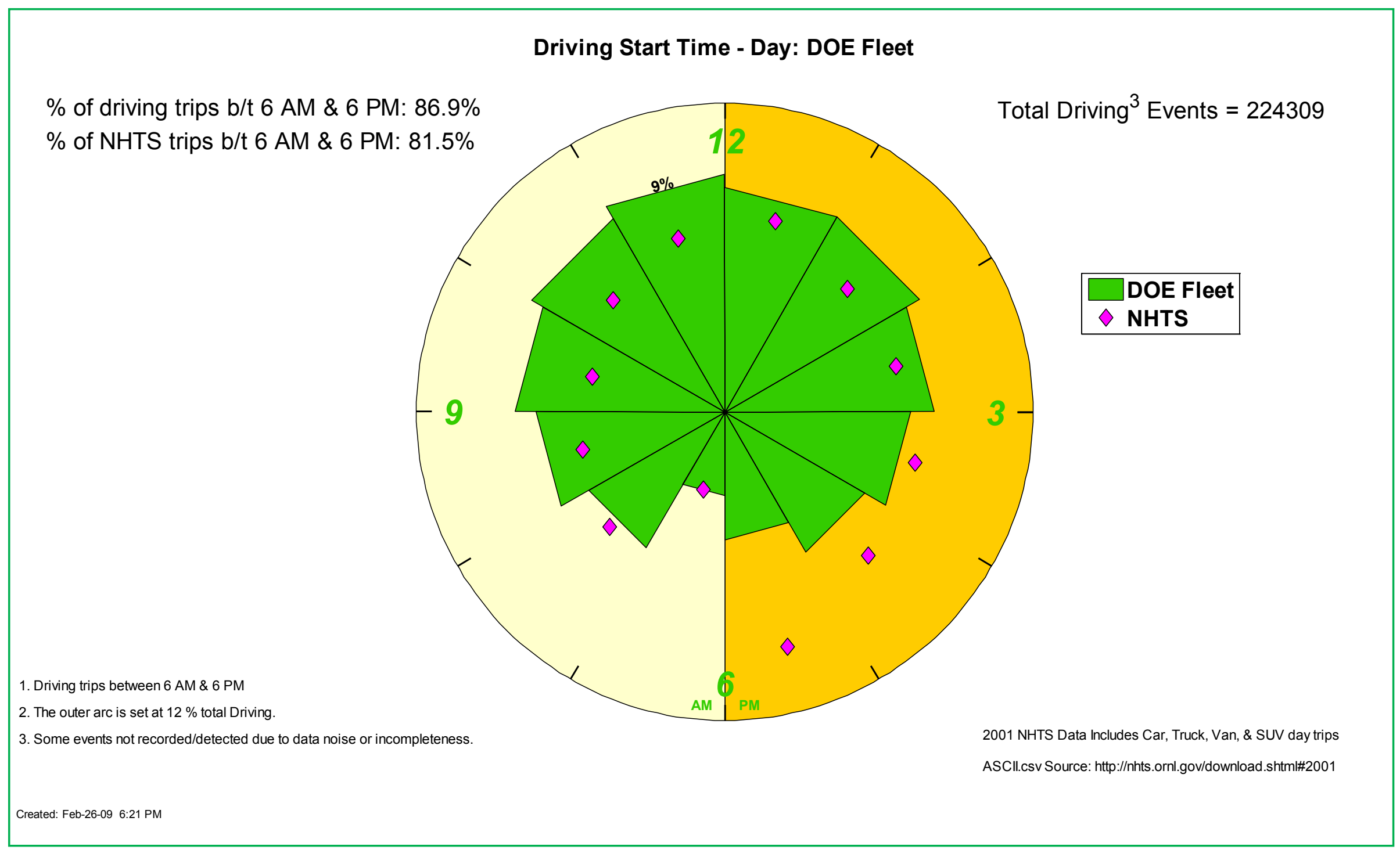




\section{CDP\#45: Driving by Day of Week}

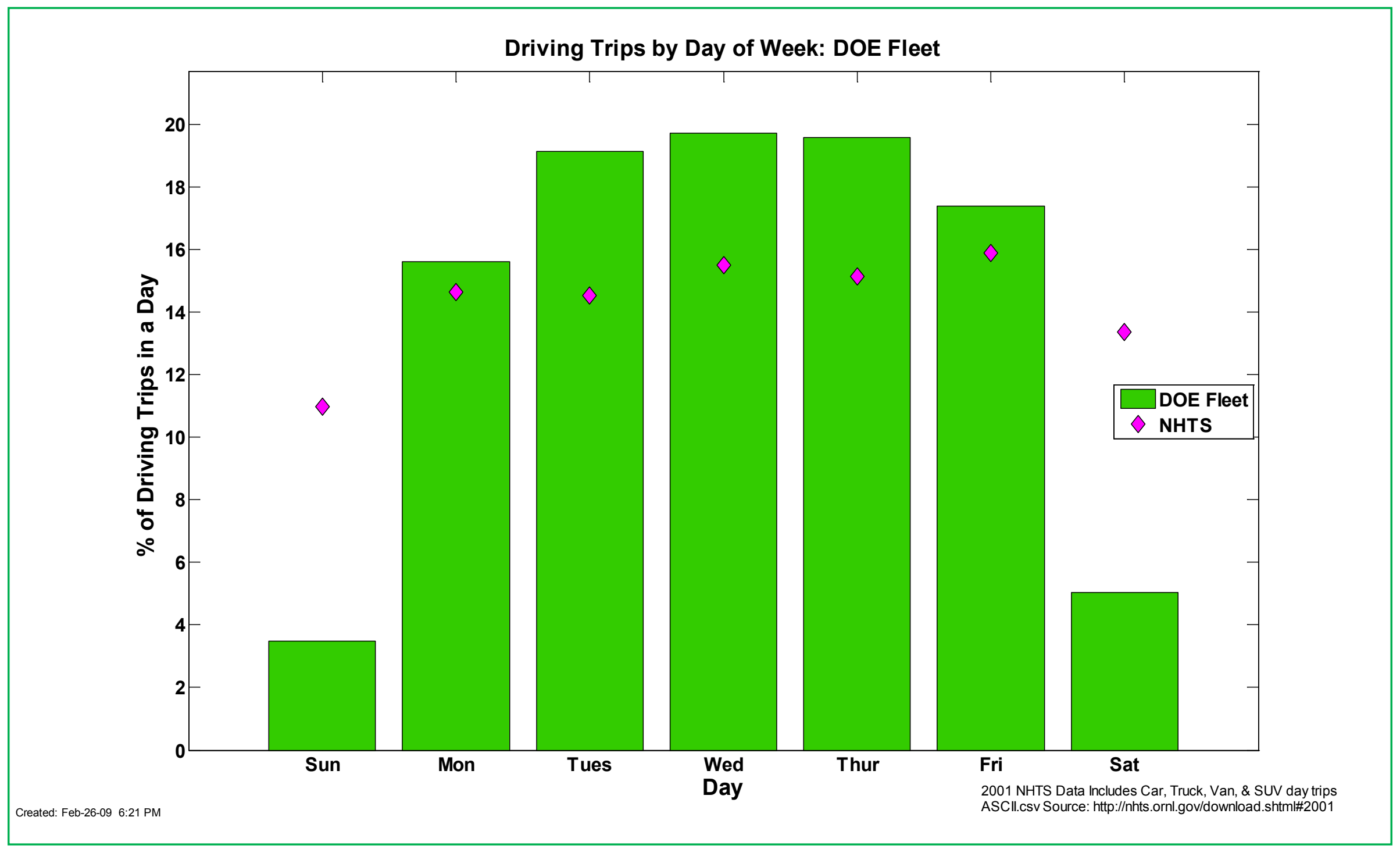




\section{CDP\#46: Fuel Cell System Operating Power}

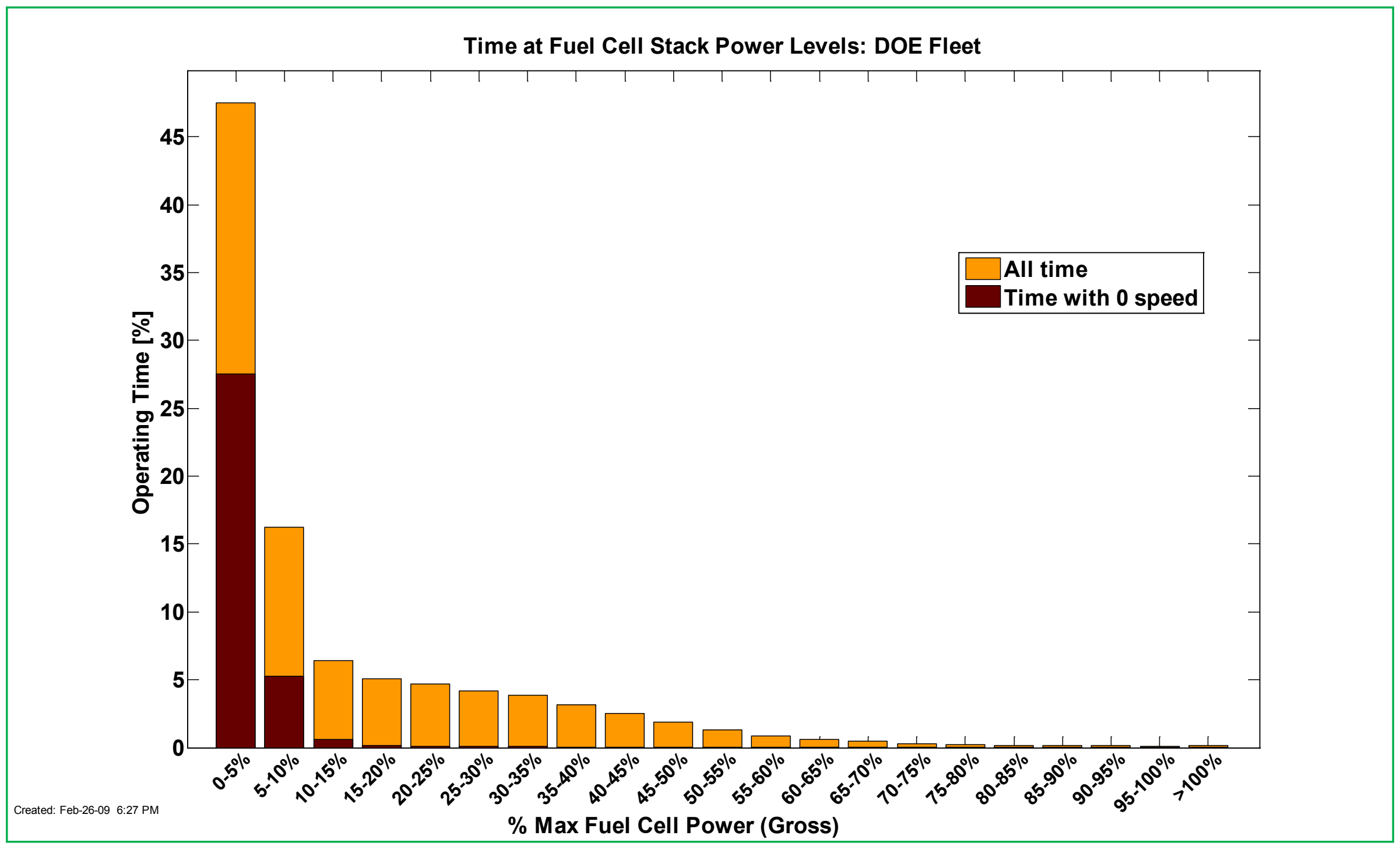




\section{CDP\#47: Trip Length}

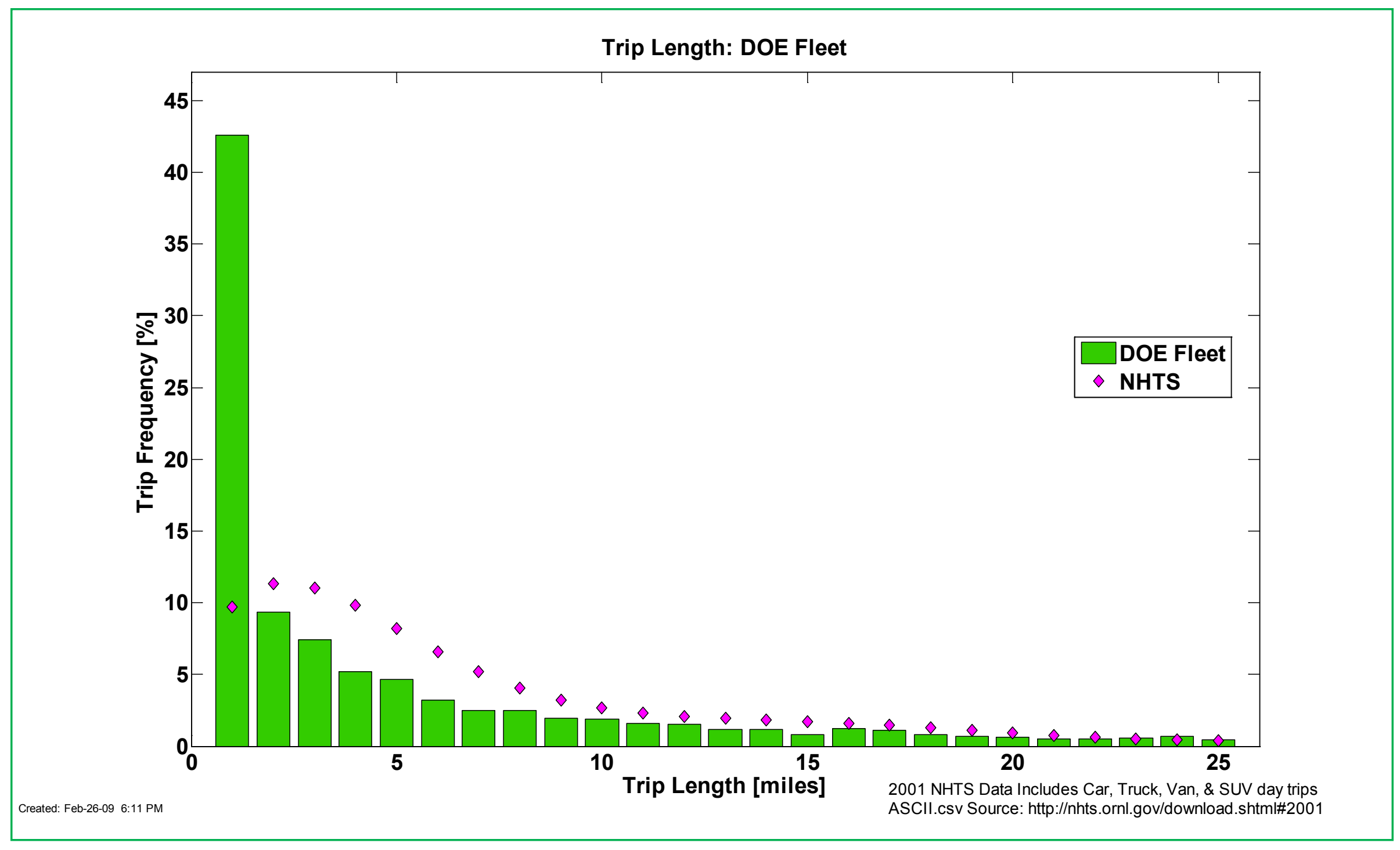




\section{CDP\#48: Primary Factors Affecting Learning Demo Fleet Fuel Cell Degradation}

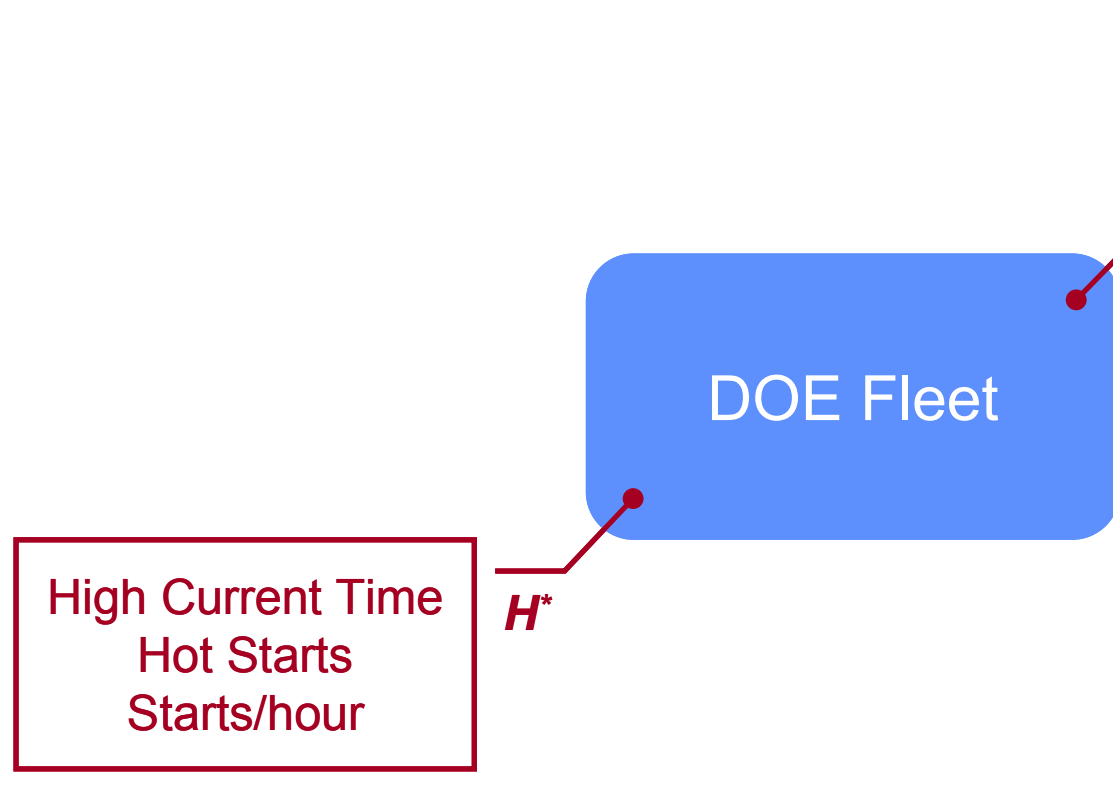

Low Voltage Time

High Voltage Time

Cold Starts

Short Trips

0 Speed Trips

Hot Ambient Temp

Due to differences among teams, the DOE Fleet Analysis results are spread out and concrete conclusions are difficult to draw.

Individual team analyses (CDP\#49) focused on patterns within a fleet.

1) On-going fuel cell degradation study using Partial Least Squares (PLS) regression model for combined Learning Demonstration Fleet.

2) DOE Fleet model has a low percentage of explained decay rate variance.
$\mathrm{H}^{*}$ : Factor group associated with high decay rate fuel cell stacks

$\mathrm{L}^{* *}$ : Factor group associated with low decay rate fuel cell stacks 


\section{CDP\#49: Primary Factors Affecting Learning Demo Team Fuel Cell Degradation}
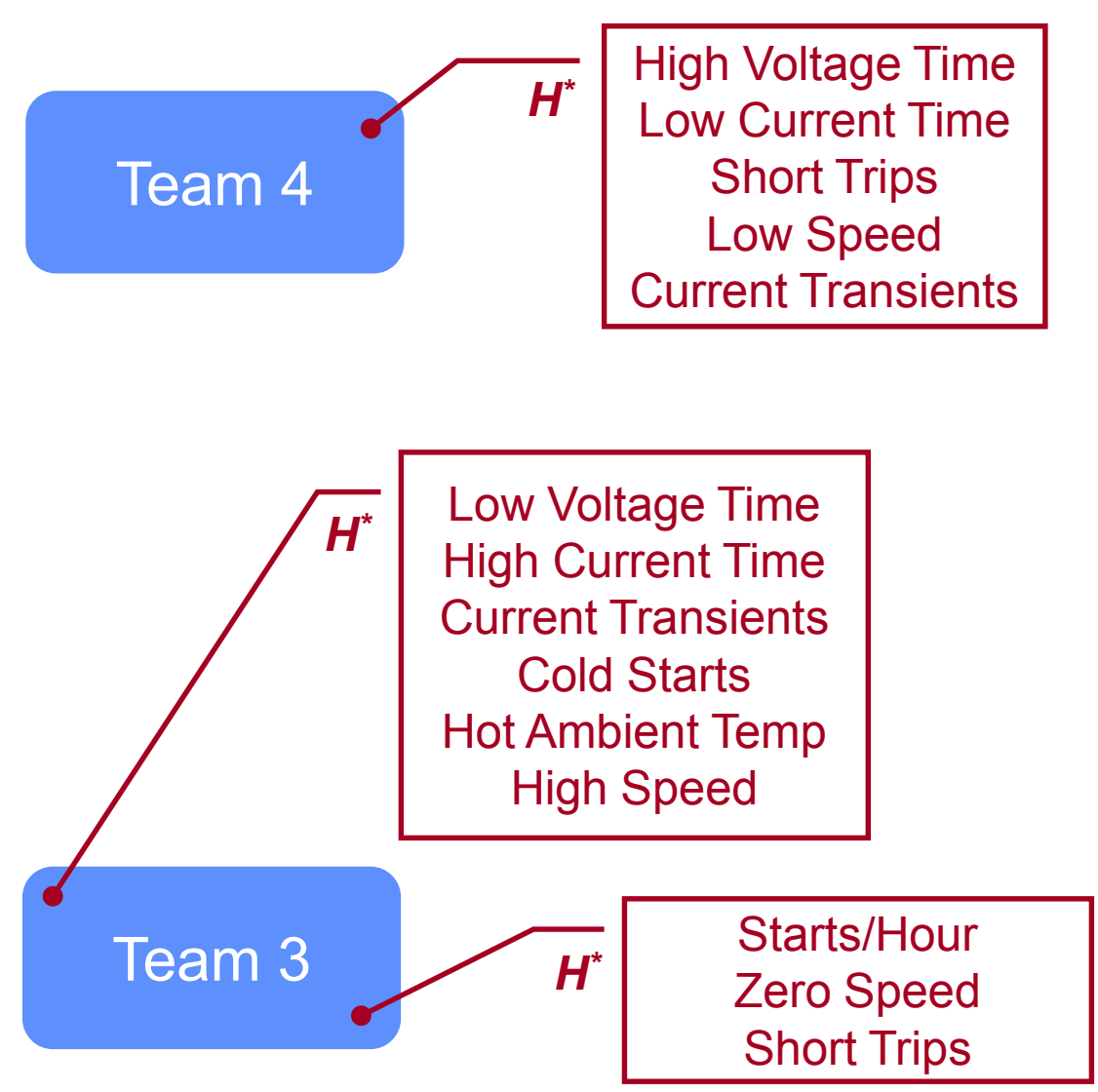

1) On-going fuel cell degradation study using Partial Least Squares (PLS) regression model for each team's Gen 1 fleet.

2) Teams' PLS models have a high percentage of explained decay rate variance, but the models are not robust and results are scattered.

3) Factor groups associated with stacks that are opposite to the identified groups here are not specified.

\section{Low Current Time \\ Long Trips \\ Warm Ambient Temp \\ Zero Speed \\ Current Transients}

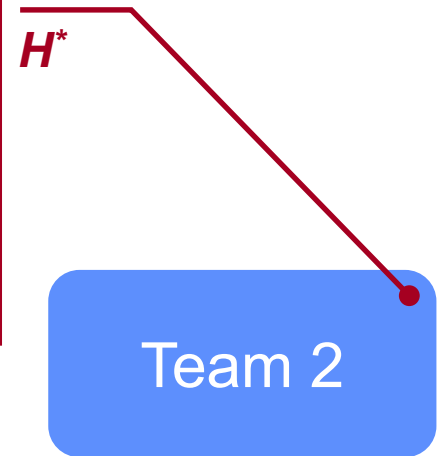

High Voltage Time

Low Current Time

Short Trips

Low Speed

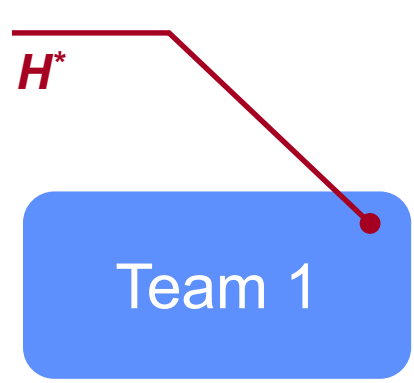




\section{CDP\#50: Refueling by Time of Night}

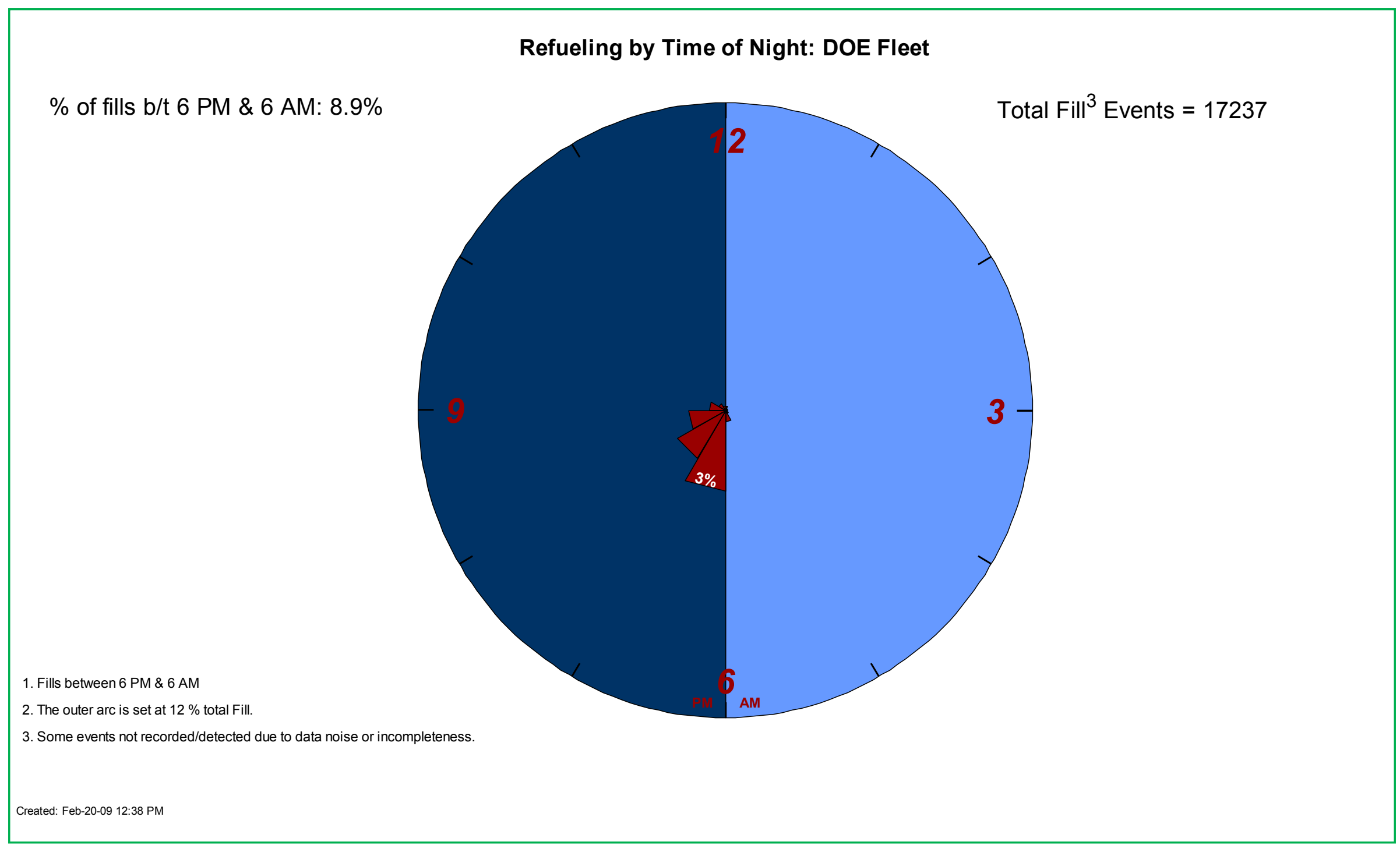




\section{CDP\#51: Driving Start Time - Night}

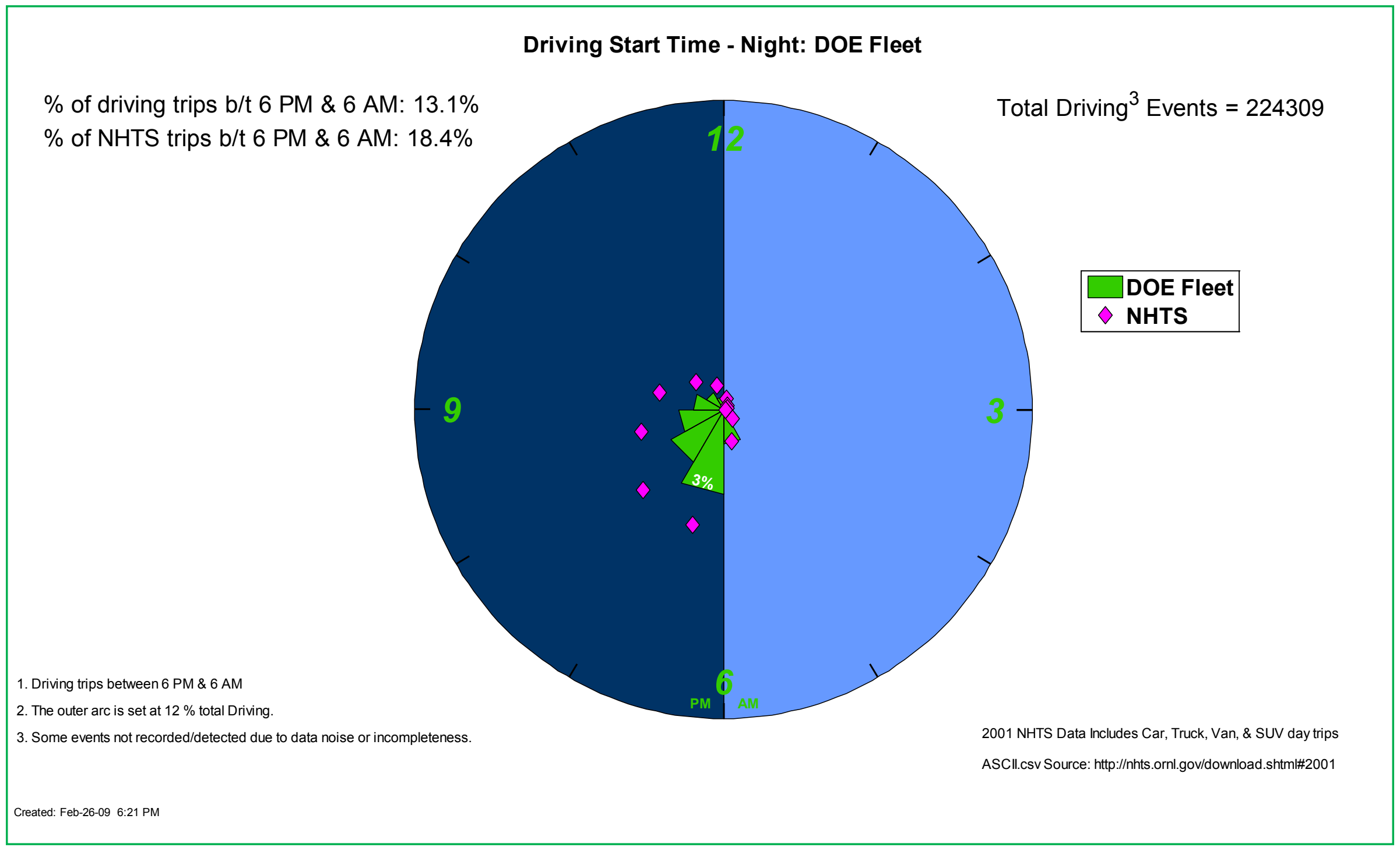




\section{CDP\#52: Refueling Data by Year}

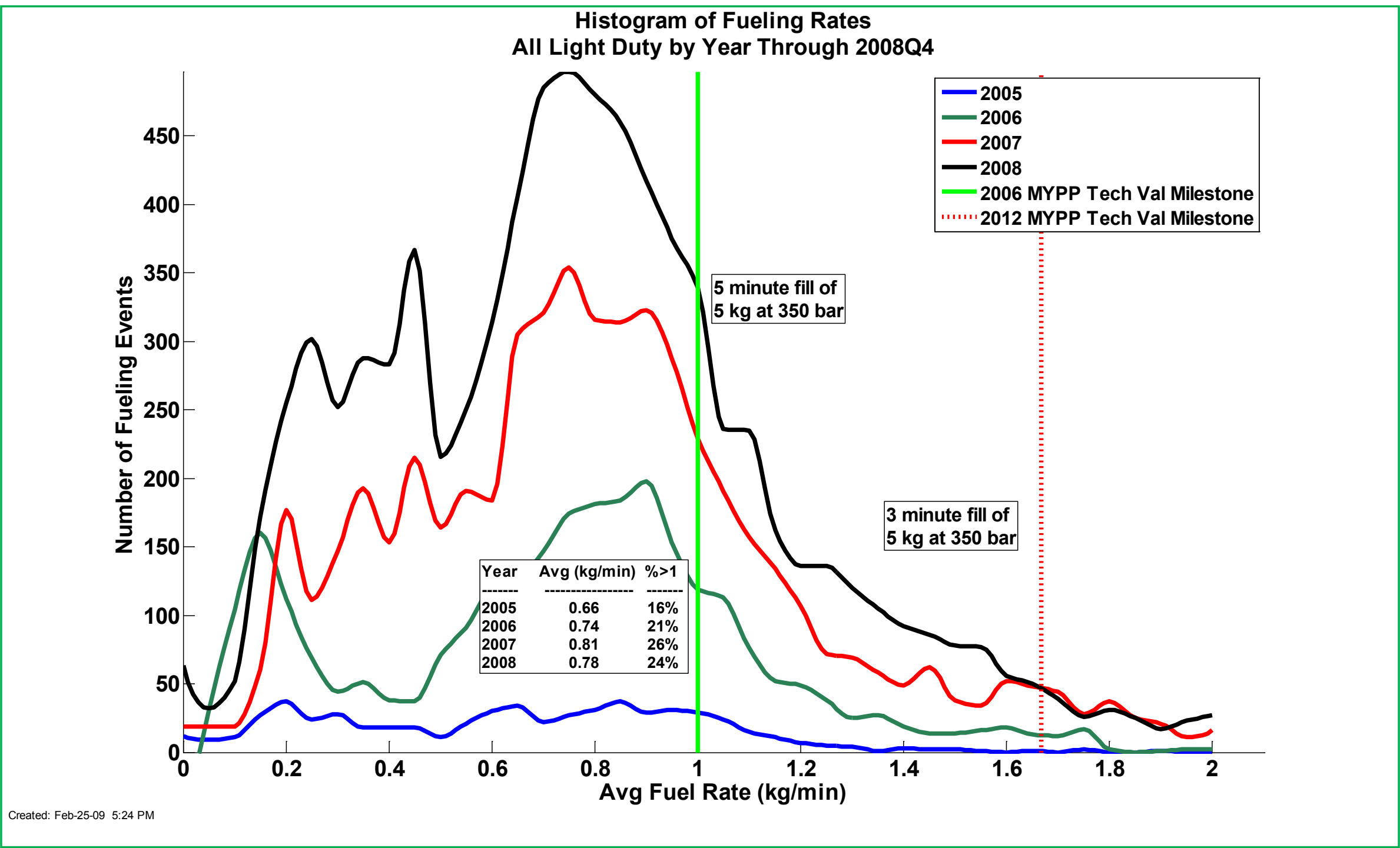




\section{CDP\#53: Fuel Cell System Energy within Power Levels}

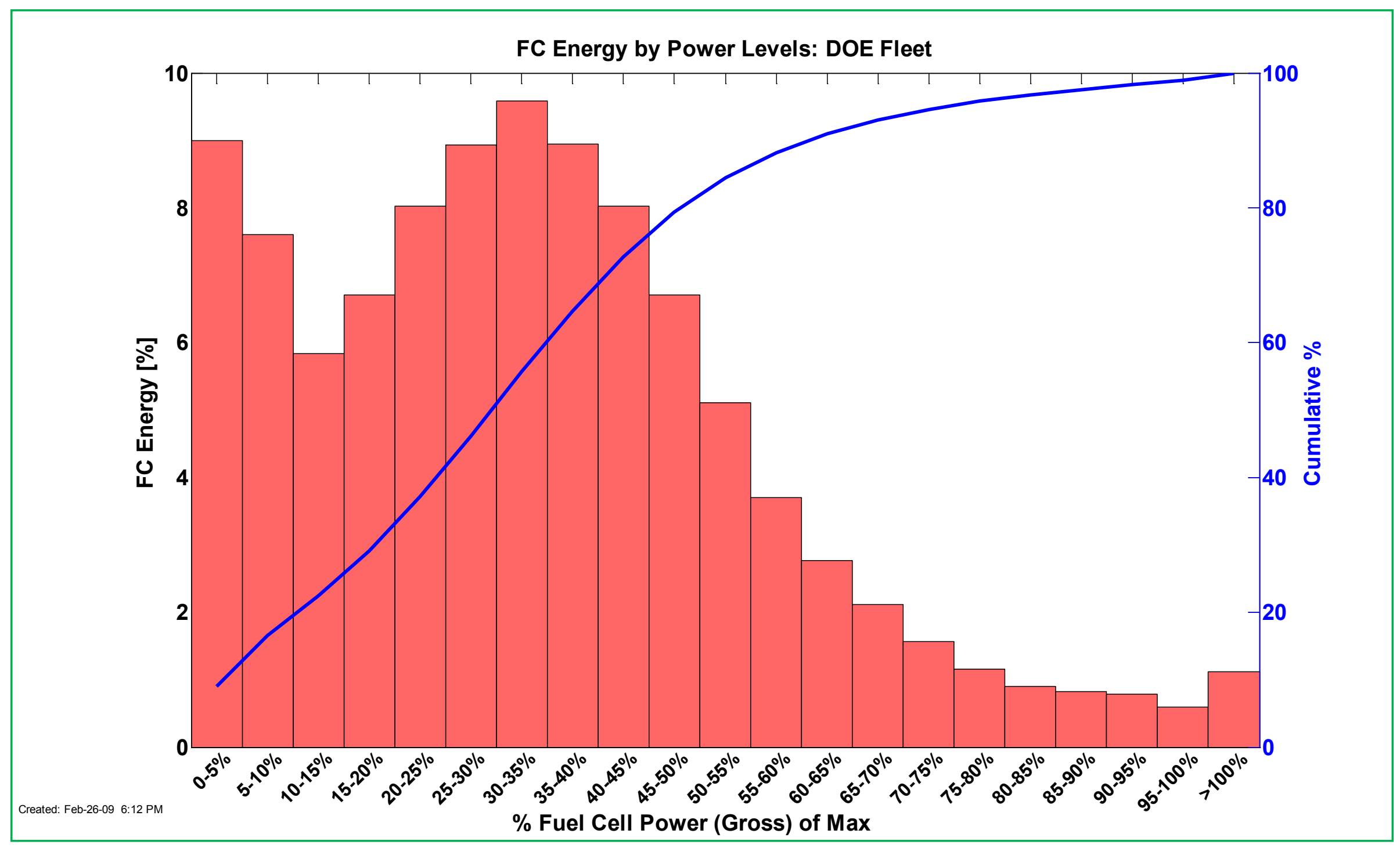




\section{CDP\#54: Time Between Trips}

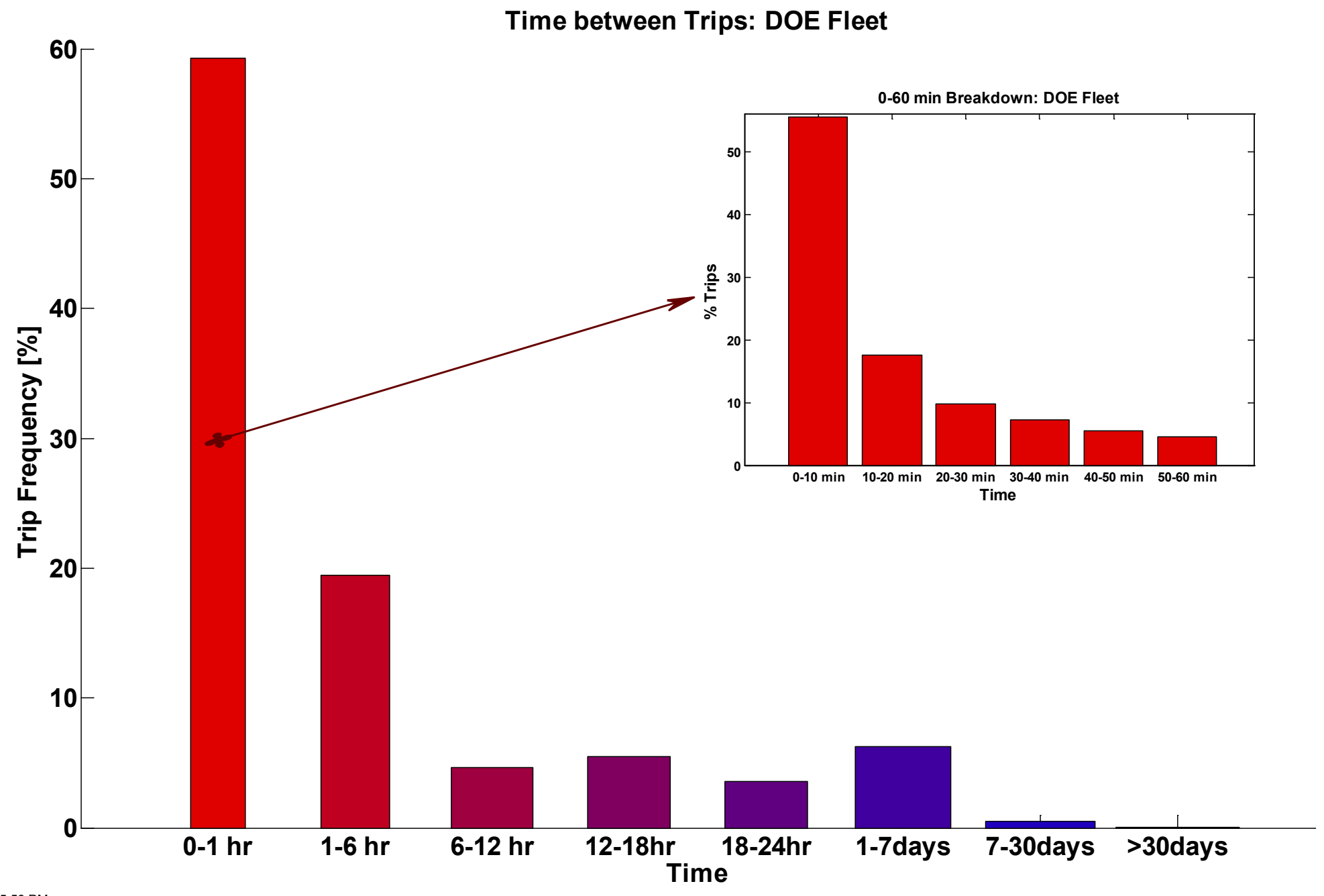




\section{CDP\#55: Fuel Cell System Energy}

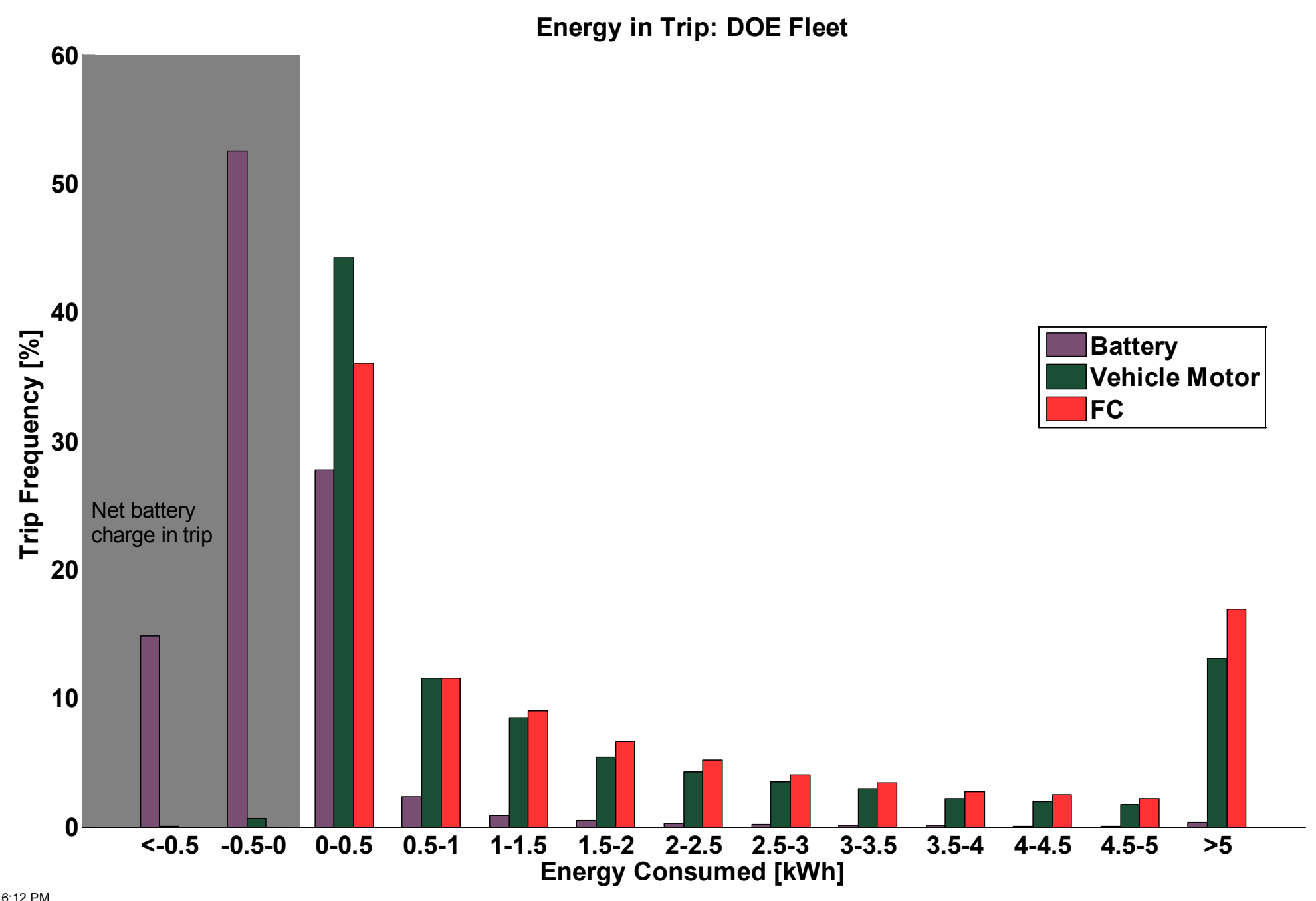




\section{CDP\#56: Daily Driving Distance}

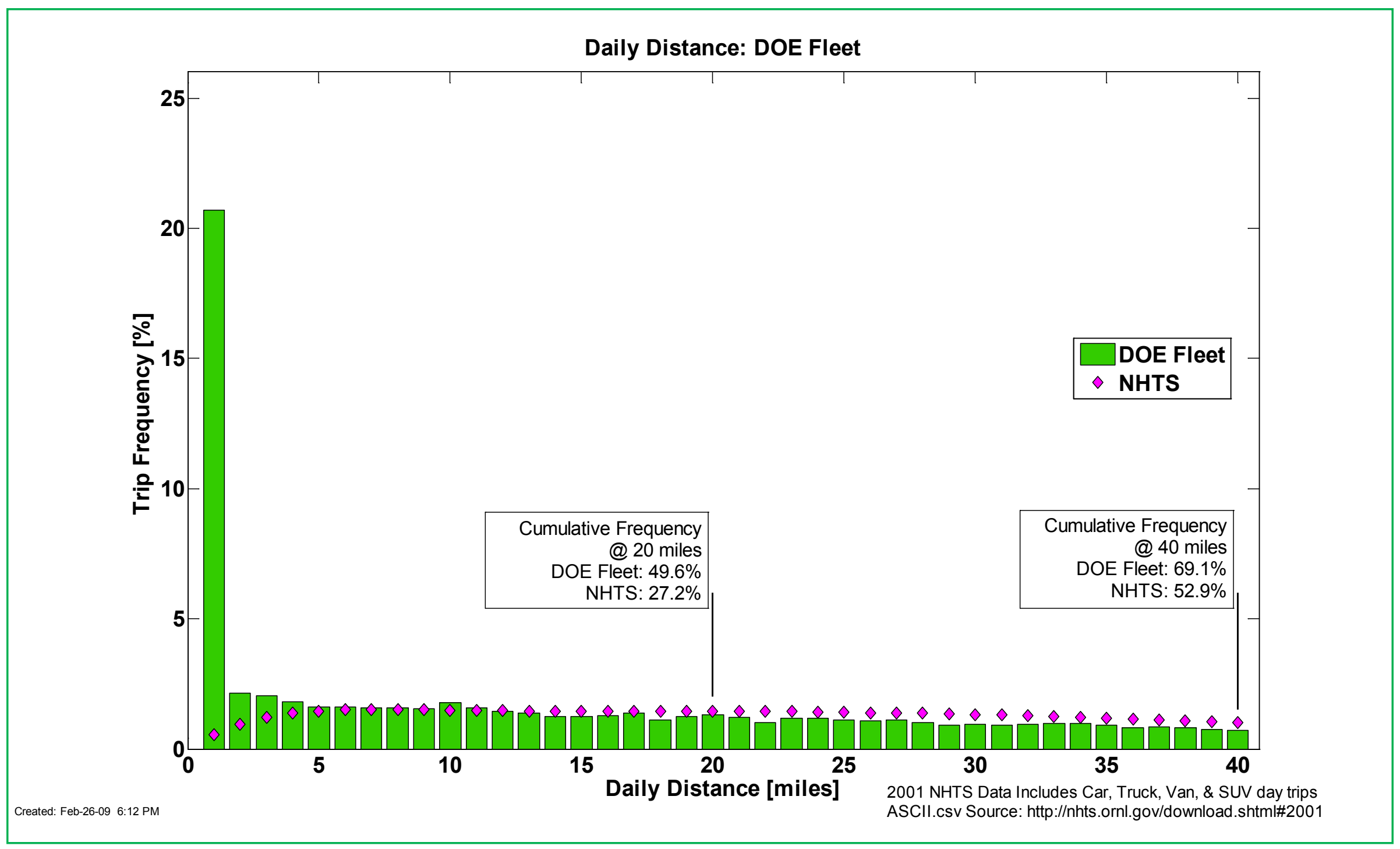




\section{CDP\#57: H2 Storage System Mass and Volume Breakdown}

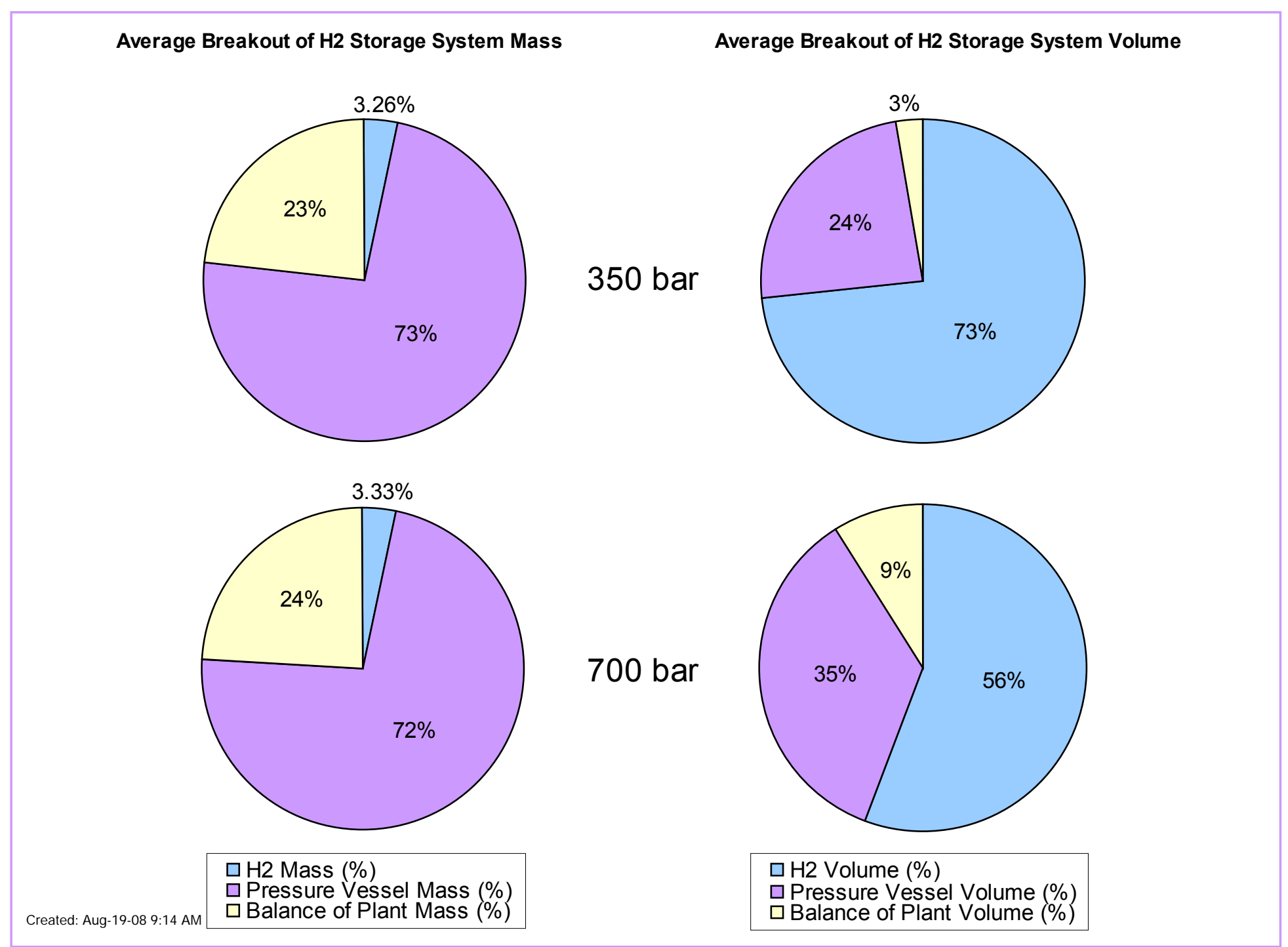




\section{CDP\#58: Fuel Cell System Power Density}

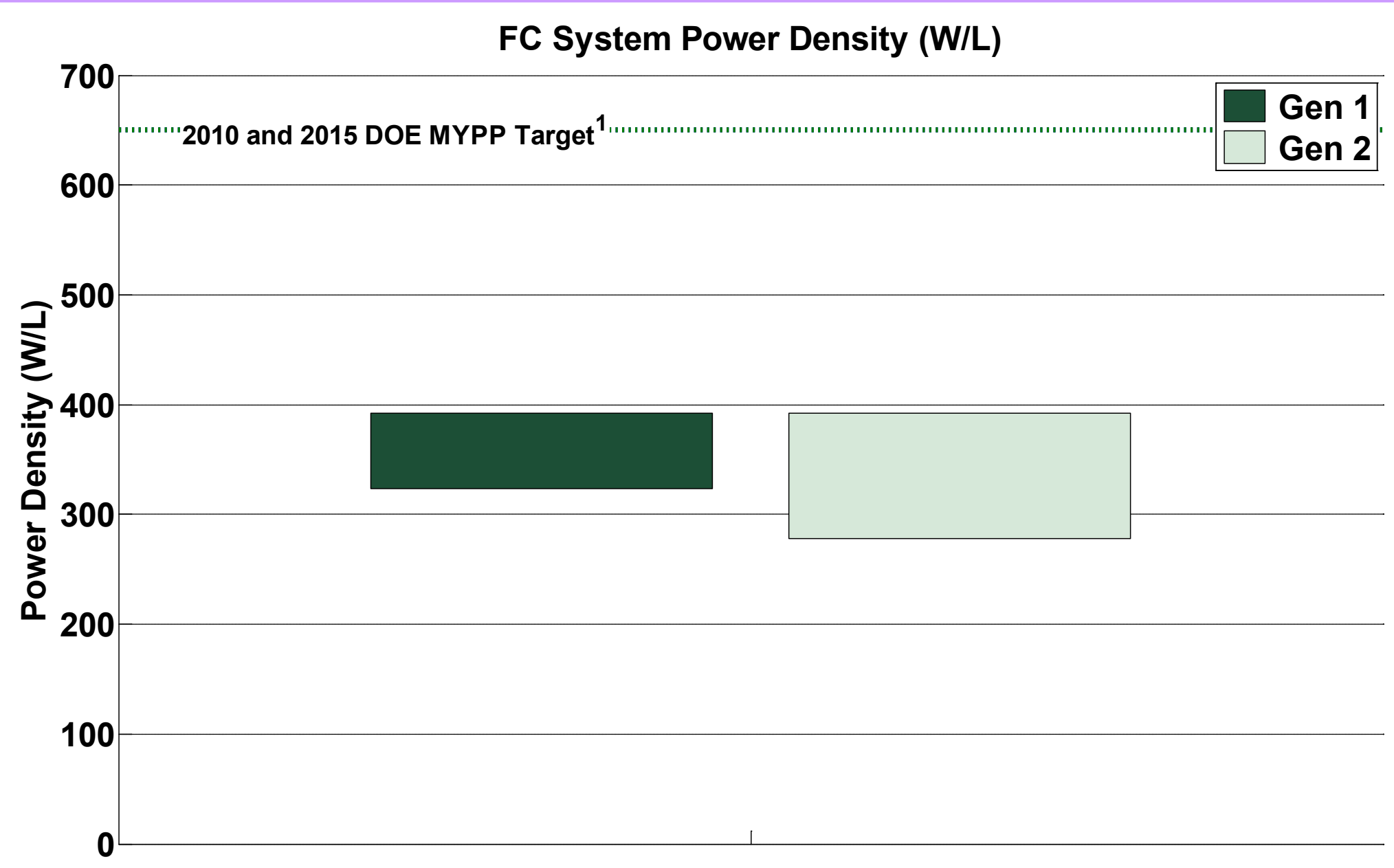

(1) Fuel cell system includes fuel cell stack and BOP but excludes $\mathrm{H} 2$ storage, power electronics, and electric drive. 


\section{CDP\#59: Fuel Cell System Specific Power}

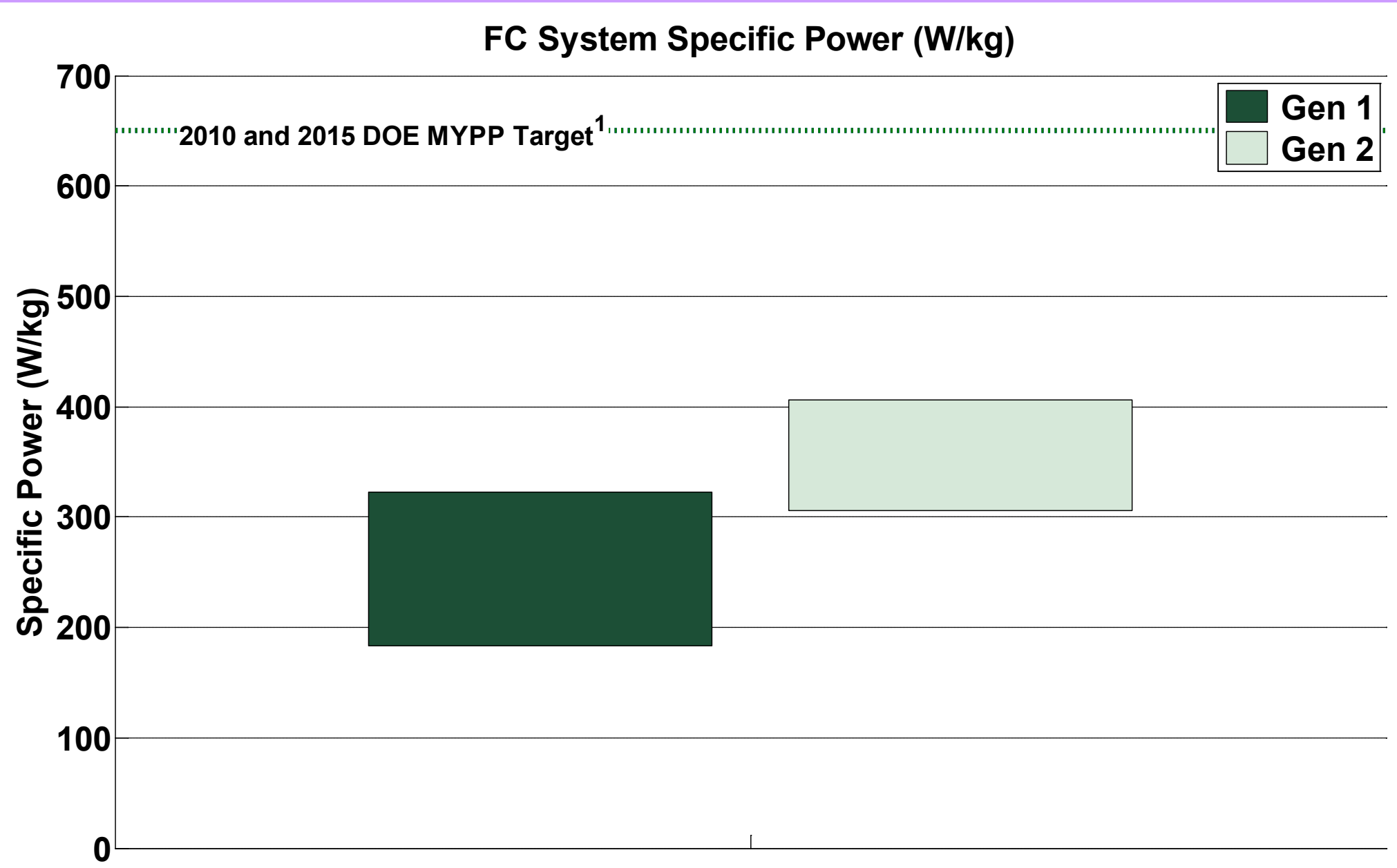

(1) Fuel cell system includes fuel cell stack and BOP but excludes $\mathrm{H} 2$ storage, power electronics, and electric drive. 


\section{CDP\#60: On-Site Hydrogen Production Efficiency vs. Capacity Utilization}

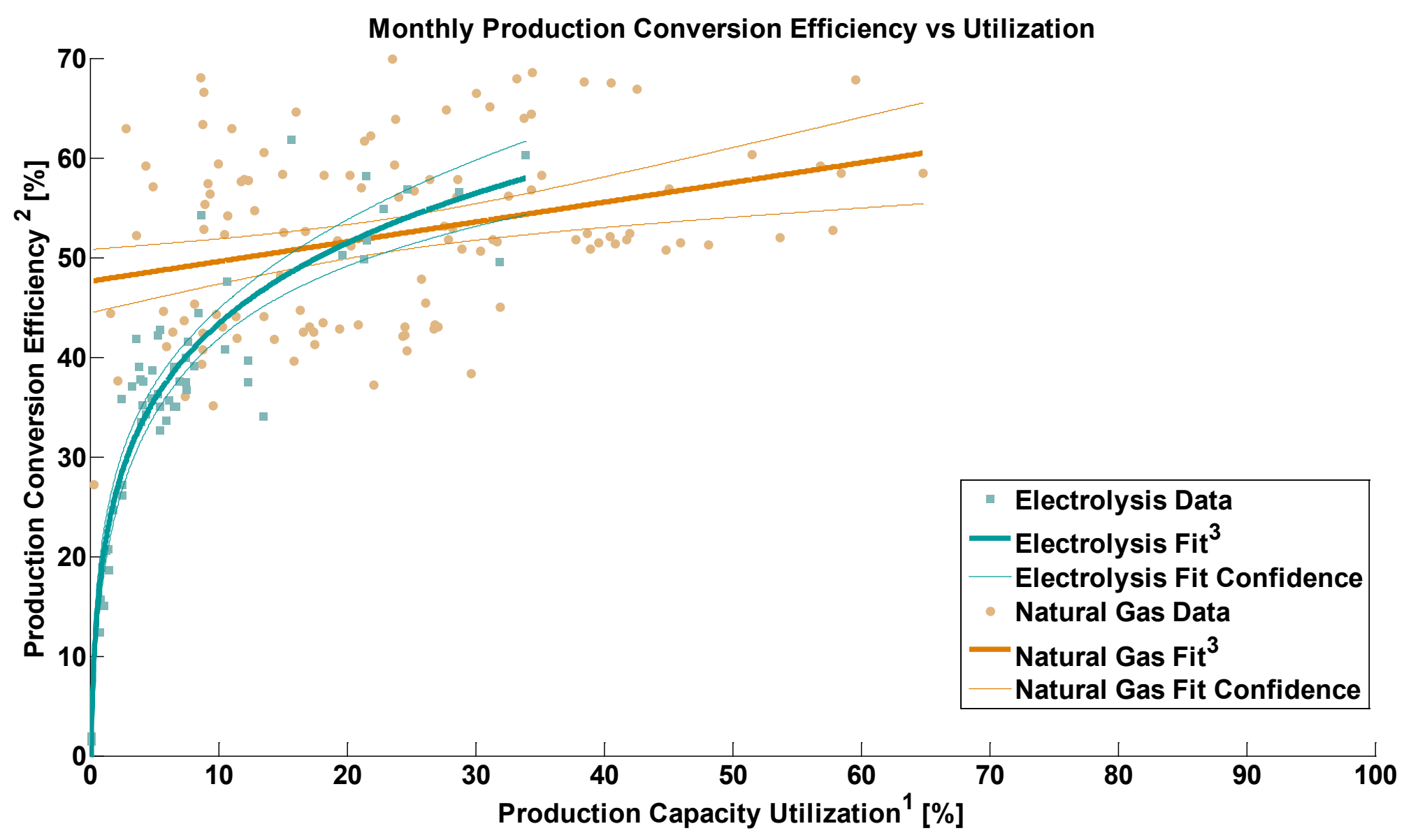

1) $100 \%$ production utilization assumes operation $24 \mathrm{hrs}$ a day, 7 days a week

2) Production conversion efficiency is defined as the energy of the hydrogen out of the process (on a LHV basis) divided by the sum of the energy into the production process from the feedstock and all other energy as needed. Conversion efficiency does not include energy used for compression, storage, and dispensing.

3) High correlation with electrolysis data $\left(R^{2}=0.87\right)$ \& low correlation with natural gas data $\left(R^{2}=0.018\right)$ 


\section{CDP\#61: Refueling Station Compressor Efficiency}

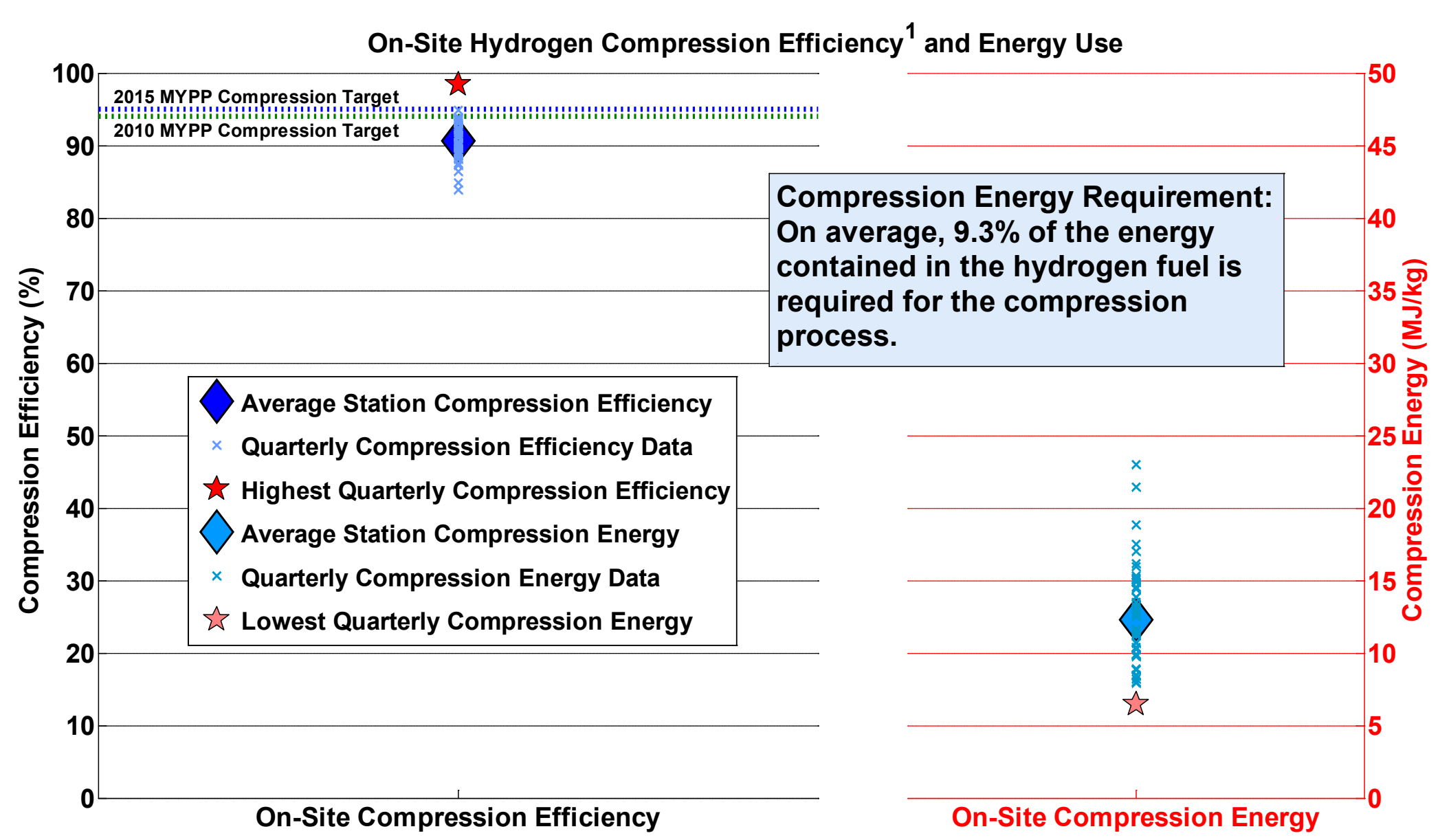

${ }^{1}$ Consistent with the MYPP, compression efficiency is defined as the energy of the hydrogen out of the process (on an LHV basis) divided by the sum of the energy of the hydrogen output plus all other energy needed for the compression process. Data shown for on-site hydrogen production and storage 


\section{CDP\#62: Learning Demonstration Vehicle Greenhouse Gas Emissions}

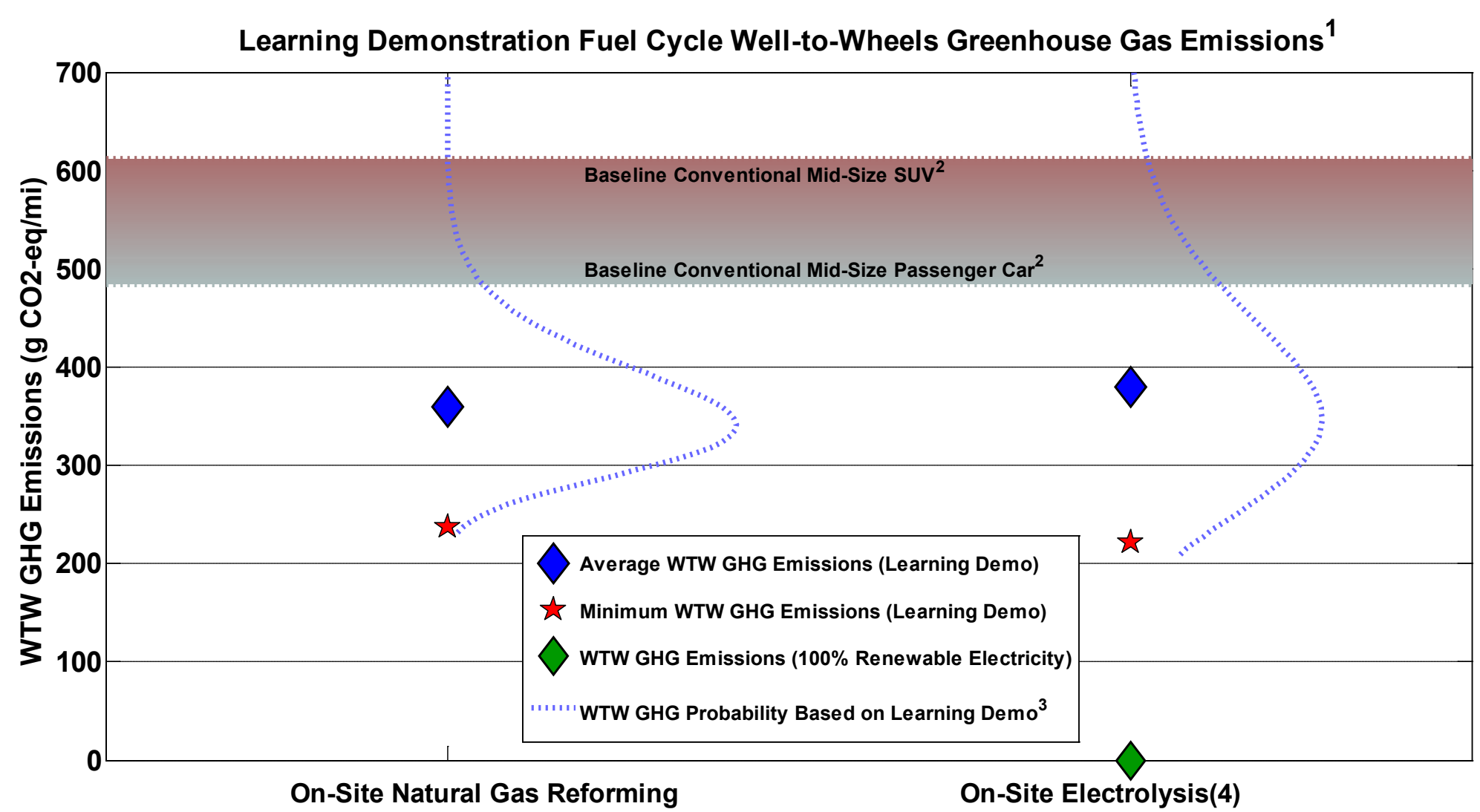

1. Well-to-Wheels greenhouse gas emissions based on DOE's GREET model, version 1.8b. Analysis uses default GREET values except for FCV fuel economy, hydrogen production conversion efficiency, and electricity grid mix. Fuel economy values are the Gen 1 and Gen 2 window-sticker fuel economy data for all teams (as used in CDP \#6); conversion efficiency values are the production efficiency data used in CDP \#13.

2. Baseline conventional passenger car and light duty truck GHG emissions are determined by GREET 1.8b, based on the EPA window-sticker fuel economy of a conventional gasoline mid-size passenger car and mid-size SUV, respectively. The Learning Demonstration fleet includes both passenger cars and SUVs.

3. The Well-to-Wheels GHG probability distribution represents the range and likelihood of GHG emissions resulting from the hydrogen FCV fleet based on window-sticker fuel economy data and monthly conversion efficiency data from the Learning Demonstration. 4. On-site electrolysis GHG emissions are based on the average mix of electricity production used by the Learning Demonstration production sites, which includes both

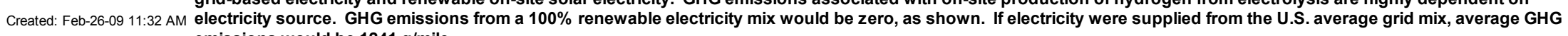
emissions would be $1241 \mathrm{~g} / \mathrm{mile}$. 


\section{CDP\#63: Hydrogen Fueling Station Maintenance by System}

Hydrogen Fueling Station Maintenance

By Number of Events

Total Number of Events $=1860$

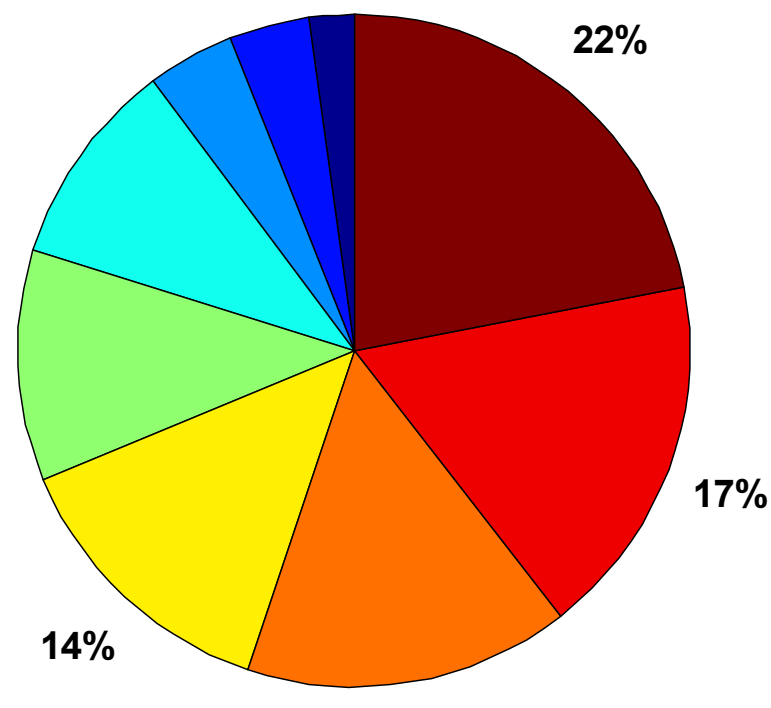

$16 \%$
By Labor Hours

Total Hours $=9093$

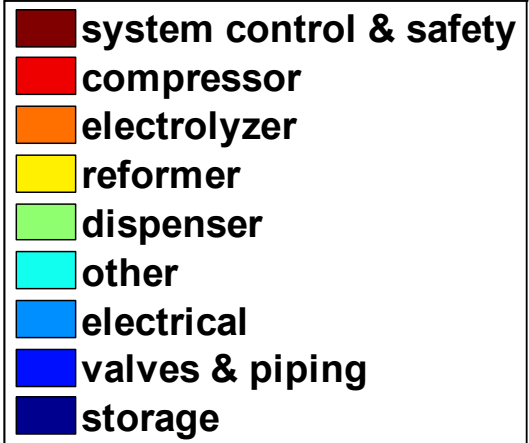

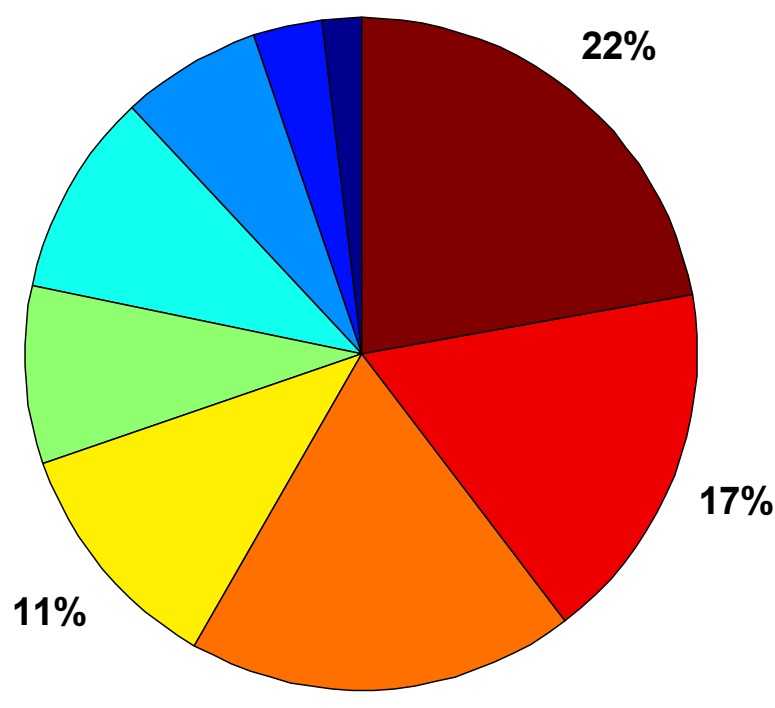

$19 \%$ 


\section{CDP\#64: Fuel Cell Vehicle Maintenance by}

System

Fuel Cell Vehicle Maintenance Events and Labor Hours

Fuel Cell Vehicle Events (9357)

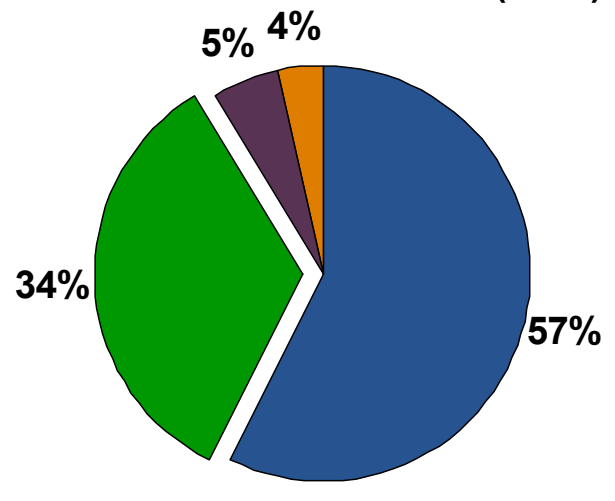

Fuel Cell System Events (3175)

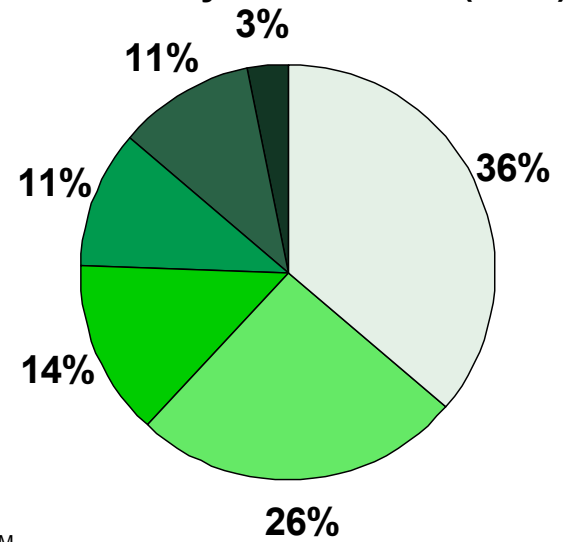

Fuel Cell Vehicle Labor (10216 hours)

\begin{tabular}{|c|}
\hline $\begin{array}{l}\text { Vehicle (non-powertrain) } \\
\text { Fuel Cell System } \\
\text { Powertrain } \\
\text { Battery }\end{array}$ \\
\hline
\end{tabular}

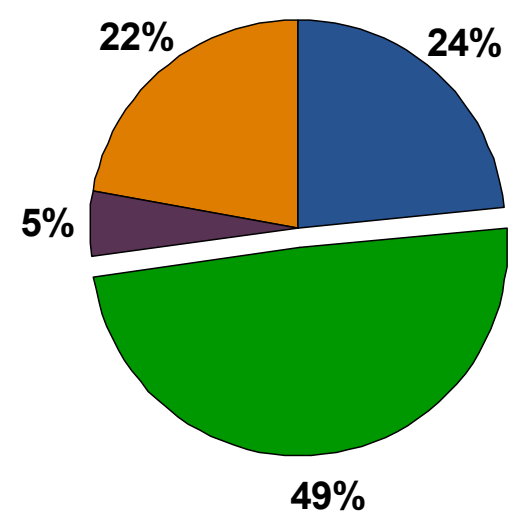

Fuel Cell System Labor (5035 hours) $<1 \%$

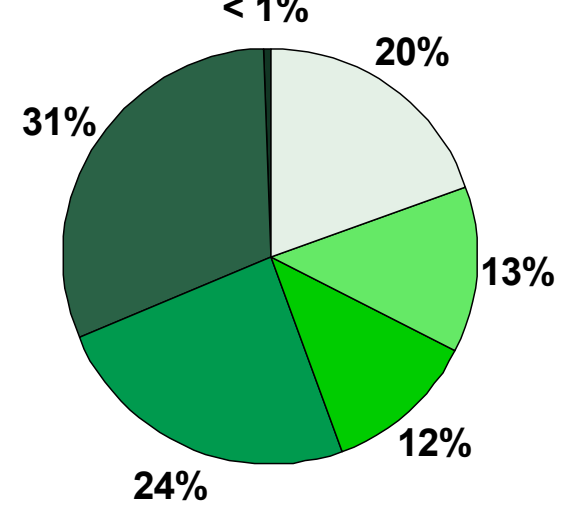

Thermal Management Air System

Controls, Electronics, Sensors Fuel System Fuel Cell Stack Other 


\section{REPORT DOCUMENTATION PAGE}

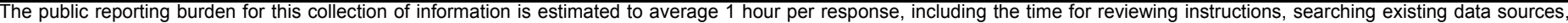

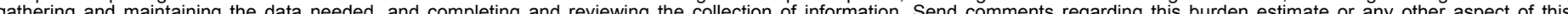
(0704-0188). Respondents

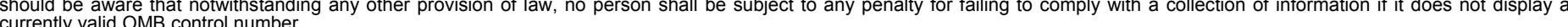

PLEASE DO NOT RETURN YOUR FORM TO THE ABOVE ORGANIZATION.

\begin{tabular}{l|l|l|l} 
1. REPORT DATE (DD-MM-YYYY) & 2. REPORT TYPE & 3. DATES COVERED (FrOm - TO)
\end{tabular}

March 2009

Technical Report

4. TITLE AND SUBTITLE

Controlled Hydrogen Fleet and Infrastructure Demonstration and

Validation Project: Spring 2009

K. Wipke, S. Sprik, J. Kurtz, and T. Ramsden
6. AUTHOR(S)

5a. CONTRACT NUMBER

DE-AC36-08-GO28308

5b. GRANT NUMBER

5c. PROGRAM ELEMENT NUMBER

5d. PROJECT NUMBER

NREL/TP-560-45451

5e. TASK NUMBER

FC087810

5f. WORK UNIT NUMBER

7. PERFORMING ORGANIZATION NAME(S) AND ADDRESS(ES)

National Renewable Energy Laboratory

1617 Cole Blvd.

Golden, CO 80401-3393

9. SPONSORING/MONITORING AGENCY NAME(S) AND ADDRESS(ES)

10. SPONSOR/MONITOR'S ACRONYM(S)

NREL

11. SPONSORING/MONITORING AGENCY REPORT NUMBER

12. DISTRIBUTION AVAILABILITY STATEMENT

National Technical Information Service

U.S. Department of Commerce

5285 Port Royal Road

Springfield, VA 22161

13. SUPPLEMENTARY NOTES

14. ABSTRACT (Maximum 200 Words)

Graphs of composite data products produced by DOE's Controlled Hydrogen Fleet and Infrastructure Demonstration and Validation project through March 2009.

15. SUBJECT TERMS

hydrogen; hydrogen demonstration; hydrogen validation

\begin{tabular}{|c|c|c|}
\hline $\begin{array}{l}\text { a. REPORT } \\
\text { Unclassified }\end{array}$ & $\begin{array}{l}\text { b. ABSTRACT } \\
\text { Unclassified }\end{array}$ & $\begin{array}{l}\text { c. THIS PAGE } \\
\text { Unclassified }\end{array}$ \\
\hline
\end{tabular}

\begin{tabular}{l|l|} 
17. & LIMITATION \\
OF ABSTRACT & $\begin{array}{l}\text { 18. } \\
\text { NUMBER } \\
\text { OF PAGES } \\
\text { UL }\end{array}$ \\
\end{tabular}

19a. NAME OF RESPONSIBLE PERSON

19b. TELEPHONE NUMBER (Include area code) 